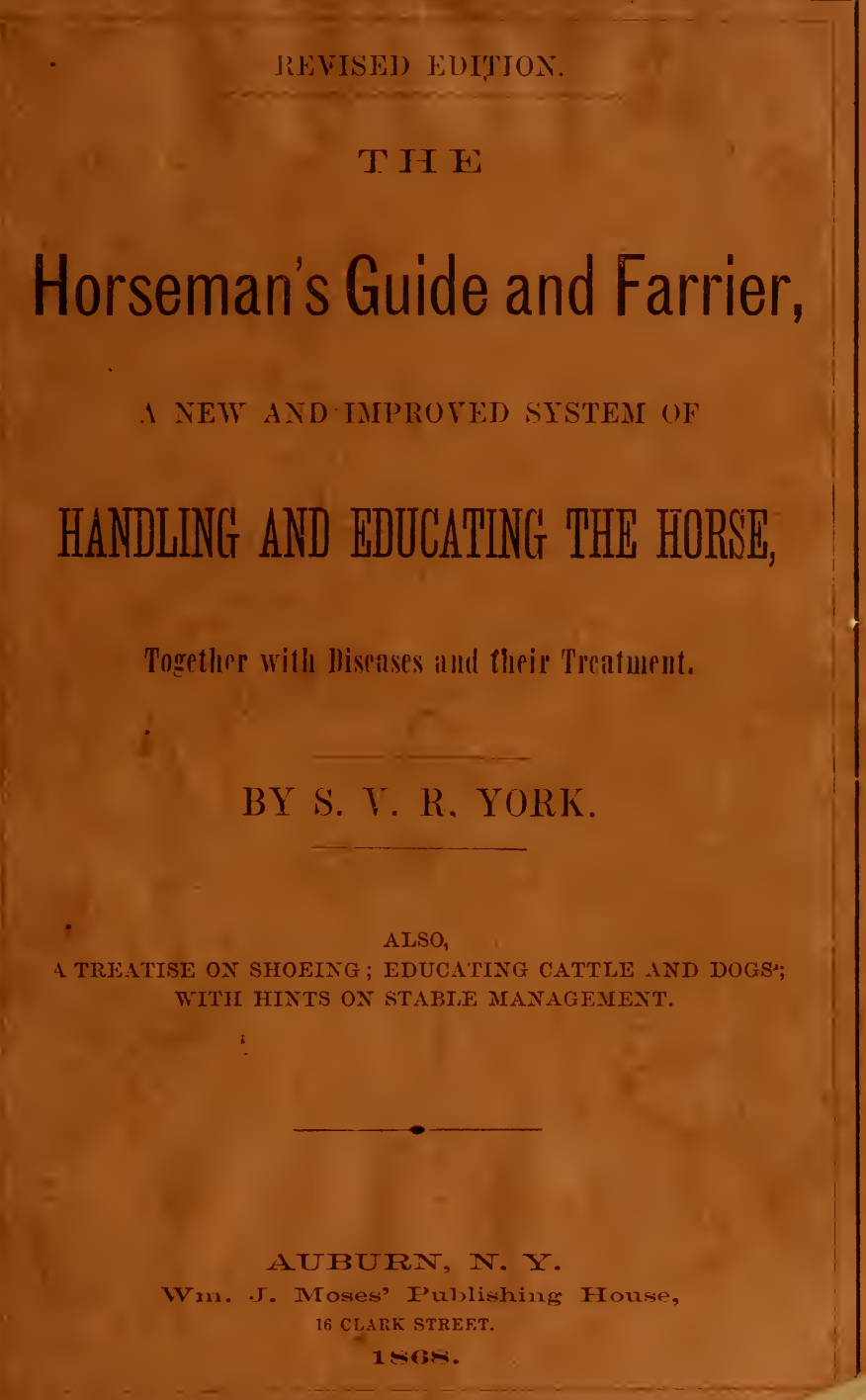

HANDLING AND RDUCATING THE HORSE,

Together with liserses and their Treatment.

$$
\text { BY s. V. R. YORK. }
$$

AUBURN, N. $Y$.

Wm. J. Moses' Publishing House, 16 CLARK STREFT.

1ะ6ะ. 


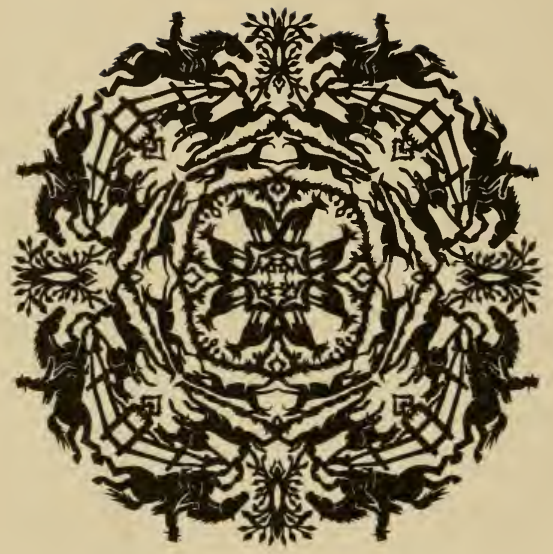

JOHN A.SEAVERNS 




\title{
REVISED EUHION.
}

\section{TḦE}

\section{Horseman's Guide and Farrier,}

\author{
- A NEW AND IMPROVED SYSTEM OF
}

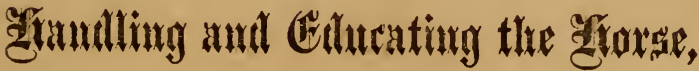

Together with Diseases and their Treatment.

\section{BY S. V. R. YORK.}

\footnotetext{
ALSO,

A TREATISE ON SHOEING; EDUCATING CATTLE AND DOGS;

WITH HINTS ON STABLE MANAGEMENT.
}

AUBURN, N. Y.:

WM. J. MOSES' PUBLISHING HOUSE, 16 CLARK STREET.

1868. 


\section{TO PURCHASERS.}

Persons buying this work have every right of using, but no right of teaching, or transferring to others, the book or its contents. By so doing they will lay themselves liable to prosecution.

Entered, according to Act of Congress, in the year A. D., 1865, by S. V. R. YokK, in the office of the Uistrict Court for the District of Vermont. 


\section{PREFACE.}

The writer of this little work, entitled THE HORSEMAN's GUIDE AND FARRIER, has made it his constant business for a term of years of teaching one of the best systems by which to handle wild and vicious horses, that has ever been introduced into the United States or Canadas, and has been so acknowledged by all that have had the pleasure of seeing the system practically illustrated by the introduction of the most vicious horses the States and Canada could produce; and, having a familiar acquaintance with the wish of all lovers of this noble animal - the horse - he brings the system before the public in printed form, so that all who favor him with their patronage may be benefited by its perusal.

But in treating upon this subject, I am well aware of the difficulties under which I labor; I am conscious of the fact that I am quite apt to excite the prejudices of men, who, having managed horses to a considerable extent, and having ways of their own, with which they are satisfied, are likely to cry humbug to any idea which, to them is new and strange. I am also aware that there already exists in the minds 
of many intelligent persons, a settled opposition to all professionals, whose business is pretending to teach and improve the horse; an opposition arising from the many failures among that class, and the consequent damage done to their animals by being handled by such men, or under their instruetions. I have no reason to expect that I can obliterate these prejudices at once; but have faith to believe that if I am given a careful hearing, and my advice put into practice, I shall do much to improve the opinions of the people on the subject of the "Education of the Horse." I do not expect to improve their opinion of "Horse Taming," - not at all. It amounts to but little, only for the time; its effects are only momentary. The distinction between tuming and educating is clear and positive, and cannot be gainsayed by even the most careless observer. I think I can make this perfectly clear, if you carefully peruse this work, and practice its teachings. I have devoted my time for the past ten years to the investigation and study of the subject, and feel quite confident my efforts have been of value to the public. I do not by any means claim to be infallible, but speak of this to satisfy the public that mine is no system picked up in a day, but feel that it is the result of incessant labor for years. I do not claim all of the ideas I advance to be original with me, but whether they are, or ideas of others, neither are recommended without first having been put thoroughly to the test by actual personal experience. I advise no plan which I have 
not successfully tried, and found to be valuable. There is, to a certain extent, a moral responsibility resting upon authors of works of this nature, which is embarrassing in a high degree. The rules which he sets forth are sometimes deviated from without the knowledge of the operator himself, either from his not clearly understanding the meaning, or from his having too carelessly listened to the instructions received, or perhaps too loosely scanned the printed, and the desired result is not reached. In a measure, this leads to a distrust of the system. Occasionally circumstances may arise in the handling of the horse, which no foresight could have provided against, and if the operator does not find in the instructions given, a remedy for his difficulty, he lays it aside in disgust. Nevertheless I submit this work, confident of being able to be of great public service. In the forepart of this volume, I shall almost exclusively treat upon the education of the colt, and the treatment of his habits, after which I shall speak of a subject which, in almost all its aspects, needs to be treated from quite a different stand-point. The colt is impelled to his awkwardness and bad habits by natural impulses of timidity and consequent fear; while the mature horse is actuated more by a strong self-will, his habits being formed through mismanagement of his irrst instruction. Therefore, the rules which apply to the elucation and treatment of colts, are not, in all instances, the rules necessary to be observed in the education and treatment of the Horse. Such 
governing rules, however, as, being honest with the animal, exercising kindness, forbearance, firmness, and perseverance, apply in both cases. Now, dear reader, with these introductory remarks, I shall commence my volume, introducing the points in alphabetical order, endeavoring to so fully explain that none need go astray. 


\section{TABLE OF CONTENTS.}

To Purchasers .................

Preface......................... History of Celebrated Horses trained and exhibited by S.V.R. York

Granite State Boy................

Royal George....................

May Flower...................

Alarm ........................

Young Columbus................

General Remarks................

First step to be taken with a Wild Colt......................

How to Halter-break a Colt.......

How to Hitch a Colt in the Siall the tirst time................

Handling the Colt's Feet......... How to ride a Colt................ Bitting the Colt.................. To get the Colt used to the Bit.... Hirnessing the Colt the First Time Hitch ng him to the Wagon the First Time..................

Hitching the Coit in Single Harness to Wagon, First 'Time......

Learning the Colt to Back........ Subduing the Colt............... How to Sub lue Vicious Horses... Dimensions and Use of Surcingle Castrating.................... How to Drive Runaway Horses.. How to Lrive a Kicking Horse... Another plan for Driving a Kicker in $\mathrm{H}$ irness................... How to Break a Kicker in Double Harness ................... How to Use a Balky Horse........ How to Break a Halter Puller.... Another and Better Plan for Breaking a Halter Puller............ A Kunaway, Bolting, or Plunging Horse ......................

Pawing in the Stable............... Kicking in the Stall.............. Bad Biters..................... Bad to Harness, or Groom........ liollin in the Stall............... Getting Cast in the Stall........... I)riving on one Rein............. Hard Pullers................... Carrying Tonque Over Bit, and Out of Mouth............... How to Shoe a Vicious Horse..... For Teaching a Horse to B ack, or one that is in the habit of Bolting The Plan for a Breachy Horse...
2 How to Catch a Forse in Pasture 3 New and Latest Improvements: Halter Breaking............. 82

$9 \quad$ Bitting the Colt $\ldots \ldots \ldots \ldots \ldots \ldots, 8,84$

11 Safety Bridles................ 86

11 On Shoeing.................... 94

12 Clips ........................ 99

12 The Hind Shoe.................. 99

13 To Prevent Overreaching or Click-

13 ing....................... 100

Interfering with the Hind Feet.. 100

23 Interfering with the Forward Feet 101

26 The Bar Shoe................ 101

Quarter Cracks................ 101

27 Teaching Tricks.................. 103

29 To come at the crack of the Whip

31 or word of Command........... 103

34 To make a Bow............... 103

37 To say No.................. 104

39 To Lie $110 w n . . . \ldots . . . \ldots \ldots . . .104$

To sit Up..................... 105

To Shake hands................. 107

How to tell a Horse's age........ 108

Jockey Tricks.................. 109

Training Steers................ 111

Training Dogs.................. 114

Training the Shepherd to Drive.. 115

The Watth Dog............... 119

The Trick Dog............... 121

The First Step with the Trick Dog 121

To leirn him to Sit Down........ 122

To Teach Him to Make a Bow... 122

To Sit Up.................... 123

To Stand Up.................. 123

To Get into a Chair.............. 124

To Make Him Go Lame......... 125

To Kun on His Forward Legs.... 125

To Learn Him to Find Things.... 126

Turf Calendar................. 127

Latest and Fastest Time Recorded 129 Stable Mranagement :

Air...................... 131

Litter........................ 135

Light ...................... 137

Grooming.................. 139

Exereise................... 141

Breeding..................... 144

Closing Remarks............... 158

Signs of Disease in the Horse.... 161

The old English Horse Farrier, Dr. Tidball.................. 167

A Brief Dictionaay............... 186 Rules and Regulations for the Government of 'Trotting, etc....... 199 


\section{RE CIPES.}

1 Fistula and Poll Evil before

Breaking................... 167

2 After Breaking............. 1h7

3 Blue Ointment............... 167

4 Hooks, or Weak Eyes......... 168

5 Fye Lotion................. 168

6 Spavin and kingworm Oint-

ment ..................... 168

7 Hoof Bound............... 168

8 Hoof Ointment.............. 168

9 Big Leg.................. 168

10 Liquid Blister............... 169

11 Hoof Evil, or Thrush........ 169

12 Founder................... 169

13 Lung Fever................ 169

14 Button Farcy............... 170

15 Water Farcy................. 170

16 Nasal Gleet................ 171

17 Chronic Cough.............. 171

18 Cleansing Powders............ 171

19 Fits.................... 171

20 Jaundice Yellow Fever....... 171

21 Nicking Balsam........... 172

22 Thumps, or Palpitation of the

Heart.................... 172

23 Shoulder Jam or Sweney...... 172

24 Stoppage of the Urine........ 172

25 Hhysic Ball................. 173

26 To Remove Warts........... 173

27 Inflammation of Kidneys..... 173

28 Stifle Sprains............... 173

29 Loss of Appetite.............. 173

30 Restorative Liquid............. 174

31 Hoof Liquid................ 174

32 General Liniment ............ 174

33 Sore Mouth or Tongue........ 174

34 Mange .................... 174

35 To Stop Blood.............. 175

36 Chest Founder............. 175

37 Melanders................. 175

38 Soap Liniment.............. 175

39 Opodeldoc.................. 176

40 Heave and Bone Ointment.... 176

41 Lockjaw.................. 17n

42 Heave Powders to Trade on... 176

43 Gravel on the Foot........... 176
44 Nicking................. 176

45 Cure for Colic................. 176

46 Big Head.................. 177

47 Botts...................... 177

48 Gravel....................... 177

49 To Remove Sum trom Eye ... 177

50 Weak Eyes................ 177

51 Wounds.................. 177

52 Scratches.................... 177

53 Sweating Liniment.............. 177

54 Dope to Trade On ........... 178

55 To Remove Callousness....... 178

56 Fistula After Breaking........ 178

57 Salve to Heal Wounds........ 178

58 Fistula and Poll Evil......... 178

59 Heaves .................... 179

60 For Curbs................. 179

$61 \mathrm{Mud}$ Fever and Cracked Heels. 179

62 Cure for Ringbone and Spavin 179

63 Physic Balls................ 180

64 Physic for Cattle.............. 181

65 Tonic for Horses and Cattle... 181

66 Cordial " $\quad$ ".. 181

67 Diuretic Ball............... 181

68 Diuretic Powders............. 181

69 Condition Powders........... 181

70 Fever Ball................ 182

71 Sedative and Worm Ball...... 182

72 Anodyne Ball............. 182

73 Cordial Astringent Drench.... 182

74 Blister Ointment............. 182

75 Powder of Angleberries....... 182

76 Fever Powder for Horses...... 183

77 Astringeut Ball for Horses.... 183

78 Stomach Purgative Ball........ 183

79 For Fomenting Swollen Legs. 183

80 For Distemper............. 184

81 To Remove Splints.......... 184

82 For Worms in Horses........ 184

83 Spavin Preparation............. 185

81 For the Eye............... 185

85 For Windgalls and Soft Puffs 185

86 Thrush.................... 185

87 Hoof Rot................. 185

8४ Heave Remedy............... 186 


\section{TEE}

\section{HORSEMAN'S GUIDE,}

\section{A ND FARRIRR.}

History of the Celebrated Horses Trained and Exhibited by s. v. IR. York.

In giving you a history of these celebrated horses, I consider it a duty I owe myself and the public generally, that I correct a few misstatements. Mr. A. H. Rockwell, of Broome Co., N. Y., in his publication of 1865 , claims to be the first teacher that ever gave successful exhibitions in driving trained horses without reins. He also claims that the points introduced for training, are traceable back to his system. To the public let me say, I had been teaching horsemanship (successfully) for two years previous to Mr. Rockwell's having adopted the profession. Mr. R. is a man I never saw, but I know his history well, and am familiarly acquainted with his system. I believe him to be a gentleman, and as far as I can ascertain he has been a successful teacher, and I say God speed to every man who is laboring to increase the value and usefulness of that noble animal, 
the Horse. Yes, any man who gives his time and energy to the self-sacrificing business of teaching rational horsemanship, should be a man entitled to the respect of an intelligent people. But when $\mathrm{Mr}$. Rockwell claims to be the first man that has ever driven a trained horse without reins, I know he is in error. In 1857, Mr. A. H. Tidball - a partner I travelled with some three years and a half - trained and drove successfully, a spirited stallion called Granite State Boy, before the Horse-Breeders Association at Ravenna, Ohio, that was trained under my system, which is different in every feature from Mr. Rockwell's; after which, we gave successful exbibitions through Upper and Lower Canada, and the lower British Provinces. At the same time we had under training Young Royal George, which was exhibited through the New England States.

In 1863 I purchased of Mr. Lovejoy, of Bethel Hill, Maine, a thorough-bred horse, which I took to Guildhall, Vermont, and in ten days from the time I gave him his first lesson, I drove him on exhibition before a large crowd of people at Norwich, Vermont, and continued to give public exhibitions until the Spring of 1865. When at Cooperstown, N. Y., I sold him to Mr. Jackson, who has kept him since as a stock horse. In August, 1865, I bought of Mr. Jonathan Buell, of North Eaton, Washington Co., $\mathrm{N}$. Y., the brown colt, called Alarm, which I now have on exhibition. In June, 1866, I also bought of Mr. Benjamin Cummings, of North Brookfield, 
Mass., Young Columbus. I commenced training him the 25th of July, 1866, at Bradford, Vermont, and now am driving him successfully on exhibition, without reins. $\mathrm{He}$ is also well trained as a trick horse. I only had him under training one week to be driven double with Alarm without reins, when they made a graceful appearance in the streets of Canterbury, Connecticut, amid the cheers of the throng who had gathered to witness the feat.

Alarm and Young Columbus (driven together without reins ) for beauty, agility and perfect obedience to the requirements of their driver, when on exhibition, passing through crowded streets, avoiding vehicles and obstacles of every kind, stand unrivaled by any effort of the kind on record.

GRANITE STATE BOY.

This fine mettled horse was raised by Hiram Drew, of Mercer Co., Pa. Color, coal black; weighs 1150 pounds ; fine style and action; if living, is sixteen years of age, and I think owned in southern Ohio.

ROYAL GEORGE.

This fine bred horse was raised by Mr. Arthur Brown, of Vonkleek Hill, Upper Canada ; is a beauful bay, with black mane and tail, one hind foot white; weighs 1075 pounds; is twelve years old; was sired by old Royal George; owned by Mr. Dorherty, of Caledonia, Upper Canada. He is now exhibited as a trick horse in a Circus ring. 
MAY FLOWER.

This justly celebrated horse was bred by $M_{1}$. Lovejoy, of Bethel Hill, Maine; his color white, dotted with dark specks; mane and tail white; weighs 950 pounds; splendid style and great endurance. He was sired by a thorough-bred imported horse; his dam a full blood Messenger. Previous to my purchasing this horse, he had been under training by the Rockwell system, taught by Mr. Magner, which failing, left him more vicious and unmanageable than before. He was a bad biter, also a willful, bolting, plunging, runaway horse, and had become perfectly unmanageble by Mr. Lovejoy, of whom I purchased him. In ten days after applying my system, he became perfectly tractable, and was successfully exhibited, as above stated.

\section{ALARM.}

This celebrated Colt was raised in North Eaton, Washington Co., N. Y., by Jonathan Buell, and came into my hands unhandled, in the Spring of 1865 , and although but three years old, exhibited an alarming temper, biting, striking and jumping at any one who chanced to come within his reach. After having been under my training two weeks, he was harnessed to wagon for the first time in his life, and driven without reins through the streets of Cambridge, $\mathrm{N}$. $\mathrm{Y}$., to the astonishment of all who knew his history. He was sired by Nimrod Morgan; dam an imported English mare. He now stands sixteen hands high, 
weighs 1200 pounds; color, a beautiful dark brown. $\mathrm{He}$ is a very stylish driver, and has been exhibited constantly since his training.

\section{YOUNG COLUMBUS.}

This justly celebrated fine mettled horse is nine years old this spring, (1867); stands sixteen hands high ; is of a dark chestnut color, and weighs 1180 pounds. I purchased him of Benjamin Cummings, North Brookfield, Mass. I gave him his first training at Bradford, Vermont, as on previous page. He has entirely given up his willful, vicious habits, inherited from his celebrated sire, Old Columbus, who was a terror to his keepers. His dam, a fast trotting mare sired by old Membrino. For beauty, style and perfect obedience to the requirements of his owner he is unsurpassed. The first and only race he ever trotted was at Barre, Mass. Time, 2:25, to harness.

\section{General Remaks.}

According to the known history of the horse, he has been the friend and servant of man for nearly four thousand years. All classes of people, from the highest rulers and warriors, down to the lowest peasants on earth, have shared his friendship and utılity. The horse has also had its admirers and friends among all classes of men; even the poor Arab treats him as one of his own family by lodging him in the tent with his wife and children. And yet his education is only in its infancy.

His value has been so estimated, from his first sub- 
jugation to the present, that a portion, at least, of all civilized nations, as well as the Indian who catches him wild, have participated in the pleasures and profits of the horse. And his value at the present time depends, to a great extent, on the knowledge and skill we possess in using him; for when we call out the finer feelings of his nature by kind treatment, we are delighted and comforted in the manner and willingness in which he renders.his services for our benefit; while to those who know no other way of governing him than by brute force, he often becomes fretful and vicious, and even a dangerous servant; consequently, we see that his real value to us rises or falls, according to our ability and manner of governing him.

He has been imported and transported from nation to nation; he is used to do our hardest drudgery, as well as to pride himself in honoring kings; he is used to convey us to places of amusement and worship; in fact, there is no vocation in which man is engaged that the horse is not made useful to further his purpose. And in all places, and among all classes, we find his value corresponding with the state of society where he is employed. And here is another idea about the horse which is worth its weight in gold, viz : his cultivation and improvement have a tendency to promote good society. For man, while cultivating the finer feelings of his nature, (as he must, in order to control the horse properly,) arrives at that degree of refinement in his mind which is so necessary for a member of good society to possess. I have known 
men to buy a pair of horses, paying from three to four hundred dollars for them, which was considered by many, an enormous price. The purchaser, after keeping them a few months, would sell them again for double the price he paid, to the astonishment of those who considered the first price extravagant. This may be attributable to the dealer's knowledge of the market, and his skill in training and improving their condition while they remained in his hands. So we see, too, that the study of the horse is calculated to elevate the mind of men, as well as to replenish his purse.

How often do we see young men, whose almost first act in life is to buy a horse, and sometimes, before they are able to pay the purchase money, and even part with the last cowr, and every other valuable before they will part with their horse. This shows the great attachment man has for the horse, which can be traced back through history to the ancient nobleman, as well as the wild Arab. This will be made more apparent hereafter.

Among all the studs* kept by the ancient noblemen, Jou will find that there was scarcely ever one found which was not kind and submissive to his master; the reason of this was because their mode of governing them was invariably that of kind treatment. The passion of love, in all animals, when cultivated and fully developed, is even stronger than that of fear. 
When the Arab falls from his mare (observes Smith on breeders,) and is unable to rise, she will stop and neigh until assistance arrives; if he lies down to sleep, as fatigue sometimes compels him in the midst of the desert, she stands watchful over him, and neighs and arouses him, if either man or beast approaches.

Allow me to give place to the following anecdotes (which are well authenticated,) partly to show the love and great attachment of the Arab (as well as others) for the horse, as well as that of the horse for his master.

An old Arab had a valuable mare that had carried him for fifteen years in many a hard fought kattle and in many a rapid, weary march. Although eighty years old, and unable longer to ride her, he gave her and a scimeter that had been his father's, to his eldest son, and told hirn to appreciate their value, and never lie down to rest until he had rubbed them both as bright as a looking glass. In the first skirmish that the young man was engaged in, he was killed, and the mare fell into the hands of the enemy. When the news reached the old man, he exclaimed, "Life is no longer worth possessing, for I have lost both my son and mare, and I grieve as much for one as the other," and he immediately sickened and died.

The following comes home to the boson of every one possessed of common feeling: The whole stock of an Arab of the desert consisted of a mare. The French Consul offered to purchase her in order to 
send her to his sovereign, Louis XIV. The Arab would have rejected the proposal at once, with indignation and scorn, but he was miserably poor. He had no means of supplying his most urgent wants, or procuring the barest necessaries of life. Still, he hesitated; he had scarcely a rag to cover him, and his wife and children were starving; the sum offered was great; it would provide him and his family with food for life. At length, and reluctantly, he consented to the separation. He brought the mare to the dwelling of the Consul; he dismounted, and stood leaning upon her; he looked, now at the gold, and then at his favorite; he sighed, he wept. "To whom is it," said he, "I am going to yield thee up? To Europeans, who will tie thee close - who will beat thee-who will render thee miserable? Return with me, my beauty, my jewel ; God preserve thee, my beloved, and rejoice the hearts of my children;" and then sprang upon her back, and was out of sight in a moment. Ah, jockey, think of this; did you ever part with a favorite that caused your wife and children to weep?

Sir John Malcom, in his sketches on Persia, gives several anecdotes, but of a more amusing character, one of which we will notice here: "When the enemy, returning from his former mission, was encamped near Bagdad, an old Arab rode a bright bay mare, of extraordinary shape and beauty, before his tent untiI he attracted his attention. On being asked if he would sell her, 'What will you give me?' was the 
reply, 'That depends upon her age; I suppose she is past five?' 'Guess again,' said he. 'Four?' 'Look at her mouth,' said the Arab with a smile. On examination she was found to be rising three. This, from her size and symmetry, greatly enhanced her value. The envoy said, 'I will give you fifty tomans, (a coin nearly equal in value to a pound sterling.) 'A little more, if you please,' said the fellow, apparently entertained. 'Eighty, a hundred.' He shook his head, and smiled. The offer at last came to two hundred tomans. 'Well,' said the Arab, 'you need not tempt me further; it is of no use. You are a rich elchee ; you have fine horses, camels and mules, and I am told you have loads of silver and gold. Now,' added he, 'you want my mare, but you shall not have her for all you have got." "

The foregoing is a very humane system of treating the horse, and one that is attended with the best success in subjugating all horses for domestic purposes ; and yet there is another method by which they may be trained and subjugated, that no less shows the superiority of man, than the willingness of the horse to obey him, when his wishes are made known to him; without medication. The domesticated horse seldom needs anything more than kind treatment at our hands to render him obedient to our commands, after he has learned what we desire of him, for his instinct leads him to love and obey man, although the horse, not unlike other animals in this respect, is possessed of a kind of wild fear of man (in a natural 
state, that must be overcome before we can successfully proceed to learn him anything else. This the Mexicans, as well as the Indians, accomplish in their way with the lasso, in catching them wild by decoying and riding up to a herd of them, and throwing it over the head of one, (around the neck of the animal,) and then follow him in the chase until he is choked down. After this, he is not hurt, but caressed and talked to, when he is hampered and led to camp without further trouble, where he soon learns to love and obey his master.

Now, I do not expect to be fortunate enough to make myself renowned in relating my experience or observation of the horse, in this respect; but trust mainly on the merits of this subject, to become useful to those who feel an interest in this important topic.

First, the horse is governed, and receives his instruction through the five senses, viz. : seeing, tasting hearing, smelling and feeling; the one of seeing seems to rather predominate. But the most of these are more acute than even man's, for they partially supply the place of reason in the animal. Secondly, he is governed (like all other animals) by his instinct, which is combined in the five senses; and one of the qualities of his instinct is to fear the approach of man, whom he looks upon as his superior. This is more especially the case when he is in a wild state; but when this wild fear is changed to love by kind treatment, it is increased an hundred fold. Another 
of these is to love and obey man, when domesticated and educated, which he generally does, unless his animal propensities are aroused by ill-treatment; for it is an undisputed principle in the nature of this animal not to offer resistance to our wishes, when made known to him in a manner that he can understand us; and, of course it follows that this must be done in accordance with the laws of his nature.

Man is not only placed at one end of this great chain, but he forms the hook that hangs it up on the throne of Jehovah, and the swivel and pivot also upon which the whole turns; and it extends fros thence to the - yes, beyond the surface, to the very center of the earth, and the bottomless dcep; and, notwithstanding its crooks and nooks, and all its mysterious windings, there is a current of electric life running through the whole length thereof, that proceeds from the great battery from which all knowledge and instinct flows. Man stands at the head of all created beings, for all will tremble and crouch with fear at his approach, except when attacked in a warlike manner, or when there is no chance to flee. Then if man is placed at the head of all these it shows the irnportance of his studying his own nature, and if he arrives at the highest state of his moral culture, to which he is attainable, all the better, so as not to abuse the power invested in him, and enable him to turn all these things to the best and most profitable account. What, then, has man to fear from the brute creation, when he becomes acquainted 
with his ability to govern and control them all, and when he sees the most ferocious beasts flee at his approach? As I stated above, the domesticated horse loves man, and I very much doubt whether there is another creature on earth that is so universally beloved by man as the horse. They look upon man as their friend, and when in trouble will run to him for help and protection. As an evidence of this fact, I need only relate one circumstance that I witnessed with my friend and neighbor in Michigan. He had a mare that owned a colt about a week old, running in a field wherein was an old well fourteen feet deep, which had been covered with plank, which, by some means had got off, so that the colt fell into the well. This happened about the break of day, and before I had got out of bed I heard the noise and clatter of a horse's hoofs, which awoke me. This was followed by a loud neigh of a horse at my door. I scrambled out of bed, and went to the door just in time to see the old mare returning towards the well that was some forty rods distant. Seeing her look down into the well, and then start for the house again, I anticipated the trouble she was in. I summoned hclp, and started for the well; but not without being met sereral times by the old mare, (who seemed to be almost frantic,) as if to hurry me on to the place of disaster. When I arrived, the colt was splashing in the water at the bottom. I immediately got him out with the help of ropes that I took along with me, when they both followed me back to the house; and whenever 


\section{2}

I stopped, the mare would stand by me, and even lick my hand, as well as the colt, in thankfulness for the assistance I had rendered her in rescuing her colt.

But to return more directly to the subject in question. I will proceed to show what man should be to accomplish his purpose with the horse, and then by what means he can do it. The timidity of many persons only prevents their becoming successful horse trainers, fully equal to the great Damptius of the present day. It requires almost a reckless courage, a patience that never tires, and a temper that nothing can ruffle. With these requisites, any one may enter the pleasing labor of subjugating and educating the horse, with almost a certainty of success. All men are not endowed with this gift; though any one of common ability, who studies the horse minutely, will soon learn by his quick perception and judgment, to govern the horse, notwithstanding the great difference of organization and temperament that belongs to this animal, which does not always consist in a uniform plan of operating with all, but must be varied, according to their individual capacities, after subduing their wild fear.

This is a study, which, if pursued systematically, will be one of the most ennobling, as well as profitable branches of the industry of breeders and the farmer's occupation, for it will enhance their horse's value at least one-half (in some cases ) by rendering them more docile and safe to guide and handle. In a word, the man should be, in every respect, of good 
disposition, and the law of kindness should be fixed in his mind as the key-stone of all successful theories of treatment towards the horse, and we shouid look for help only where help is to be found.

\section{The First Step to be Taken with a Colt.}

Go to the pasture and walk around the whole herd quietly, and at such a distance as not to cause them to scare and run; then drive them very slowly, and if they stick up their heads and run, wait until they become quiet, so as not to frighten them ; then quietly pass around them again, and gently drire them in the direction you want to go. Do not flourish your arms, or halloo, but quietly follow them, leaving the direction free for them that you wish them to take; thus, taking advantage of their ignorance, you will be able to get them into the barn-yard very easily. If colts have always run in the pasture uncared for, as many do, there is no reason why they should not be as wild as the deer, and require the same gentle treatment. If you want to get them without trouble - for the horse in his natural state is as wild as any of the undomesticated animals, though more easily tamed - the next step will be to drive them from the yard into the barn, not into the stable, but on to the barn floor. This should be done as quickly as possible, so as not to excite any suspicion. The best way to do this is to lead a gentle horse into the barn first, and hitch him: then quickly walk around the colt, or colts, as may be, and gently drive them in the direction of the door; 
seeing the horse in the barn, they go in without further trouble. The next step is to remove the quiet horse and shut the door. This is the colt's first idea of confinement, hardly knowing how he got into such a place, nor how to get out of it; so he must take it as quietly as possible. See that everything is so arranged that he cannot jump over or crawl under; also, a clean floor.

Everything is now properly arranged for the colt to receive his first lesson. And how is it to be accomplished? Some individual, unacquainted with a correct system of handling wild and vicious horses, would say the plan I adopt, by which to halter and lead quietly, wild horses, would so frighten them it would prove a failure. But quite the reverse. Prepare yourself with a good spring-top whip, with long switch. Step into the barn; close the door; all is now safe. You are alone with the colt, nothing to attract his attention but yourself. Stand quietly for a few moments, and he will eye you closely; then take your whip in right hand; give it a sharp crack; at the same time approach the colt, so the distance from him is the length of the whip, and give him some sharp cuts around the hind legs, and under the flank; never strike him forward of his quarters. After applying your whip in such a manner for about one minute, then take your whip in your left hand, at the same time hold out your right, and gently approach him, saying, "Ho! boy ;" but in approaching him, if he turns and runs from you, again apply 
your whip sharply; then again approach him saying "Ho! boy." In operating in that manner for about five minutes he dare not turn his quarters, but will stand and face you, and you can lay your hand upon . his neck, pat and caress him. In doing so, you gain his confidence, and when he follows you he comes for protection, but when he turns to leave you, he is sure he will get punished. By using your whip in that manner for twenty minutes, he will follow you around the barn the same as a pet dog, keeping his head close by your side.

This exercise was fully illustrated by Mr. Jonathan Smith, of Virginia, which is thus described by S. W. Cole: A vicious mare was given him to tame, which it was said he could not manage unless he dealt with the devil, for she was a wild, skittish young thing, high tempered, and disposed to kick and bite. He ordered her into a barn, and then entered and fastened the door: Before she had time to survey him, he was giving her the lash smartly. Around she went, kicking and jumping; no rest was given; the sweat flowed, and she slackened in her movements. When she approached him, he slackened his whip, held out his hand, and said, "Come along;" again she was off, and the lash applied. This was repeated several times before she would advance, and when she moved towards him, he approached and patted her; and as he moved away and said, "Come along," she followed. In a moment she darted off; he applied the lash smartly; she stopped, trembled, and 
approached him. He patted her neck, and said, "Come along," and she followed him several times around the barn; when she lagged, he was away and the whip applied. After that, she would not remain two feet from him. He ordered the door to be opened, and the mare followed close to him through the crowd, and back to the stable. This shows and proves clearly, the first step, and only correct way of forming an acquaintance with wild and vicious horses.

\section{How to Halter-Break a Colt.}

Your colt is now brought up by the use of the whip, and follows close by your side. The next step is to teach him to lead with a halter. This can be accomplished in ten minutes by the use of a cord.

Procure a cord about fifteen feet in length, and one-half inch in diameter, made of cotton, or hemp, cotton is preferable. Make a knot fast at one end; at the other make a loop of sufficient size to slip your hand through. Your cord is now ready. Take the end that has the single knot, place it around the horse's neck, just back of the head, and get the exact size; tie a loop, then place it around the neck, and make it fast - in the same manner you would tie a cord around your cattle's horns to make them fast in the stable. After which take hold of your cord one foot below your horse's neck, pass it through between the neck and cord that is fastened around his neck; bring it forward and loop it into his mouth; now take your hand into the loop at the other end of the 
cord, and you can control him as you please. Step back from your horse; do not get forward or back of him, but stand to one side, about opposite to the shoulder; at the same time give him a sudden convulsive pull, and then let your cord hang loose. If he should prance and juinp to the opposite side of you, give him another pull the same as before. Do not pull your cord, thinking to drag him after you by steady pulling, but give him a few convulsive pulls, after which let your cord slacken; and by exercising him in that manner for ten or fifteen minutes, he will very promptly step up by your side, no matter in what direction you may turn. Remove your cord, buckle on your halter, and you can lead him quietly just where you like.

\section{Hitching the Colt in Stall the First Time.}

After halter-breaking your colt, it is then necessary to give him a rest before working him farther, and to hitch him in the stall for the first time observe the following rule: Examine your stable very closely, in order to ascertain that there are no loose or broken plank in the floor, also see that the rack, manger, and lining of the stall is sound and all right. All is now in readiness; lead him quietly up to the stall. If he shows any sign of fear, let hini stop for a few moments; talk gently; also pat him on the neck. By so doing, you will dispel his fears, and he will quietly pass into the stall. Now for the plan of hitching him. If you should hitch him with the tie-strap, as 
is generally practiced, some little noise on the scaffold above, (such as scratching of hens, or the like,) would cause him to scare, pull, break loose, and soon he is a confirmed halter-puller. The plan I adopt for hitching the colt the first time is simple and effectual. Procure a piece of rein webbing fifteen feet in length, or a strap one and one-fourth inch wide, of same length. Get the centre of said web or strap; now buckle a common web surcingle around his body, just back of the shoulder, then lay your webbing across his hips, carry one end forward between the surcingle and body on the left side, the opposite end between the surcingle and body on the off side of the colt, the centre rests across his hips, the ends carried forward; now take the centre of the webbing in your right hand, give it one turn over; that leaves it crossed upon his hips; now carry the center back, and pass his tail through the loop that you made by turning the centre of the webbing over - the same as crupping with harness; step forward, reach your left hand through under the colt's neck; and tie them snug around the chest; next, carry the end of your tie strap through the hole or ring in manger; bring back, and make fast to the webbing that passes around the chest. Your colt is now made fast in the stall by the use of the webbing attached to his tail; you need have no fears of his breaking the halter or injuring himself. Place him in that position a few times, and there is no danger of his ever breaking a common halter. If you should at any time use a 
rope in place of webbing, wind the crupper part with a piece of soft cloth; otherwise you would injure his tail. This plan will break the worst of halter pullers.

\section{Fanding the Colt's Feet.}

I consider it the duty of every one that raises. a colt, to prepare it for the smith before he takes it to the shop to get it shod, for many valuable colts have been made almost worthless through this neglect. There are few horses that may not be gradually rendered manageable for this purpose. By mildness and firmness they will soon learn that no harm is meant, and they will not forget their usual habit of obedience; but if the remembrance of corporal punishment is connected with shoeing, they will be more or less fidgety, and sometimes very dangerous. I wish that it was a law in every smith-shop that no man should be permitted to strike a horse, much less to twitch or gag him without the owner's consent, and that a young horse should never be struck or twitched. The plan that I adopt to handle the feet is very simple, and not less effectual. By adopting this plan, your colt can, in a few moments, be taught to stand perfectly still to be shod. As soon as you get your colt thoroughly broken to the halter, get a strap, or a piece of webbing, eighteen feet in length; now tie one end of the strap or webbing around the colt's neck, just where the collar comes; work it well back to the shoulder; you are now standing at the left side of the colt; do not be in a hurry - work handy, and 
carefully, be very uniform in your words and acts ; now take the other end of your strap, gently pass it back between the forward legs, bring it through to the left side; now lay it over his back; with your right hand under his chest, you can draw it through again to the left side; now place the end up into the loop around the neck - you will now find your strap crossed just back of the left fore-arm - gently raise the left foot, and lay it into the strap that comes between the legs - the outside strap is wound around the ankle; now take the end that is passed through the loop around the neck in your right hand, your left holding the colt by the head; you will see that you have the foot secure, with no possible chance to injure himself in the least, as the whole strain comes over the back, and around the neck; let the colt stand until he attempts to free the foot, but if you hold him firm, he will soon find it useless, and give up, and yield his foot to you ; the moment that he yields, and not till then, relieve him. You have now fully convinced him that you are not going to hurt him, and that he cannot get his foot from you; you will have no more trouble with that foot. Now try the right foot in the same manner; handle each one thoroughly ; remember that it is just as necessary to handle the fore feet as the hind ones, for a horse that is vicious to shoe forward is more dangerous than one that is bad behind. Now handle the hind feet. Have the strap around the.neck, and between the fore legs, as before, and carry it back through the 
hind legs, around the near hind leg below the fetlock, and bring forward through the loop around the neck; take the colt by the head with your left hand, and the strap in your right, pull back on the strap, which will cause the foot to be drawn forward; this the colt will resist by kicking, but draw tightly on the strap, and hold him firmly by the head; he will soon find resistance useless, and will let you handle it as you wish. Now step to the right side of your colt, and proceed as on the left; remember that you must be firm, yet kind, and ever willing to submit to him when he does to you, but never let him know his strength compared with your own, and never let him know that he is the strongest. By faithfully pursuing this plan as explained and demonstrated before the class, I am confident that you will meet with the most favorable results. Remember that you must be particular and persevering.

\section{To IRide a Colt.}

You have gained the confidence of your colt, by the use of your whip; now be very careful that you do not betray it, for if very wild he will be very suspicious, and watch every move, therefore it is very important that you are uniform in all your acts and words. The old fashion plan of riding the colt, I think, very wrong. I well remember of attempting to ride a colt under the directions of an old experienced horseman. I was placed upon the colt's back while he was rearing and plunging, and the next mo- 
ment found myself standing on my head in the snow, some three rods from the colt, and after making several useless attempts to mount him, gave it up as a bad job, while, by adopting the present plan, in a few moments the colt could have been ridden with perfect safety, just where we wished to go, and if this plan is faithfully pursued, I am sure that any colt can be mounted, and rode, in a few moments, without incur. ring the risk of being pitched upon your head, and learning your colt a habit that will be dangerous, as well as very unpleasant. I say this with great confidence, for during nine years' experience with the wildest colts that could be produced, it has never failed in a single case. Before you attempt to mount a colt, it is very important that you teach him the word whoa, which I claim to be the most important word in horsemanship, and if you wish your horse to learn and obey a word, you rnust first learn him the meaning of that word, and then only make use of it when you want him to stop. Never use the word whoa to call your horse's attention in the stable, as many persons do, such as, "whoa, get over; whoa, back; whoa, come here," etc., until the horse gets completely confused with the word, and cannot comprehend your meaning. Hence the necessity of being uniform in word and act. In fact, if you wish your horse to understand and obey you, you must always be honest.with him - never tell him what you do not mean - never deceive him under any circumstances, but gain his confidence, and never betray it. I would 
just as soon think of betraying the confidence of my brother man, as the horse I was training. In teaching your horse the word whoa, take a strap, six or eight feet in length, lay it across his back to the right side, fasten to the ankle of the right foot, holding the strap in your right hand, the left on the halter or bridle; now lead the colt a few steps and say whoa, at the same time pull on the strap, which will throw him on three legs, and suddenly bring him to a stop, and in a very short time teach him that the word whoa means to stop. After educating your colt thoroughly in this manner, then attempt to mount him by placing your knee to his side, just back of the forearm, and draw yourself gradually to his back; if he should attempt to move, pull on the strap, using the word whoa, and he will soon think more of his foot than of you, for he cannot think of both at the same time, as it is impossible for a horse to think of two things at once. You must now be very careful; do not try to work fast, and do not be in a hurry, for you will frighten him with your quick, hasty moves. If you will work slowly for five minutes, you will be on his back, and he will show no disposition to dismount you. I feel confident in your success, for I have never failed in mounting the worst that could be brought, in half that time. Move slow and careful until you get your right leg over his back, and in the same gentle manner get into an upright position. You now have your bridle reins in your left hand, the strap in your right, which is at- 
tached to the foot, and if he attempts to make a wrong move, the word whoa, and a pull at the strap, will make all right. Bear in mind, however, that there is a great difference in the temper and intelligence of colts, some being quick to learn, while others are very stupid. Remember that the more dull and stupid the subject, the more need of patience and perseverance, always bearing in mind that you are a man, and are dealing with a dumb brute - that if you are not capable of controlling yourself, you certainly are not capable of controlling a poor dumb brute. Your colt will now allow you to mount and dismount at pleasure. You cannot expect him to be handy to the rein until after he is properly bitted, which is the next step with the colt.

\section{Bitting the Colt.}

When I speak of bitting the colt, I do not expect the first lesson to give a lofty, easy, graceful carriage of the head; it requires some few days driving to so develop the muscles of the neck to carry it easy and graceful without tiring him. The first lesșon in bitting is to educate him to come to the rein quick and handy; that is readily accomplished by the use of what is denominated a Mexican tie, which is simply a cotton or hemp cord.

Mr. Tidball, the originator of this, used a hair cord, but finding that too severe for a colt with a very sensitive mouth, I concluded the cotton or hemp better; cotton is preferable. Now, dear reader, let me say 
to you that this cord, if properly used, is very valuable; if not used judiciously, it is dangerous, and would have a bad effect. It is one of the most powerful instruments for controlling the mouth, ever made public. Now then, for its practical use. Procure a half inch cotton cord about fifteen feet in length, tie a knot in each end, pass the end through twice, so the knot will not slip; (a single tie is apt to slip out;) in one end make a loop about four inches in diameter, or one that you can pass your hand through easy. This loop should be tied with a sailor's bow-line knot, which is made thus : Hold both hands well out from you; take one end of the cord in your right hand between the thumb and forefinger, the end from you and the main rope extending toward you in the palm of the hand, and lying across the little finger, the palm being up; hold out your left hand with the palm up; lay the rope across the forefinger of the left hand, and draw it towards you through the palm until it is drawn through about two feet from the end you hold in your right hand; with your right, wind the cord once round and close to the left; pass the end you hold in your right under the cord on the back of your left hand, passing it from the wrist towards the forefinger, and drawing it through about three inches, leaving the desired loop hanging below, keeping the palm of the left hand up; pass the end with the right hand under the cord beyond and outside of your left, passing it from right to left; then bring it back over the cord on the back of your left 
hand, passing it from the fingers towards the wrist, barely passing the knot on the end through; with the right hold firmly upon the end, and the loop which was left hanging when you passed the end three inches through; withdraw your left hand, and with it take hold of the main rope and draw the knot tight. You may think the directions for tying this knot rather a complicated affair, but study the instructions given carefully, and you will have but little difficulty; however, if you should fail in the first attempt, try again; two or three times trying, you will succeed. The small loop is not used for bitting, but as you will see, is used for different purposes in handling the horse. Now for the other end of the cord as used for bitting. Take the other end of the cord, pass it around the neck of the colt about midway between the ears and shoulder, and get the size of the neck, then remove from the neck, and tie a bow-line knot, the same as directions for small loop; now slip it over the colt's head, and back on his neck as far as practicable; with your right hand take hold of the cord about eighteen inches below the neck, and carry it through between the loop and neck forward, and place the running loop so formed into the colt's mouth; now you have him in the position for bitting. Take hold of the cord that hangs down from the loop around the neck, in your right hand; step directly in front of the colt, place your left hand upon his nose, gently pull upon the cord with your right hand; with your left press against his nose. 
You see, by gently pulling with your right, and pushing with your left, you carry his nose back in the direction of his chest; that position gives him an arched neck, that is the first position of the head; the second is to carry his head well up; to accomplish this, it is necessary to step about four feet in front of your colt's head, with the cord in your right hand, and give a light pull forward and upward, saying, hold up your head, sir, another pull, at the same time repeating the word, (hold up your head.) The next move is to educate him to come to the rein quick to the right and left; now with your cord step to the left side of the colt (eight or ten feet back) and give him a sudden pull, and then to the right side, and give him another pull with the cord. By repeating the lesson about twenty minutes each day, for three or four days, your colt is well bitted; he will come to the rein quick and handy. The next is to make him acquainted with the bit.

\section{To gret the Colt used to the Bit.}

Nothing is more desirable than to have a horse carry his head and neck gracefully. To effect a graceful carriage of a horse's head and neck, various apparatus have been devised - one of which is the common old-fashioned bitting harness, and I must say I am bitterly opposed to its use. The practice which has been adopted by most farmers, of placing the bitting harness on the horse, and buckling up his head as high as they well can--also, drawing 
the side straps very short, and then turning him out in a pasture field, is not only cruel, but it gives a very ungraceful stiffness to the horse's neck. How often it has been the case where horses, turned out in such a position, have reared and thrown themselves upon the ground, struck the head upon a log, stone or some other hard substance, and lost their life! In the first place, put your cord around your horse's neck, and into the mouth, just as recommended for bitting the colt. Lead your horse out of the stable; let your cord be about fifteen feet in length; take your whip in the right hand; touch him lightly on the quarters with the whip, and occasionally give him a pull with the cord, but in doing so, if he should attempt to approach you, wave your whip to keep him the proper distance; and as often as he drops his head, give him a sudden pull with your cord, which will cause him to keep his head in a proper position. Give him a lesson of this kind about fifteen minutes each day for three or four days, after which get prepared a heavy surcingle. This is placed around your horse with a crotch made the same as the end of a common sawbuck. This is fastened, and placed on the top of the surcicle and riveted fast, leaving the top ends about two feet above the horse's back, with inch buckles attached. Your bridle is now put on with open reins, the end of each fastened to the buckles above. Have no side reins, but lead him out with your cord, as before. When he attempts to crowd on the bit, a little pull will put him 
in a right position. When the horse has become somewhat used to the bit, you should buckle the stays a little shorter, and let him wear it so for a short time. He will soon find out that he cannot lower his head, and, as his mouth will be rather tender, he will naturally raise his head to take off the pressure of tine bit from his mouth. You thus give voluntary exercise to the muscles of the neck, and in a short time it becomes natural and easy for the horse to carry his head well up. Every time you put on the bitting, you can shorten your straps a little, until he carries his head in the right position.

\section{Fanessing the Colt for the First Time.}

If the colt is shy about allowing you to put on the harness, upon backing him out of the stall first put the cord around his neck, with running loop in the mouth, (same as for bitting) and give him a sharp pull side wise, at the same time repeat the word whoa, also gently pat him upon the neck. Now lead him to the place on the barn floor where you wish to have him stand while harnessing, quietly take down your harness from the pegs; if the colt moves from his position, lay down your harness and give him two or three more sharp pulls with the cord, at the same time, with a firmness, repeat the word whoa; do not speak too loud, be careful in pulling him around not to hurt him; a few pulls with the cord, patting and caressing about the neck and face, frequently repeating the word whoa, will so quiet him, that you will 
have no farther trouble. I well know this operation requires a little time and patience. When the harness is well on, take it off and repeat the process until he will allow you to harness him without scringing. In bridling the colt, observe the same rules with cord as for harnessing; with your cord lead him around the yard for half an hour, to acquaint him with the moving of the straps and the feeling of harness in his unaccustomed position. If he should attempt to escape, one pull with the cord will bring him to you in a moment. After a little time, you may commence driving him with the reins; take the precaution to attach your webbing to the ankles of the left forward foot; bring it back between the girth and body of the colt; hold it in your hands as a third rein; if he should attempt to run, pull upon your webbing; take his left foot from him; that leaves him on three feet, and in your power, at the time rereating the word whoa ; that brings him to a stop. A lesson of two or three hours each day for three or four days, turning him in different directions, to stop and go at the word, impressing upon his mind that your are his superior, and can control him at pleasure, and he is now ready for hitehing in harness for the first time.

\section{Hitching the Colt to Wagon the First Time.}

In hitching the colt to wagon the first time, I think it a far better and safer plan to hitch him in double harness, beside a well broke horse, also, on the off side ; and why? The first handling your colt receives 
has been mostly upon the near side, consequently he being on the off side, and the broke horse on the near side, where the colt had received his first lesson, he would not be as apt to scringe, as he would be to place the near horse on the off side. Again, should an accident occur to cause you to jump from your wagon, it would be more natural for you to jump to the near side, and in stopping your team it is more natural to get out on the near side. The harness being on both horses, you will now proceed to hitch them to wagon. In doing this, it will be necessary to have some one to assist you. Let your assistant lead the broke horse to the near side of the pole; next place your colt to the off side; let the person helping you, hold the colt by the head while you are buckling the reins, hitching the tugs, and placing the webbing or long line to the ankle of the left forward foot; perhaps it would be better to buckle a short -strap around the pastern, with ring attached, to guard against chafing. To be more fully understood, we will explain how it is made: Take a soft leather strap, one inch and a half wide, and ten inches long, with the inside edges shaved thin ; then take a strap of firm leather, fifteen inches long, and one inch wide; on one end place a buckle and loop, with a lap of two inches on the under side; in the other end punch holes for the buckle tongue; place the inch strap on the outside of the wide strap, in the centre, with one end extending one inch beyond the buckle; then stitch the two together, commencing at the buckle, 
and stitching two inches, having the loop pretty close to the buckle; then slip a one and one-half inch ring over the outer strap, close up to the stitching; then proceed with the stitching, and close up. This finishes the strap, which is to buckle around the ankle of the forward foot. A strap or webbing fifteen feet in length is buckled or tied in the ring, and carried between the girth and the body of the colt, and back into the wagon, holding it with the lines in your hands. All is now ready; start up slowly, stopping occasionally, while on the walk, pronouncing the word "whoa," at the same time pulling up on the foot strap. You will at once perceive that you have the most perfect control over the colt's movements. Should he attempt to run, catch his foot and bring him to a stop; don't halloo at the top of your voice, but with a firmness say whoa. You may think your colt would stumble and fall, but strange as it may appear to you, it is almost impossible when in that position for him to fall, or even stumble while in motion. The colt being unused to work, it will be necessary to give him a short drive the first time, as you do not want him to get leg-weary, and become sullen; after which you can give him short and lively drives until he becomes way-wised, and obeys the rein and word quickly. When he has by this means become accustomed to being handled without scringing, or showing signs of fear, you may then hitch him up single. 


\section{Hitching the Colt in Single Harness.}

Put on your harness carefully, which should be strong in every respect, and well fitted to your colt; lead him around for a short time, until he becomes familiar with the harness, then check him quite loosely at first. Fake your webbing, or the strap, that you have used to handle his feet, attach one end to the ankle of the right forward foot, carrying it back through between the bellyband of your harness and the colt. Now take your reins from the pad, and you have three reins, two to his head and one to his foot. Now drive him about a short time; when you want him to stop, use the word whoa, and take his foot. Now place the web or strap between his hind legs, touching him gently on each leg; if he should attempt to jump or kick, say whoa, pull on the foot strap, then gently approach him, pat and caress, to let him know that you are with him, and that he has done right in stopping. Continue this until he will start and stop at the word; come to the right or left, as the reins indicate. He is now prepared for the wagon. Do not be tempted, under any circumstances, to use an old rotten harness, or to hitch your colt to an old rotten, rattling wagon, liable to give way on the first move of the colt. Many valuable colts have been so frightened through such carelessness, as to become almost useless.

Make everything safe and sure, as safety and certainty should be your motto.

Before you hitch your colt into the shafts, lead him 
around the wagon or sleigh, and let him examine every part of it. Then back him into the shafts; stand on the left side of your colt; have the strap or webbing attached to the right fore foot, and over the back, holding it constantly in your hand. Now gently lift the shafts and make him fast. If- he should attempt to move, the word whoa, and the use of the foot strap, would quiet him. Now step to the right side, take the foot strap, pass one end over the bellyband of the harness, and carry it back on the right side of the wagon, over the hold-back strap, using that as a third rein in your hand. You see now that you are all safe. If he attempts to run, pull upon this strap, which instantly throws him on three legs, therefore he is obliged to stop; if he attempts to run back, the same remedy stops him; if he attempts to kick, call his attention to his forwaad foot instantly.

Now all that is necessary is to be careful, and use a little common sense in teaching your colt what you want him to do. In a very short time you have a colt that you can recommend as properly broken, safe and kind for any one to drive, which is almost the first question asked by the purchaser.

I have now taken you through the whole list of training your colt, and hope you will never lose sight of all the important principles of my system-Patience, Perseverance, and Kindness, with a good share of Firmness, and also remember that colts should be trained not broken. Train a colt in the way he should go, ant ho will never need breaking. Do not do as 
many people do-let their colts run until they are four or five years old, and then undertake to break them the old-fashioned way. This is impracticable, for you as often break their constitutions, their courage, their spirits, and sometimes their necks, and very often the breakers themselves get hurt. The colt should be taught step by step, with patience and perseverance, what you wish him to do; not driven to do what he does not know, what he cannot understand, while smarting under the lash.

I will now commence with the old bad horse's harness trick. I have very often remarked that ninety nine out of every hundred vicious horses in harness, are horses with ungovernable mouths. If we goverm the mouth, we will, in almost every instance, have a controllable horse. I will ask, did the reader ever see a balky, kicking, bolting, plunging, runaway horse, with a fine, easy, governable mouth? I never have, therefore I always give the vicious horse a thorough training with the bitting cord befere hitching up. In a short time he will learn to yield the mouth readily to the pressure of the bit, after he has been thoroughly trained with the cord. I wish to convince him beyond a question that I have the power to handle him just as I wish, and will just say that I consider it necessary to handle all horses in a manner to convince them that they can be controlled. Let your lessons be thorough, but not very long; be gentle and patient with the colt, but make the old 
stubborn and vicious horse feel the extent of your power until he submits; then repeat until he yields unconditional submission; then be gentle and kind, yet firm in your treatmont afterwards.

After testing all other plans that have been brought before the public, I must say that ny present system for handling a vicious horse - to subdue him - or for performing surgical operations, is far ahead of anything ever made public; and if I had retired from the business of teaching Horsemanship, I would not be deprived of the use of this one point for ten times its cost. The first step in the management of a bad horse, is to show him that his willfulness must yield to superior power. This you can do best with the use of my surcingle, which I will now explain, so that you need not make a mistake.

\section{Learning a Colt to Hack.}

Learning the colt to back is the next operation, and is a matter of great importance, as the future value of your colt depends upon his being thoroughly broken. It should be commenced while bitting the colt; and before you ever attempt to harness, you should teach him to back promptly at the word, in the following manner: Have on bitting bridle, stand in front and a little to the left of your colt, your left hand on the bridle, in your right a light spring top whip; now give a quick pull on the bridle, at the same moment a light blow on the nose with your whip, and say, "back, sir ;" ease up on the bridle, 
your whip at your right side, patting and caressing on the neck with your right hand; in a few moments try it again. By repeating this a few times, he will learn what you mean by saying "back, sir." He is now ready to harness.

\section{Subduing the Colt.}

The plan for subjugating wild colts and vicious horses, has been experimented upon more than all other points in horsemanship. At present there are five different modes of operating, as follows: Mr. J. S. Rarey's plan of strapping the foot; Messrs. Rockwell \& Hurlbut's whirling until he staggers, or falls to the ground; Messrs. D. Magner \& Dudley claim to have an improvement upon the last named by tying a loop in the end of his tail, taking the tie strap of the halter, pass it through the loop, bringing his head to his side, and tied fast to the tail; he then, with a bow-top whip, steps behind the horse, cracks him sharp in the quarters, and keeps him whirling urtil he falls. Another plan, as introduced by Prof. Hamilton, is to procure a piece of rein webbing ten feet in length, attach one end to the ankle of the left forward foot, made fast with a timber hitch, which is made thus: take the end of the webbing, carry it to the inside of the pastern, bring it around the ankle to the outside, thence under the main webbing over to the outside and back of the pastern, then pass the end under and up through between the ankle and webbing, passing the end through twice, and slipped 
up close, (a knot tied after that manner cannot slip or injure the pastern, and will also unitie without trouble.) After the whole web is made fast to the pastern of the left forward foot, the other end is carried through under the chest, and over the horse's back to the near side; a half-inch cord is now tied around the horse's neck, about midway between the head and shoulder; a running loop is then passed through between the neck and cord, carried forward and looped into the mouth. He now lifts the left forward foot, takes the webbing that is brought over the back to the near side, draws it close, winds the webbing around his right hand, and presses the knuckles hard on the left side of the back; with the left hand reaches to the off side of the horse's neck, grasps the cord that is looped into the mouth, and carries his head against his right shoulder. After moving him upon three legs for a little time, he then throws him upon the left side. All of the abovenamed plans may answer very well, but I never adopt any of them, only with the green colt. In handling a wild colt, if he (at times) becomes stubborn and willful, I grasp the halter with the left hand, with the right grasp the tail, and give him a few sharp whirls to the left until he is somewhat dizzy, I then slip to the opposite side, with the right hand grasp the nosepiece of the halter, with the left the tail, give him a few sharp turns to the right; if he is sullen and refuses to move, with your left boot give him a few kicks across the quarter, that will give him a start, 
after which you can whirl him either way as fast as you like. This will have a good effect upon a wild colt that has acquired no vicious habits; but for the old horse I use my surcingle. Study and fully understand its use and you will not fail to bring them to an unconditional surrender. Read carefully the next point in order, and its use will be fully explained.

\section{How to Subdue a Vicious Horse.}

Much has been said of Mr. J. S. Rarey's system of surjugating vicious horses. It is known almost the world over. He has taught his system in the United States, Upper and Lower Canada, and has also had the pleasure of operating before the royal Court in England; and as far as our knowledge extends, his system is met with approval of all those that have attended his lectures. But after giving him all the praise that is due, you must consider Mr. Rarey's system for subjugating vicious horses is like all other new inventions that are brought before the public in a short time there are very great improvements.

The plan I adopt by which to subdue vicious horses, I consider far superior when compared with Mr. Rarey's. We both accompiish the same object, but by a different way of operating. And why do I employ such means by which to subdue vicious horses? It is to put him in a position that he is unconscious of the amount of his strength, satisfy and convince him that I can control him to my liking, and when once conquered he submits himself to my 
will, after which he will do almost anything I may require of him.

Now, dear reader, before you attempt to do anything, it is necessary to know just what you are going to do, and how you are going to do it, and if you are experienced in the art of taming wild horses, you ought to be able to tell within a few minutes the length of time it would take you to bring a wild horse perfectly under your control.

I have given you the first step. He is brought up, and will follow you by use of the whip. Now, the next point is to subdue and conquer him. Let your cord remain upon your horse the same as for halter breaking. By the use of the cord you will be able to keep him quiet while placing the surcingle around his body, and other steps necessary for his subjugation. Mr. Rarey bedded the floor with straw, but I think it better to have a clean floor, and pad well the knees. If your floor is clean and dry, there is no danger of your horse slipping; if you use straw upon the floor, it is apt to give under his feet; he would slip, and perhaps get injured. Now for the plan, and use of the surcingle.

\section{Dimensions and Use of Surcingle.}

This is six feet six inches in length, two and a half inches in width, with twelve one and a half inch rings attached to it; the first ring is five inches from the buckle on the back edge; the second, one inch from the first on the front edge; next, six inches from the second. (This third ring is used for making the left 
forward foot fast.) The fourth ring, six inches from the third, placed to the back edge. The fifth and sixth rings are used as pulley rings to bring up the right forward foot - the fifth ring five inches from the fourth, the sixth, four inches from the fifth; the seventh, two inches from the sixth, on the front edge; eighth, eight inches from seventh on back edge; ninth, nine inches from eighth; tenth, three inches from ninth on back edge; eleventh, five inches from tenth; twelfth, two inches from eleventh, on back edge. The second and seventh rings are attached to the front edge of the surcingle, used for bringing the horse's head on his side when performing surgical operations. The first, fourth, eighth, tenth and twelfth, are attached to the back edge by the use of short straps fastened with copper rivets; these are used for fastening both hind feet to the surcingle when performing operations, such as castrating, fireing, etc.

You are now acquainted with the plan; now for its practical use. Take your surcingle, approach your horse on the left side, put it around his body; buckle so the third ring will be just in the position by which to fasten the left forward foot. Place in the third ring a strap eighteen inches in length, one inch and a quarter wide, with buckle and two loops, the same as a common hame strap; this put through the third ring, the end slipped into the loop on the unfinished side, and drawn through. The strap now hangs by the third ring, fastened by a loop just back . of the left forward arm. On the right side of the 
horse, just back of the arm, are the fifth and sixth rings. You have prepared another strap fifteen feet in length, and one inch wide. One end of this strap is buckled on the fifth ring, also a small strap eight inches in length, with one ring attached. This is buckled around the ankle of right forward leg, ring on outside. The other end of fifteen feet strap passes through the ring at the pastern, and brought up through the sixth over the horse's back. All is now in readiness for handling your horse.

You are standing on the left side of your horse. Take up the left fore foot, and bend his knee till his hoof is bottom upward, and nearly touching his body ; the strap hanging to the third ring is brought around the ankle and buckled. The left foot is now secured, and leaves your horse standing on three feet, and in your power. You are standing on the the left side of your horse. Grasp the bridle-rein on the left side of the horse's neck, six inches from the bits. Reach over the horse's back with your right, holding the strap that comes from the opposite foot; bear against his shoulder till you cause him to move. As soon as he lifts his foot, your pulling with your right will raise it in the same position as his left, and he will have to come on his knees. Keep the strap tight in your right hand, so that he cannot straighten his leg if he rises up. Hold him in this position and turn his head towards you; bear against his side with your shoulder, not hard, but with a steady, equal pressure, and in about ten minutes he 
will lie down. As soon as he lies down he will be completely conquered, and you can handle him as you please. Take off the straps, and straighten out his legs; rub him gently about the face and neck with your hand, the way the hair lies; handle all his legs, and after he has lain ten or twenty minutes, let him get up. After resting him a short time, lie him down again. Repeat the operation three or four times, which will be sufficient in most cases, for he is perfectly conquered, and has submitted himself to your will, and can be educated to do almost anything you may require of him.

By the use of the surcingle, you can place your horse in any position you like, without the assistance of any one. He can be castrated in twenty minutes by one alone - can be educated to know that a Buffalo robe, umbrella, piece of paper, or any object, however frightful, is harmless, and after once educated in that manner, you have no further trouble.

\section{Castrating.}

The plan usually adopted for throwing and castrating the colt, has been attended with more or less danger, time and trouble. The operator has prepared a rope about one inch and a half in diameter, and some twenty feet in length; in the centre is made a loop, which is slipped over his head and neck down to the shoulders, the ends carried back and around the ankles of the hind feet. One man is placed on each side of the colt, holding the ends of said rope; 
the third man at his head. The two men holding the ends of the rope, pull, while the man at his head endeavors to back him. After some severe struggling, he is thrown back upon his haunches. I must say the plan is not only cruel, but attended with a great amount of danger. The colt does not recover from his injuries for some time. Two valuable colts, to our certain knowledge, were rendered worthless by the use of the above mentioned step in throwing them. One had his thigh broken - the other so injured across the loin that he became useless. By the use of my surcingle, as described on previous page, any boy fifteen years of age, can lay down a horse easily, and place him in any position for performing surgical operations of any kind, without the assistance of any one. In sections where I am travelling, in the spring season, colts are sent to me daily to be castrated, and not in a single case have I occupied more than ten minutes in performing the operation, without any assistance. By the use of my surcingle it can be accomplished in ten minutes (alone,) easier than to adopt the old-fashioned way, with half a dozen assistants.

\section{How to Drive a ER unaway Horse.}

This is easily effected by buckling a strap eight inches in length, one inch wide, around the ankle of the left forward foot, with inch ring attached; another strap, fifteen feet in length, one inch wide, with one end buckled to the hame ring, the other end slipped 
through the ring attached to the pastern, and from thence under the hip-strap into the wagon. By adopting this plan you can remain seated and control him as you please. When you move your horse, pull on your strap, and by so doing you bend the leg inward, so as to bring the bottom of the hoof nearly up to his body. Your horse now stands on three legs, and you can manage him as you please, for he can neither rear, run, nor do anything of a serious nature. This simple operation will conquer a vicious horse quicker than any other plan that can be adopted; it does not hurt him, while it enables him to perceive that you can render him powerless. His foot claims all his attention, and you can drive him at your pleasure. He may at first get very mad, and strike with his knees, but will soon give over, after which you may go to him, let his foot down, and caress him. You must bear in mind that he will tire very quickly on three legs; hence you should let him have his foot as soon as he seems to be fatigued. You can let him have his foot without getting out of the wagon; let your strap be a little slack, the ring on the pastern slipping backwards and forwards as he travels, so that no obstruction is in the way. Drive him with his foot down as long as he is quiet, but if he attempts to do anything wrong, pull on the strap and take his foot from him again. If he manifests a desire to run, let him have the lines, but keep the strap firm that is attached to his foot; he will soon tire, and stop at the word. By driving him in that way a short time, 
you will have effectually mastered his disposition to run, or try to get away. I have seen horses, totally unmanageable from their vicious propensities, so gentled by this process that in a few hours they might be driven anywhere with perfect safety; and one great advantage of the plan is, that the results are permanent.

\section{How to Drive a Kicking Horse.}

It must be remembered that this is a vice foremost in point of danger. A vicious kicking horse is more dangerous than one possessed of any other vice. If your horse is a little nervous, lie him down with your surcingle, and gently harness him as though he were ever so kind. Then put on your ten-cent cord bridle. This is made by taking a half-inch cord twenty feet in length; get the centre, and loop two gang-runners one foot apart; now place it on the horse's head just back of his ears, with loop on each side ; the ends are brought down, crossed through the mouth, and back through the loops above. Now your bridle is arranged on his head. Take the ends (after brought through the gang-runners) back through the turrets of your pad; place your horse between your shafts ; buckle the belly-band close, so your shafts cannot rise; then place a pully on the top of the shafts, each side of the horse's quarters; make them fast. Then bring the cords from the turrets that are attached to the pad under the wheels of the pulley, over the horse's quarters, and make them fast. Your horse is 


\section{7}

in just the right position. Have no fear, for you can drive any kicking horse with it anywhere you please. If he attempts to raise his quarters, he throws his head violently into the air, and can do no harm; it has a peculiar advantage over him, for it does not hinder the travelling, as there is nothing attached to his feet; and all you have to attend to, is your lines. Drive him in that manner for three or four days, after which remove it, and your horse is effectually broken of the vice.

\section{Another Plan for Driving a Kicker in Harness.}

Place him between your shafts as before; place your cord bridle upon his head, and arrange it same as first lesson for driving kickers in harness. Now get a two inch ring, place it on the top of the back strap, where the hip straps cross; get a piece of harness leather four inches long and one inch wide. Stand the ring on the edge, take the four inch strap, pass it through the ring, and stitch fast on each side. The ring is now made fast to the back strap on top of the horse's hips. Take the ends of your cord bridle, (after passing them through the gag-runners,) bring them back to the horse's quarters, and pass both ends through the ring that is attached to the back strap ; the cord that is passed through the gag-runner, on the left side of the horse's head, that being passed through the ring, is brought down across the left hip, and made fast to the shaft; the one on the right side of the head is passed through the ring, carried down 
over the right hip of the horse, and made fast to the off side shaft-drawn close enough to keep his head well up. I think the explanation given, sufficient to give the reader a full understanding of the horse's position. Get into your wagon; start your horse; all you have to attend to, is your reins. You see at once if the horse attempts to raise his quarters, he sends his head violently into the air. The cord bridle in his mouth is very severe, and has a powerful controlling influence. In hitching him up the first time, I would recommend hitching him to a two-wheeled vehicle, with shafts strong, made of poles some three inches in diameter. Should you have a horse of this kind, in kicking should he curb his mouth against his chest, and kicking almost straight back, without raising his head but little, place an iron standing martingale two and a half feet in length from the hames to the bits; that will leep his head well up, and he can do no harm. Drive the kicker in that position for eight or ten days; drive him in such places where he would be most likely to get frightened and attempt to kick. I think that length of time will subdue and conquer the most of kickers.

\section{How to Handle a Kicking Horse in Double Harmess.}

In handling a kicking horse in double harness you can virtually adopt the same plan as recommended in single harness. Hitch him to pole by the side of a well broke horse; procure a heavy wagon shaft, 
with a bow at the butt, the same as for carriage. Step to the side of your horse, pass the small end through the lug strap (as in single harness) turning it sidewise, then carry the point of the crooked end under the end of the evener, leaving a lap of some four inches, and make fast with two half-inch bolts, bend projecting outward, after which procure a strap four and a half or five feet long, (owing to size of horses,) one inch and a half wide, with billet buckle and loop attached to each end, the same as your reins are buckled into the ring of the bits. One end of this strap is buckled around the false shaft, where it passes through the tug strap of the harness of the kicking horse; the other end is passed through under the chest of each horse, just back of the forward legs, and buckled into the outside tug buckle of the opposite horse. That is to prevent the shaft from raising when the horse attempts to kick. Now place your cord bridle upon the horse's head, as recommended in single harness ; bring the ends back, and pass them through the ring made fast on the top of the hips; on one side bring one of the cords down across the hip, and make it fast to the pole; the other end over the hip, and make fast to the false shaft. He is now in almost the same position as when between the single shafts. The strap under the chest prevents the shaft from rising, should he attempt to kick, also the horses from spreading. I have another plan of working a kicking horse in double harness, and why I do not recommend it in all cases is because the opera- 
tor is too apt to get careless, and neglect to watch closely the moves of the horse. The operator can always tell by watching him closely, when he is premeditating a vicious move; a little scringing, dropping of the ear, frisking of the tail, hogging down on the bit with a sudden start, all indicate something wrong. Consequently, you see it is highly necessary to watch his moves closely.

The plan I was about to speak of is as follows, and my experience in handling horses warrants me in recommending it a good one: Hitch your kicker by the side of a well broke horse; procure a strong, half inch cord, fifteen or eighteen feet in length, pass it around the horse's neck, get the size, tie your bow-line knot, slip it over the head, and well down toward the shoulder; then take hold of the cord below, pass it through the loop, between the neck and cord, and place the running loop into his mouth, same as for bitting; then attach the long foot strap to the ankle of the inside forward foot; carry the other end back between the girth and body, into the wagon; also your cord. Get some friend to ride with you for the first time, he driving the team, you handling the cord and foot strap. If he attempts to kick, take his foot from him, give him a sudden pull with the cord. I have broken some of the worst kind in a . very few days by adopting this plan. You have a powerful controlling influence over them, as they can neither run nor kick. Try it. 


\section{How to use a Balky Horse.}

If ever I felt that the horse deserved the philanthropic sympathy of man, it has been when I have seen a man, ignorant and brutal in his own nature, trying to move a balky horse. I will have, been amply repaid, and will have certainly given every one who buys this book a rich equivalent for his money, if by its perusal I induce a more civilized mode of treatment. You are to remember that balking is an acquired habit, and not from any disinclination on his part to pull. I know that sorne men will take the very best pulling horse, and in a short time make him balk, simply from mismanagement. It is not the dull, indolent horse which balks, but the highspirited and fiery horse of blood and mettle; this is so, because those who undertake to drive them do not understand them. Notice which horse of a team it is that balks, and you will mostly find it to be the one of the highest mettle. He hears the command to go, and being more ready to obey than the other, he springs off; but, not being able to start the wagon, he is thrown back on his haunches, stopping the other as well as himself. The driver whoops and snaps his whip, and by the tirne that the slower horse has started, the free horse has made another effort, failed, and now both are balked. Both horses recognize that something is wrong, and neither knows what. They are alike afraid to move. Then the driver plies the whip, whoops and slaps the lines, all of which only tend to make the matter worse. This has been 
seen by almost every person. The horse was willing to go, but did not know how to move the load; and we ask any sensible man to tell us if the horse should be beaten for not doing that which he did not know how to do. You can make a horse do almost anything which he can fully understand; and I do contend that by proper education, any balking horse can be started in a few minutes. Some have adopted the plan of buckling a strap to the ankle of one forward foot, standing in front, and by pulling the foot forward, the collar presses against the shoulder, and he will move. Others have adopted the plan of throwing a handful of sand in his eyes, but to this plan, though it succeeds, I am bitterly opposed. I would sooner own a balky than a blind horse.

If you get hold of a horse that has been long in the habit of balking, just set apart a day for his education. Go into some pasture field, hitch your horse to a light load, something that he can move easily. If he refuses to pull, get a half-inch cord, ten feet in length, tie it around his neck and loop it forward into his mouth, just as recommended for halter-breaking. Step to one side, give him a sudden pull, and he will move a step towards you. Step to the opposite side; give him another pull; by repeating it ten or twelve times, he will start willingly. Then increase your load, and if he refuses to pull, use the cord as above. I have seen the worst of balky horses in three hours time made perfectly kind-to pull in any spot or 
place. The plan is simple. And why is it so effectual? There is nothing you can place in a horse's mouth by which you can control him with such ease. The corl is placed around his neck, and brought forward into his mouth, and by a sudden pull with the other end, it is drawn suddenly across his tongue, comes in contact with the nerve of his lower jaw, which he cannot long endure, and he willingly moves off. If at any future time he should show any symptoms of balking, a lesson with the cord is all that is necessary.

\section{How to BBreak a Falter Puller.}

Always use a leather halter, and be sure to haveit made so that it will not draw tight around his nose. If he pulls on it, it should be of right size to fit his head easily and nicely - so that the nose band will not be too tight, or too low. Never put a rope halter on an unbroken colt, or a horse that is in the habit of pulling at the lialter, under any circumstances whatever. They have caused more horses to hurt or kill themselves, than would pay for twice the cost of all the leather halters that ever were needed for the purpose of haltering colts. It is almost impossible to break a horse of the vice with a rope halter. He will pull, rear and throw himself, and thus endanger his life. And I will tell you why. It is just as natural for a horse to try to get his head out of anything that hurts it, or feels unpleasant, as it would be for you to try to get your hand out of a 
fire. The cords of the rope are hard and cutting; this makes him raise his head, and draw on it, and as soon as he pulls, the slip-noose (the way the rope halters.are always made) tightens and pinches his nose, and then he will struggle for life. Who would run the risk of a fine horse breaking his neck rather than pay the price of a leather halter? If you have a horse that, from mismanagement, has acquired the habit of pulling at the halter, place your leather halter on his head; the strap you bitch with, have it twenty feet in length. You may hitch him in a stall or to a post outside, or any place where he is in the habit of pulling. If in a stall, run the end of your rein through the hole in the manger, then back through the ring of the halter, and, as you pull it through the ring, bring his head within two feet of the manger, then between his forward legs, and make fast to the ankle of his left fore foot. I think you can see clearly there is no possible chance for him to break his halter, or get loose. If he makes an attempt to pull back, he brings his left hind foot forward under the body, is fearful he will fall, and steps forward in a moment. After he has made the attempt to break his halter, three or four times, you may take any object, however frightful, and hold it in a position to frighten him, and he will not make an effort to pull back. I have seen the worst of the kind effectually broken of the vice in thirty minutes. 


\section{Another and Better Plan for IBreaking a Halter-Puller.}

Lead your horse to a place most convenient for hitching him. It don't matter whether to a post, in the stall, or elsewhere. Place a common strap halter upon his head, then procure a piece of rein webbing fifteen feet in length, or a strap one and a fourth inch wide, of same length; get the center of said webbing or strap. Now buckle a common web surcingle around his body, just back of the shoulder, then lay your webbing across his hips ; carry one end forward between the surcingle and body, on the left side, the oposite end between the surcingle and body on the off side of the colt; the center rests across his hips, the ends carried forward. Take the center of the webbing in your right hand, give it one turn over; that leaves it crossed upon his hips ; carry the center and pass his tail through the loop you made by turning the center of the webbing over, the samie as cruppering with harness. Step forward; reach your left hand through under the horse's neck; take hold of the end of the webbing on the off side; with your right hand take the end on the left side ; bring the two ends together under the neck, and tie them around the chest. Then carry the end of your tiestrap through the ring in manger, or some point where he has been in the habit of pulling; bring back and make fast to the webbing that passes around the chest. Your halter-puller now is in the right position; if he refuses to pull, induce him to do so 
by frightening him in some manner. My experience with halter-pullers warrants me in saying this plan is lasting and effectual. You can hitch him in the stall, let him remain in that position through the night. He can lie down, get up, and move around the stall without injuring himself in any way. Hitch him each day at different points where he has been in the habit of pulling, after which you need have no fears of his breaking a common halter

\section{A Runaway, Bolting, or Plunging Horse.}

This is a very dangerous vice, one accompanied with a great amount of danger to limb and life. If the horse, when making an effort to run, becomes very wild and desperate, and in bolting, would jump off some bridge or precipice, it is highly necessary to have some means of controlling him, and to bring him to a sudden stop. To accomplish this, use the cord with small loop placed around the under jaw of the horse ; the other end is carried over his neck, brought back, and pussed through the small loop attached to the under jaw, and thence back into the wagon. The running loop over the horse's neck should be kept well back to his shoulder. Now prepare two long foot straps, and attach the end with short strap to the ankle of each forward foot. The other ends pass through between the girth and body of the horse, outsile of the traces and into the wagon. Hold your long footstraps and cord in your hand with the reins, then drive him along in places where 
he would be most apt to scare. If he attempts to run or bolt, give him a strong pull with the cord, at the same time say (with firmness) "what are you doing, sir? go 'long." That may cause him to straighten up, and perhaps give him a sudden start; if so, give him another pull, and say, "carefully, sir!" If the second pull does not check his speed, and you think he may get the best of you, then is the time to pull on the foot straps; take his feet from him, and drop him to his knees, pronouncing the word whoa. That brings him to a stop without any failure. Now ease up on your foot straps; do not hold him by the feet after dropping him to his knees, for in so doing he would be likely to struggle, fall over, and perhaps break your shafts. Again start him, if he attempts the same move, take his feet and bring him to a stop. He will not attempt the same move but a few. times. - There is nothing that will so frighten a horse, as to think he is going to be pitched on his head. The plan will effectually conquer and subdue that willful disposition. After driving him a few times with both webs, you may then feel safe to drive him with one. Every few days repeat the lesson with cord, and one long foot strap; a lesson each day for a few days will produce the desired result. The same plan is adopted with colts that are in the habit of running, and kicking at dogs, hogs, pieces of paper flying in the street, and the like. They are constantly on the lookout for such objects, and the diviver or owner is never safe. Place the cord as recommended 
above, into the mouth, and the webbing to the foot, or both if necessary; for my experience in handling horses has convinced me that some horses have the strength and will, to run a fourth of a mile on three feet; that is the reason why, in some cases, I use the long strap attached to both feet. In that case you disconcert them at once. If the colt is very headstrong when frightened, place the webbing to both forward feet, and cord in the mouth. Also with open bridle, so he can see all around him. Take a dog into the wagon with you ; as you are driving quietly along toss the dog out on the same side you are driving your colt. If he attempts to kick and run, give him a sudden pull with the cord; at the same time take his feet from him, saying whoa. Get out, pat and caress him; then repeat it again. A few lessons will break him.

\section{Pawing in the Stall.}

Get a common trace chain, about two feet long; fasten it to the leg that he paws with, just above the knee, with a hame strap, and let the chain swing to the side of the leg. He will soon be glad to keep it still.

\section{Kicking in the Stall.}

Some horses acquire this vice from mere irritability, and uneasiness in the stall. If the horse kicks with but one foot, he can be broken very easy, by attaching a wooden clog to the ankle of the foct that 
he kicks with. If with both feet, take the saddle part of a harness, and buckle on tightly, then take a short strap, with a ring and buckle around the forward foot, below the fetlock. To this strap attach another strap, bring up, and pass through the turrets down to the hind foot, below the fetlock. With this attachment on each side, the moment that he kicks he will pull his forward feet from under him, which brings him to his knees, and he will be careful not to do so very often. Let him stand in the stall in this way until he gives up the foolish habit.

\section{Vicious Biters.}

If he is a stallion, with the confirmed habit of biting and striking at your approach, I can give you but little encouragement. I would not think it worth while to attempt to break him, but would advise you to castrate him at once. However, I have bought several bad biting stallions, and effectually cured them of the vice while in my possession; but on the approach of a stranger, they would show more or less viciousness. I have known owners of such horses to whip them until they would tremble in every joint, and were (seemingly) almost ready to drop, but have never, in a single case, known them cured by such treatment. In twenty minutes he is as determined as ever, to renew the combat. He seems unable to resist the temptation. I sometimes think it a species of insanity. If you bave a mare or gelding in possession of the vice, you can easily cure them. Place 
the small loop of the cord round the under jaw, with running loop over the neck; have the small loop fit so close around the jaw that he cannot spit it out, also under the tongue. The other end carry out of the stall, and hang on the peg where you hang your harness. Now, as you step up to the stall, take hold of the cord with one hand, the other place on his quarter, and say, "stand over." If he attempts to frisk, or bite at you, give him a sudden pull and say, "take care, sir!" then pass into the stall. If he again attempts to bite at you, give him another sharp pull, saying, "what are you doing, sir?" Give him a few lessons of this kind, and a cure is performed.

\section{Bad to Bridle, Harness, or Groom.}

A horse that is bad to bridle, is generally one that is tender about the ears; those bad to groom or harness are naturally very sensitive skinned. A sharp curry comb is very irritating, and in the act of harnessing, should there be a sore or chafed spot, it creates a spasmodic, nervous movement of the skin. Such horses can easily be broken of the vice by the use of the cord. Place the long loop around the neck, with running loop in the mouth, as for bitting. Stand by the shoulder, give him a sharp pull with the cord, at the same time repeating some word, such as "whoa, boy," "be careful," "be quiet," or the like. Now step to his side, pat and caress him about the head, neck, and shoulders. Steadily pull the cord through the mouth with your right hand; with your left softly handle 
his ears until he becomes quiet. A few times bridling with the cord will cure him of the vice. For grooming or harnessing, use the cord the same. If he will not stand quiet to be harnessed or groomed, a few sharp pulls to the right and left will bring him to a surrender. Use the cord each time for a few days, and he will become docile and quiet.

\section{FEolling in the Stall.}

In the first place break your horse from rolling in the stable, for it is a habit that cannot be indulged in without a chance of being cast. Some borses will get cast, bruised, and half strangled, yet he will roll again the next night, and continue to as long as he lives. My plan to break up this habit is to place a thin, soft pad under the surcingle, with sharp nails so arranged that they will run through the pad and prick him, when he altempts to roll.

\section{Getting Cast in the Stall.}

If there is anything that will vex, and irritate the proprietor of a stable, it is to have some one of his horses getting cast in the stall. Every night a thundering noise is heard, and some one calls out, "you have a horse cast." Up he gets, hurries to the stable, and with a great deal of hard labor they finally succeed in getting the horse to his feet, stiff, and badly galled. Observe the following and you will have no such trouble. Place on your horse a five 
ring strap halter, ( a five ring halter he cannot slip,) where the strap comes over the head, just back of the ears, attach a one and a half inch ring; do not slip the top piece through the ring; you must make it fast, so it will not slip to the right or the left; get a strap four inches long, one inch and a quarter wide; set your ring in the center of the strap that comes over the top of his head, then run the four inch strap through the ring, stitching both ends, leaving the ring fast in the centre; with the tie-strap of your halter, make fast to the ring of the manger; leave sufficient length to put his nose within one foot of the floor. Over his head, and in the floor above, attach a staple and ring; now put his nose within one foot of the floor, and get the distance from the ring in the top of the halter to the ring in the staple above, about a foot back from the manger. The horse has the liberty to lie down, but cannot lay his head sidewise, consequently he cannot get cast. The above never fails.

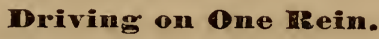

Even the angles of the mouth with the bitting cord. Then keep the blinders up so that he cannot see the driver, for this is often the cause - he is often watching back with one eye, and carrying his head to that side, constantly pulling upon the opposite rein. Oftentimes it is caused by the grinders being sharp; if so, file them off. 


\section{댐al Pullers.}

It is often remarked, and by horsemen, too, if yon have a hard puller upon the bit, give him all the road he wants, and let him go. If he goes too fast, jerk him up, first with one line, then with the other. I have known some hard pullers, by giving them the rein, and all the road they wanted, would run until they would fall, and repeat the same thing day after day. The idea is perfectly absurd. It will amount to nothing but a broken down constitution. Let me speak of a simple plan by which you can control such horses at pleasure. Get a common snaffle bit, around which weld two iron rings one inch and a half in diameter. The bit is now placed in the horse's mouth, with rings slipped close to the cheek bars; get a half inch strap, ten inches in length, with billet buckle and loop attached to each end, same as for buckling check reins in bits; now place it across the horse's nose, and buckle each end into the rings that are welded around the bit. That brings the rings very close each side of the upper jaw ; stich to the centre of the strap across the nose, one end of another half inch strap eighteen inches long; to the other end attach the buckle on the top of the bridle and between the ears. This is to keep the nose piece from dropping over the nostril. 'The bit is now arranged. Place your horse between your shafts; buckle your reins and start him along: Drive him with a slack rein as long as he is quiet. If he attempts to go very fast, pull upon the lines. As 
you pull, the rings around the bit crowd with more force against the sides of the face, throwing his mouth wide open, and causing the most excruciating pain. Drive him a few days with a bit so arranged, after which any boy twelve years of age can drive him with perfect ease.

\section{Tongwe Over the IBit.}

Attach to your bridle a check bit, as follows:Procure a small steel bar bit; a small one, so the cheek bars will sit close each side of the horse's face. To this bit buckle checks and cheek pieces of bridle; through this bit drill two holes, leaving a space between, and in the centre, of two inches and a half; get a thick piece of harness leather six inches long; cut it in the form of a diamond, two and a half inches wide, with ends rounded off to a point. The centre of this piece of leather is doubled over the bit, with edges just covering the two holes; it is now stitched together across, and close to the bit; also edges of points are stitched firmly together; as the bit is placed in the mouth, the rounded points of the leather run back into the horse's mouth, and top of the tongue. He is now checked up, and the bit kept snug in his mouth; your reins are not to be buckled to this check bit, but another is used for driving. Get a common snaffle bit. This is made fast to the cheek pieces of the bridle with a couple of small half-inch straps five inches long, with buckle and loop attached, letting it hang in the mouth, one inch below the check 
bit; to this attach your reins. You now have a driving, as well as a check bit. If the horse attempts to work his tongue over the bit, the piece of leather, so attached, will prevent him at once. Should he (as is seldom the case) carry his tongue under the bit and out of the mouth, to the holes drilled through the bit attach a piece of large wire, passing the ends through; let the centre drop one half inch below, same as a wide wire staple. When you put the bit in his mouth, pull his tongue through the loop, seeing that the space is large enough for it to sit easy. These plans will soon break a horse of the contemptible habit.

\section{To Shoe a Horse that is Vicious.}

I care not how vicious a horse may be when shoeing him, I think I can make the worst of the kind stand perfectly still in ten minutes, so that the smith will have no further trouble. The plan which is adopted by the smiths in general is not only cruel, but has a tendency to make them far worse. A colt is taken to the shop, wild and uneducated; and during the process of setting the shoes, if he makes a wrong move, the smith gets in a fearful rage, gives him a sharp blow with the hammer or rasp, the horse rears and plunges, and is so frightened he will not allow a hand laid upon him. The next move is to fetter or cast him. A rope is put around his neck, then to the ankle of each of his hind feet, then forward; with perhaps two men at each end; they pull 
on the rope, and the horse is thrown back upon his haunches. I have seen fine horses so injured across the loins by adopting this plan of throwing them, that they were never again fit for use.

Another plan is to put a pair of tongs upon his nose, then a rope to the ankle of one of his hind feet, and through a ring made fast to his tail; his foot is drawn back; and made fast to the side of the shop.

Now, I ask any man if there is any common sense in employing such means by which to shoe a wild horse. If a horse struggles, which he is sure to do, he must get badly injured. In shoeing a bad horse, never confine him. : Get a small cord, about ten feet in length, place it around his neck and into his mouth, just as recommended for halter breaking, balking, \&c. All it will cost you is five cents, and by its use you can shoe the worst of the kind without trouble. In attempting to raise the foot, if the horse should rear or attempt to kick, let go the foot and give him a sudden pull with the cord; then pat him on the neck, saying, "Ho! boy; ho, boy;" then hold the cord in your hand, and with the right pick up his foot. If he does not stand quiet, put his foot down, and give him two or three sudden pulls with the cord. Handle him in that manner ten minutes, and he will not dare to move. Smiths, in many places, have said they would not be cleprived of the use of the above plan for one hundred dollars. 


\section{For Teaching a llorse to Back, or a Horse that is in the habit of Bolting.}

The cord is all that is necessary for teaching your horse to back. Place a pair of them around his neck and into his mouth, one on each side. Get behind your horse, and you can teach him to back at the word in twenty minutes. For a bolting horse, use but one. If he is in the habit of bolting to the right, place the cord on the left side, and back into the wagon. If to the left, place it on the right side of the neck, and into the wagon; and when he attempts to bolt, a sudden pull will bring him in the right direction. Drive him with a cord a short time, and he is broken of the vice. To educate him to the word "Whoa," a little pull, accompanied with the words, 'Ho! boy,' is all that is necessary, and he will obey you

\section{The Plan for a IBreachy Horse.}

A breachy horse is one that costs the farmer a great amount of time and trouble. He goes to the pasture field, but is never sure of finding him where he perhaps left him the evening previous. Mr. Cole's plan, by which to prevent a horse from jumping, is to place a leather surcingle tight around his body, with inch ring under the chest, fastened to the surcingle; also, a strap one inch wide, eight inches in length, buckled around the ankle of the left hind foot, with ring attached; a strap one inch wide, three and a half or four feet in length, (the length of this strap is governed according to the size of the horse,) one end 
buckled in the ring under the chest, the other end to the ring attached to the ankle. If the horse should attempt to jump, placed in such a position, he deprives himself of the use of the left hind foot, has not power in the right, sufficient to rise-consequently he must fail in his attempt. In most cases the plan proves quite effectual.

To improve this surcingle, and prevent its working back, attach another ring to front edge, and under chest; to this ring attach another strap as follows: procure a strap one inch and a half wide and two feet long; split this strap in the centre to within four inches of one end, being the same as the crotch end of an old fashion standing martingale; the wide end is passed through the ring under the chest, with two inch lap, and stitched fast, eight inches from the ends of split strap; a buckle is made fast, leaving a billet eight inches in length. Now bring one of the split straps around the left arm outside; carry it back between the forward legs, pass the eight inch billet through the ring under the chest, again forward, drawing up the slack and buckling fast; the other part of split strap is carried around the nigh arm of the horse, and made fast same as left one. You see the horse has the privilege of walking around the pasture, but cannot easily trot or run, and should he attempt to jump, in the act of raising forward, the straps tighten, he has no use of his forward legs, and is disconcerted at once. I have known horses fail to jump a fence four rails high, with that simple attachment. 


\section{Ilow to Catch a Illorse in Pasture.}

The prevailing opinion of horsemen generally is, that the sense of smell is the governing sense of the horse, and that no means can be employed by which to catch a wild horse in pasture without the use of strong smelling oils. Sullivan, Faucher, as well as others, have got up receipts of strong smelling oils, to catch and tame a wild horse - sometimes using the castor of his leg, which they dry, grind into a powder, and blow into his nostrils, sometimes using the oil of rhodium, cummin, and organum, that are noted for their strong smell, and sometimes they scent the hands with the sweat from under the arms, and blow their breath into his nostrils; all of which, as far as the scent goes, have no effect whatever in gentling or subduing the horse, or conveying any idea to his mind, though the work that accompany these efforts - handling him, touching him about the nose and head, and patting him, as they direct you should after administering the article-will have a very great effect, which they mistake for the effect of the ingredients used. By using the oils, you can approach a wild horse in pasture, and, after caressing him for a length of time, get your halter on his head, but when you attempt to lead him, he is off as wild as ever.

Faucher, in his work entitled The Arabian Art of Taming Horses, page 17, tells us how to accustom a horse to a robe by administering certain articles to his nose, and goes on to say, that these articles must first be applied to the horse's nose before you attempt 
to break him, in order to operate successfully. Now reader, can you, or any one else, give one single reason how scent can convey any idea to the horse's mind of what we want him to do? If not, then of course, strong scents of any kind are of no account in taming the unbroken horse; for everything that we get him to do of his own accord, without force, must be accomplished by some means of conveying our idea to his mind. I say to my horse, "Go long," and he goes; "whoa," and he stops, because these two words - of which he has learned the meaning by the tap of the whip, and the pull of the rein, that first accompanied them - convey the two ideas to his mind of go and stop. Faucher, nor any one else, can ever learn the horse a single thing by means of the scent alone. How long do you suppose a horse would have to stand and smell of a bottle of oil before he would learn to bend the knee, and make a bow at your bidding, go yonder and bring your hat, or come here and lie down?

Thus you see the absurdity of trying to break, or tame the horse by the means of recipes for articles to smell of, or medicines to give him, of any kind whatever. The only science which has ever existed in the world, relative to breaking horses, that has been of any account, is that true method which takes them in their natural state of mind, and improves their intelligence. Consequently, if you wish to educate your horse in a proper manner, adopt a mechanical process. He will then fully comprehend your mean- 
ing, and obey at the word. If your horse is wild, and will not be caught when in pasture, drive him into the barn and close the doors, and make them fast, after which adopt Mr. Smith's plan on fifth and sixth pages. It will bring him up to you, and he will follow you just where you wish to ; after which you can go to the pasture field, and say, "come here, boy," and he obeys the call at once, and gives you no further trouble. 


\section{NEW AND LATEST IMPROVEMENTS.}

No doubt you are well aware that my book is copy-righted, also stereotyped; and since the date of this edition, I have made some valuable improvements. I thought it a better way, to add the late improvements, than to strike out the old and interline the new. By so doing, you can have a thorough knowledge as well as the benefit of both.

\section{My First is for Malter-HBeaking.}

After your colt is made to follow by the use of the whip, the next move is to satisfy him beyond a doubt, that you can control his head. The attachment is made as follows: Get a strap one inch wide, and two feet in length; on one end of this strap make fast one inch and a half iron ring; the other end punch your holes ready for passing through a buckle that I shall soon prepare. Now, in the same ring, (attached to end of said strap,) make fast a short inch strap, of sufficient length to make fast a buckle with loop. Now, understand me ; this strap, two feet in length, is passed around the horse's neck to the off side, brought over to the nigh, passed through the buckle and made fast around his neck about one foot back from his ears with inch and a balf ring hanging on the under side of his neck 
Now procure a piece of half-inch square rubber, eight inches in length, or a piece of stiff elastic webbing, of same length. Now, understand me fully. One end of this rubber is passed up through the ring and between the off side of the horse's neck and strap; the lower end of the rubber dropping through the ring about one inch; the upper end of said rubber is stitched and made fast to inside of the strap eight inches above the ring; now procure a half-inch, hard twisted cord, (cotton or hair is preferable, ) fifteen feet in length. One end of said cord is made fast to the lower end of the rubber that drops through the ring under his neck.

Now, your halter-breaking attachment is finished, and, I think, explained so you may get one made easily. Now for its use. After you have the three points established with your colt, Fear, Love and Obey, and he follows quite handily, you then buckle this attachment around his neck quite snug; then slip it from his head down, about twelve or fifteen inches, after which pass the cord that is attached to your rubber through his mouth, and back through the ring. You have him now perfectly under your control. Now take hold of the lower end of the cord, and step to the nigh side of your colt, about opposite of his shoulder, and give him a sudden pull; then step to the opposite side, and do the same. You will see at once, you have one of the most powerful instruments for controlling the head, ever made known. You discover at once, by pulling 
upon the cord, the rubber gives, and the cord slides quickly through the mouth, and soon as you ease or slacken up the end that you hold in hand, the strength of the rubber brings it quickly back to its place. So you see at once the attachment has more than twice the subduing power that the cord has, used in the old fashioned way.

After working your colt about ten minutes with the above attachrnent, you may then remove it. Place your halter upon his head, stand by his shoulder on the near side, and with a spring-top whip, touch him lightly on his quarters, and he will readily start off, and lead quietly wherever you may wish to go. Your colt is now halter-broken, and is ready to be put into the surcingle, and made to know that he must submit to all of your requirements, the use of which you fully understand from the explanation on a previous page.

\section{Bitting the Colt.}

The attachment I use for bitting, is made the same as for halter-breaking, with the following improvement. You understand, for halter-breaking, I use but one cord ; for bitting, I use two. I explained to you how the cord was made fast to the rubber on the off side of the horse's neck, and brought through the mouth to the near side, and back through the ring. That is all right, so far, for bitting. Now, please take notice. 'The strap by which the buckle is made fast to the near side of the horse's neck, for 


\section{5}

bitting, I want made ten inches in length, so that a rubber of the same length and size may be made fast to the near side of the horse's neck, with cord made fast, the same as the off side. Now, you see, I have two elastic rubbers - one attached to the strap on each sicle of the horse's neck; also a cord made to each end. Let it be remembered, in bitting the colt, the first thing is to get an easy, governable mouth, so that he will come quick and landy to the rein; then as you commence driving him in harness, you can each day shorten your check rein a trifle, until he will carry his head gracefully, without giving hirn pain. The movement with the bitting is as follows: Take the cord attached to the rubber on the off side of his neck, pass it through the mouth to the near side, and back through the ring; the one on the near side pass through the mouth to the off sicle, and back through the ring. You now have a double cord in the mouth, the end of each separate, one hanging loosely through the ring; step to the near side of your colt, and with the off side cord, give him a sudden pull, that brings him a few steps towards you, after which step quickly to the off side, and with the near side cord give him another sudden pull, which brings him suddenly to the opposite direction. Exercise him in that manner for about ten minutes the first day; the next day, about ten minutes, and so on for four or five days, and your colt will have an easy, governable mouth, and will rein quickly and easily to the right and left. I think 
you will readily discover the value of this over all other attachments for bitting. By pulling quickly the cord on the near side of his neck, the rubber on the opposite side gives, letting the cord play through the mouth, which throws his head upward, and quickly towards you. You then step to the opposite, and give the cord on the off side a sudden pull, which will cause the rubber on the near side of his neck to give, letting the cord play through the mouth, same as before, only in the opposite direction. After using an attachment as above described, I think you will readily acknowledge them to be the best ever in use, to even the. angles of the horse's mouth, and bring him quick and handy to the rein.

\section{Safety Bridles.}

You are well aware there have been several bridles introduced before the public, under the head of safety bridles - such as the Hartman, the Miller, the Needham and Clark bridles, all of which will work very well upon some horses; others they have no effect upon whatever, I claim; and I challenge contradiction when I make the statement that I have a bridle worth all others combined, ever made public before the American people. I claim that any runaway, kicking, bolting or plunging horse can be handled successfully, and effectually broken of the vice; also will break any lugger or puller on the reins, side reiner, or one that carries his tongue over the bit and out of his mouth. The bridle is made 
as follows. However, it is not necessary to get a new one entire, unless you think it preferable. You can place the following attachment upon any of your common driving, or riding bridles: Take a common snaffle bit, one of Daniels' is preferable; they are made by hand, and of the best steel, and the only reliable bit in use; take your bit to a blacksmith shop, and get welded around the part that goes in the horse's mouth, two one inch and a half rings, made of steel wire or nailrod, rounded down to about one eighth and a sixteenth of an inch. These rings hang loose around your bit; the bridle is now placed upon your horse's head with one of those rings placed each side of his mouth and against the cheek bars of the bit. Now procure two three quarter inch straps, nine inches in length; at each end turn down a one inch lap; they are now seven inches in length, aside from laps. If your horse's head is small size, six and a half inches will be of sufficient length. One end of each of these straps is stitched fast to each of these inch and a half rings; the other ends of said straps are brought up across the horse's nose about six inches above the nostril, and stitched fast to another one inch and half ring. You now procure a strap two incheswide, and twelve feet long; eight inches of one end of this strap is narrowed down to one inch and a half wide, a lap of one inch turned at the end; this lap is passed through the one inch and a half ring on the top of the nose. From the point where it is narrowed at the end, I want it split 
through to the other end. Now, on the top of the head piece, just at the inside of each ear, I want a three quarter strap, one inch and a half long; stitched fast at each end; that forms two loops on the top of the head piece; take one end of each of the straps that you made by splitting in the centre, and pass them through the loops on the top of the head piece, and pull them through the whole length. I think you readily see how the fixture is arranged until it passes from the top of the head back. Take the two straps that pass from the head back, and pass

- them through the terrets on the top of your harness pad - the right hand one through the terret on the off side of the back, and the left hand one through the terret on the near side of the back. Now, on the top of your horse's quarters, where the hip-straps pass through the back strap, make fast a one inch and a half iron ring. It is made fast by passing a short strap through, and stitching fast at each end. Again take the straps that you have passed through the terrets of pad, and pass them both through the ring on the top of the hips, letting one of them drop on each side of the horse's quarters. Now prepare your driving reins by stitching one end of each fast to the head piece on the under side, the other ends brought down through the bit ring, also back through the terrets, forming a pulley purchase.

However, in ordinary cases, all that will be necessary is to have your reins buckled into the bit-ring, as the rings attached to the crotch that passes over 
the nose will have the desired effect. If you have a bad kicker, he is now ready to hitch to wagon. Draw your wagon up to your horse, pass the ends of the shafts through the lug-straps, hitch your traces and quarter straps the proper length, so in driving your horse, if the wheel of your wagon should drop into a hole on the road, there would be but little play forward and back; also buckle your girdle short, to prevent your shafts from raising. Now bring the straps that pass from the crotch over the nose, also through the loops on the top of the head, and back through the terrets and ring that is made fast to the back strap on the top of the hips; as you pull those straps through the ring, you raise his head as high, or a little higher, than with the ordinary check rein; on the under side of your shafts and just forward of the cross-bar, drive a one inch square staple; bring your straps down over the swell of the hips on each side; pass the ends through the staples from the inside up over the shaft on the outer side, and make them fast; take hold of your driving reins, get into your wagon and start your kicker along; have no fears of the final result, for you have your horse perfectly under your control. He can neither run nor kick, and should he make an effort he can do no harm. If he attempts to raise his quarters, he throws his head violently into the air, and the effort will set him to counting stars, instead of kicking.

If, then, he should attempt to run, you have a bit 
by which you can hold him with the most perfect ease. A few weeks' driving will effectually break him of the vice. Also for a horse that lugs or pulls on the reins, have your rings welded around the bit, as above describer, a crotch over the nose, and light strap from the crotch through the loops on the top of the head and back to the water-hook, acting the same as a Kemble Jackson check. This will break any puller or lugger. Remember, when you pull upon the reins, you do not injure the mouth a particle. It simply draws the two one inch and a half rings firmly against his jaws, confining them almost as closely as though they were twisted in a vice. Soon as he quiets down, you ease up on your reins, and it is the easiest bit in the world. A few days' driving will break him, and he will drive quietly on a slack rein.

Another point to be considered in the use of this bridle-breaking a horse from carrying his tongue over the bit and out of his mouth. Instead of a snaffle, use a bar-bit, with inch and a half rings; crotch over the nose made of half inch straps; also half inch ring on the top of the nose; another half inch strap, one end stitched fast to the ring, the other end brought up to the top of the head and buckled to the crown piece of your buckle; this will keep the bit in the roof of his mouth, and he cannot get his tongue orer it. The simple attachment will soon wear the habit away.

I have another very effectual bit for breaking a 
bad kicker in harness; I do not recommend this bit for every day driving, for it is very harsh and severe. I only use it when I have a very dangerous kicker to deal with; and when he kicks against it a few times, you may calculate he is effectually broken of the dangerous habit; after which place the bridle with rings and kicking attachment combined, upon him, and in a few weeks you may consider him kind for any one to handle or drive. The bit is made as follows: procure two heavy pieces of elastic webbing, one inch wide and four inches in length. (If you cannot get a strong, stiff piece, place two of same length together.) There is a buckle made fast to one end of each of those pieces, and buckled to the crown piece hanging down each side of the head; to the lower end of each of said rubbers there is a piece of three-eighths of an inch cable chain attached, eight inches in length, with one inch and a half ring welded at the other end. Now understand; the chain on the near side of the horse's head pulls through the mouth to the opposite side; the one on the off side is brought through the mouth to the near side; both chains are in the mouth, passing in opposite directions from right to left; the crotch and rings passing over the nose, (as described in my first bridle,) is attached to this chain bit, just the same as to the snaffle bit. The rings fast to the end of chains prevent the rings made fast to the end of the crotch from slipping over. The balance of the bridle is made and works the same as described on previous 
page. The advantage of this bit for a bad kicker is this: just as soon as he attempts to raise his quarters, the rings attached to the crotch and fast at each. end of the chain bit, cause the rubbers to give, bringing the chains in opposite directions through the mouth, which is very painful to the horse, at the same time throwing his head violently into the air. One day's driving with that will subdue the worst of kickers.

A word for hitching in double harness, and I am done. Driving in double harness, the attachment is just as handy, safe and effectual, as driving your horse between the shafts. To illustrate, say your kicker is the near side horse of the team; your evener is bolted fast to the pole of your wagon; the whiffletree on the off side is made fast to the end of the evener. On the near side of the pole the evener is eighteen inches longer than off side; consequently the whiffletree is made fast to the evener on the near side, eighteen inches from the end. Now you see the straps passing through the ring on the top of the horse's quarters can be made fast to the evener, and have the same effect as when hitched to a pair of shafts. The strap passing over the left hip is passed through a staple at the end of the long evener, on the near side, and made fast; the one passing over the right hip is passed through a staple, and made fast next to the pole. So you see at once, the bridle will have the same effect upon a kicker, when driven in double harness, as when driven in single, and between the shafts. 


\section{3}

Now, reader, I think I have explained the making and use of these valuable bridles, so that no one need be mistaken; and knowing, from long experience, the effect they have upon bad horses, it is with confidence that I recommend them to you. 


\section{ON SHOEING.}

The period when the shoe began to be nailed to the horse is uncertain. William, the Norman, introduced it into England. Far more than is imagined, the comfort and health of the horse, with the safety of the rider, depend upon shoeing. In taking off the old shoe, the clinches of the nails should always be carefully raised, or filed off, and where the foot is tender, or the horse is to be examined for lameness, each nail should be partly punched out. The edges of the crust are then to be rasped, to detect whether any stubs remain in the nail holes; and to remove the crust into which dirt and gravel have insinuated themselves. Next comes the important process of paring out, with regard to which it is impossible to lay down any specific rules. It is, however, undoubted, that far more injury has been done by the neglect of paring, than by carrying it to too great an extent. The act of paring is a work of much more labor than the proprietor of the horse often imagines. The smith, unless be is looked to, will frequently give himself as little trouble about it as he can, and that portion of horn which, in the unshod foot, would be worn away by contact with the ground, is suffered to accumulate month after month, until the elasticity of the sole is destroyed, it can no longer descend, its other functions are impe- 
ded, and foundation is laid for corn or contraction, and navicular disease, inflammation. That portion of the horn should be left on the foot which will defend the internal parts from being bruised, and yet suffer the external sole to descend. How is this to be ascertained? The strong pressure of the thumb of the smith will be the best guide - the buttress, that most destructive of all instruments, being, except on very particular occasions, banished from every respectable forge. The smith sets to work with his drawing knife, and removes the growth of the horn until the sole will yield, although in the slightest possible degree, to the strong pressure of his thumb. The proper thickness of horn will then remain. The quantity of horn to be removed in order to have the proper degree of thickness, will vary with different feet. From the strong foot a good deal must be taken. From the concave foot the horn may be removed until the sole will yield to a moderate pressure. From the flat foot little need be pared, while the pummaced foot should be deprived of nothing but the ragged parts. The crust should be reduced to a perfect level all round, but left a little higher than the sole, or the sole will be bruised by its pressure on the edge of the seating. The heels will require considerable attention. From the stress which is thrown on the inner heel, and from the weakness of the quarter there, the horn usually wears away considerably faster than it would on the outer one, and if an equal portion of horns were 
pared from it, it would be left lower than the outer heel. The smith should, therefore, accommodate his paring to the comparative wear of the heels, and be exceedingly careful to have them precisely level. The position of the heels between the inflection of the bar and the frog should scarcely be touched--at best the ragged and detached parts alone should be cut away. The foot may not look so fair and open, but will last longer without contraction. The bar likewise, should be left fully prominent (never allow the smith to cut away the bar or frog of the foot), not only at its first inflection, but as it runs down the side of the frog. The heel of the shoe is designed to rest partly on the heel of the foot, and partly on the bar, for reasons that have been already stated. If the bar is weak, the growth of it should be encouraged, and it should be scarcely touched when the horse is shod, unless it has attained a level with the crust. It has been argued by many that the horn between the crust and the bar should be carefully pared out, and by so doing give relief to the animal lame with corns. If a little spring is given to the heel of the shoe, it gives relief; also the practice of weakening the crust of the foot where it is so much needed.

I will give you some idea of the young and healthy foot. Approaching nearly to a circle, and of which the quarters form the widest part, being just as wide as it is long. But I am sorry to say that this shape is not long preserved in many horses; 
but the foot increases, and narrows in the quarters, and more particularly at the heel, and the frog is diminished in width, the sole becomes more concave, and the heels higher, and then lameness, or at least a shortened and feeble action, ensues.

It must be premised that there is a great deal more horror of contracted heels than there is occasion for. Many persons reject a horse at once if the quarters are wiring in, but the fact is, that although this is an unnatural form of the hoof, it is slow of growth, and nature kindly makes that provision for the slowly altered form of the hoof which she does in similar cases-accommodates the part to the change in form. As the hoof draws in, the parts beneath, and particularly the coffin-bone, especially the heels of that bone, diminish; or, after all, it is more a change of form than of capacity. As the foot lengthens in proportion as it narrows, so does the coffin-bone, and it is as perfectly adjusted as it was before to the box in which it is placed. Its laminæ are in as intimate and perfect union with those of the crust as before the hoof had begun to change. On this account it is that many horses with very contracted feet are perfectly sound, and no horse should be rejected merely because he has contraction. He should undoubtedly be examined more carefully, and with considerable suspicion; but if he has good action, and is otherwise unexceptionable, there is no reason that the purchase should not be made. A horse with 
contracted feet, if he goes sound; is better than another with open but weak hoels.

There is nothing in the appearance of the feet which would enable us to decide when contraction is or is not destructive to the usefulness. His manner of going, and his capacity for work, must be our guides. Lameness usually accompanies the beginning of contraction. It is the invariable attendant of rapid contraction, but it does not always exist when the wiring in is slow, or of long standing. Experience has taught me to believe that contraction in the majority of cases, is in consequence of bad shoeing. The young and healthy foot, before shoeing, approaching nearly to a circle, and of which the quarters form the widest part, and the inner quarter rather wider than the outer. But I am sorry to say this shape is not long preserved in many horses, and why? In the first place, the majority of smiths forge the shoe in a way calculated to contract the foot at every step. The shoe is turned with each side almost straight, upper side concave, with heels projecting outward, causing the crust of the heel to turn under, and contraction follows. The shoe should be turned as round as the font will admit of, leaving the upper side perfectly level forward of the quarters; from the nail lioles back to the heel, on each side, leave the outside the lowest, so if you should place a rule across the heel on the upper side of the shoe, it would rest upon the inside corner, but would not touch the outer by one eighth of an inch. Your 
shoe should be wide web. Do not let the heels project outward, but bring them round with the foot. But if by so doing, the inside corner of the heel should rest against the frog, by use of a cold chisel, the inside corner of the heel can be removed, and all will be clear. No doubt you see the advantages of having a horse with contracted feet shod as above described. A shoe of that pattern will have a tendency to expand the quarters at every step.

\section{Clips.}

These are portions of the upper edge of the shoe, hammered out, and turned up so as to embrace the lower part of the crust, which is usually pared out a little in order to receive the clip. They are very useful, as more securely attaching the shoe to the foot, and relieving the crust from that stress upon the nails which would otherwise be injurious. A clip at the toe is almost necessary in every case, and absolutely so in the horse of heavy draught, in order to prevent the shoe being loosened by the pressure being thrown upon it in the act of drawing.

\section{The Hind Shoe.}

In forming the hind shoes, it should be remembered that the hind limbs are the principal instruments in progression, and that in every act of progression, except the walk, the toe is the point on which the whole frame of the animal turns, and from which it is propelled. This part, then, should be 
strengthened as much as possible, and therefore the hinder shoes should be clipped at each side as well as at the toe.

\section{To Prevent Over-reaching, or Klicking.}

Shoe your horse heavy forward-two pound shoe -making the heel of the shoe twice the thickness of the toe. The hind shoe made short, narrow web, and very light, with toe twice the thickness of the heel. Placing the heavy shoes to the forward feet will cause him to lift his feet with more energy; also the heel of his forward feet, and the toe of his hind feet, will so reverse the action that in the majority of cases they will travel clear.

\section{Interfering with the Hind Feet.}

I think I can safely say that more than half of the horses now in use are animals that cut their ankles, and it is a great objection. A horse of that kind is rejected by many dealers, but I argue that if they are properly shod, the cause can be removed. The habit that smiths in general have of leaving the inside of the toe twice the thickness of the outer side, is all wrong. The shoe should be narrow web, and very light, each side of the same thickness. The toe calk should be welded to the toe one half inch inside of the centre, leaving the inside of said calk the highest. Heel calks the same height. By so doing, the outside of the shoe is one inch longer than the inside. It is now necessary to pare the outside of 
the foot the lowest. Your shoe is now made fast to the foot with five nails, three on the outside and two on the inner; also three clips, one at the toe, and one at each side.

\section{Interfering with Forward Feet.}

I have known valuable horses, and fast trotting horses, to cut their ankles inside of the leg, and quite often the knee-and badly, too-with the shoe of the opposite foot, and I think the plan I adopt a good one. The outer web of the shoe should be narrow and light, the inner wide and heavy, with the outside of the hoof pared the lowest. When all other plans have failed, this has proved effectual.

\section{The Bar Shoe.}

The bar shoe is often exceedingly .useful. It is the continuation of the common shoe around the heels, and by means of it the pressure may be taken off from some tender part of the foct, and thrown on another, which is better able to bear it; or more widely and deeply diffused over the whole foot. It is resorted to in cases of corns, pummiced feet, sand crack, cracked quarter, \&c. In such cases the bar shoe can be used to advantage, but it should. be left off as soon as it can be dispensed with.

\section{Quarter Crack.}

Much has been said, and various plans devised, by which to heal a quarter crack, such as scoring with a 
knife, blistering, cutting with a sharp, hot iron, riv eting, and the like. All which, in some cases, have proved a failure. Now, let me say, if you will follow my directions, you may have a sound foot in three months. Above the crack, and next to the hair, cut with your knife an incision one-half inch long, crosswise of the crack, and one-eighth or onesixteenth inch deep. Now, from the incision, draw a line one-quarter inch each side, parallel with the crack, down to the shoe. With your knife follow those lines, and cut through the enamel or crust of the foot. You see, now, there is a piece of the crust to be taken out. This is done by loosening the top of the piece next to the hair with your knife. Then, with your forceps, take hold of the piece and pull it off. That leaves a space of one-half inch of the crust taken out from the hair down to the shoe. Fill the cavity with tar, and lace on a soft piece of leather to keep the tar in its place. Keep him quiet for three or four days, and he is ready to drive. Shoe with a bar shoe, leaving some spring to the heel, so it will not bear hard upon the weak quarter, and in three months you will have a sound foot. Try it. 


\section{TEACHING TRICKS.}

As many of my scholars may wish to know how to teach their horses tricks, I will explain how it may be donc. Teaching a young horse a few tricks greatly serves to keep up an interest in him, and makes him appear intelligent, fearless, and affectionate. In teaching your horse to perform tricks, it is best to give him lessons of half, or three-quarters of an hour each, daily.

To Come at the Crack of the Whip, or at the Word of Command.

As for halter breaking, catching in pasture, and the like.

\section{To Make a Bow.}

Take a pin in your right hand, between the thumb and forefinger, and stand before, but a little to the left of your horse. Then prick him on the breast very lightly, as if a fly biting, which, to relieve, he will bring down his head, which you will accept as yes, and for which you will reward him by caressing, and feeding him a little apple, a few kernels of corn, or oats. Then repeat, and so continue until he brings down the head the moment he sees the least motion of your hand towards his breast; or substitute some signal which he will understand readily. 


\section{To Say No.}

Stand by your horse near the shoulder, holding the same pin in your hand, with which prick him lightly on the withers, and to relieve himself he will shake his head. You then caress him as before, and so repeating, until he will shake his head at the least indication of your touching him with the pin. You can train your horse so nicely in this way, in a short time, as to cause him to shake his head, or bow, by merely turning the hand a little, or moving it slightly towards him.

\section{To Lie Down.}

To teach a horse how to do this trick quickly, you must lay him down two or three times, or as often as you will find it necessary to make him understand your object. If an old horse, strap the near foreleg up to the arm, then take your little strap, previously used to tamper your colt with, and place over the back and strap around the off fore foot, below the fetlock. Then take the bridle rein firmly in your left hand, about eighteen inches from the head, and pull upon it a little towards you. The moment he steps, pull upon the strap over the body, which will bring the horse to his knees. Hold him quietly, at the same time talking to him gently. When he springs, pull sharply with the left hand, and the same instant pull down with the right, which will swing him around you, and prevent his rising high enough to injure his knees by the mo- 
mentum of the body coming down. By being gentle, the horse will usually lie down in a short time. When down, treat your horse with the greatest attention and kindness. After holding him down, ten or fifteen minutes, permit lim to get up. Repeat this lesson untii lie will come down readily. Then use only the strap over the back, which have on the near foot, and bring him on his knees gently, when he will soon lie down. When he will come on his knees readily by taking up the foot in this way, take up the foot with the hand, asking to lie down. He will soon come down. When he will come down on his knees readily by taking up the foot with the hand, simply stoop as if intending to take it up, saying, "lie down, sir." Then make him come down by a motion of the hand, and finally by telling him to lie down. If a colt, use but the single strap over the body at first, which will cause him to come on his knees. In teaching a horse to lie down, be gentle, caress and reward him for lying down, and your horse comprehending what you want, and finding himself paid for compliance, will soon be as anxious to get down for the reward, as you are to have him.

\section{To Sit Up.}

When your horse will lie down readily, you can then easily teach him to sit up like a dog. If young, and not very heavy and strong, you can easily prevent his getting up, without tying down. First, 
cause him to lie down, having on him a common bridle, with the reins over the neck; then step behind him, and place the right foot firmly upon the tail, the reins in your hands. Then say, "get up, sir." The horse, rising from a recumbent position, first upon his belly, throws out his forward feet, and raises himself upon them, springs forward, and raises on his hind feet. Now, standing upon his tail firmly and pulling back upon the reins when he attempts to spring forward and up, will prevent his doing so, and you hold him sitting up. Hold him firmly a few seconds, talking to him kindly, before permitting him to rise on his feet. Repeat a few times, when, instead of springing up, he will sit on his haunches a short time, which you are to accept as complying with your wishes. Always say, "sit up, sir," every time, and hold him in the position as long as he will bear, fondling him, and feeding him from the hand with something he likes, and your horse will learn to sit up for you as long as you please.

But if your horse is heavy, and strong, it will be necessary to resort to other means to hold him down at first. This you do by putting on his neck a common collar, and causing him to lie down. Then fasten a piece of rope, or a rein, to each bind foot, and bring forward through the collar, and draw up close, which will bring the hind feet well forward. Then step behind, as before, and when he attempts to rise on his hind feet, he finds it impossible to do so, because you hold them firmly with those straps. 
Repeat two or three times, when it will not be necessary to resort to such force.

\section{To Teach a Horse to Kiss You.}

Teach him first to take an apple out of your hand. Then gradually raise the hand nearer the mouth, at each repetition, until you require him to take it from your mouth, holding it with the hand, telling him at the same time to kiss you. He will soon learn to reach up his nose to your mouth, first to get his apple, but finally because commanded to do so. Simply repeat until your horse understands the trick thoroughly.

\section{To Shake Hands.}

Tie a short strap, or piece of cord, to the forward foot, below the fetlock. Stand directly before the horse, holding the end of this strap or cord in your hand, then say, "shake hands, sir," and, immediately after commanding him to do so, pull upon the strap, which will bring his foot forward, and which you are to accept as shaking hands, thanking him for it by caressing and feeding. And so repeat, until when you make the demand, he will bring the foot forward in anticipation of having it pulled up. This is a very easy trick to teach a horse. By a little practice, a horse may be easily trained to approach, make a bow, shake hands, and follow like a dog, lie down, sit up, Gd the like, which make him appear both polite and intelligent. 
Never lose courage, or confidence in your ability because you may not bring about good results easily. To accomplish anything of importance, remember, requires no ordinary resolution and perseverance. There would be no credit or importance attached to mastering and managing bad horses, if not difficult, and apparently dangerous. No duty requires more firmness of purpose in the control of the passions, or more fidelity to the principles of firmness and truth, than that of horsemanship.

If you would really be a successful horseman, you must never seem to forget, by your conduct, that you are a man, and that your real superiority over the animal consists in the prudent exercise of your reasoning powers. Brute force is not your forte, and the instant that you give way to passion, your reason must yield to the control of blind instinct, and you at once abdicate your intellectual superiority over the animal. Try to prove, by the example of your action in the performance of the duty, that to be a good horseman requires higher qualifications of fitness than that of the huckstering dishonesty and depravity, so generally evinced in the conduct of those claiming the distinction.

\section{How to tell a Horse's Age.}

At two years old, colt sheds two centre nippers. At three years old, colt sheds the adjoining teeth. At four years old, colt sheds outer or corner teeth. 
At five years old, bridle tooth is up, and six years, cups leave two centre teeth below.

At seven years old, curs leave adjoining teeth.

At eight years old, cups leave outer or corner teeth.

At nine years old, cups leave the two centre nippers above.

At ten years old, cups leave adjoining teeth.

At eleven years old, cups leave corner upper teeth.

At twelve years old, or past, groove on inside of bridle tooth disappears in horses. Mares very seldom have them, and when they do, they are no criterion to be guided by.

\section{Jockey Tricks.}

How to make a horse appear as though he was badly foundered.-Take a fine wire and fasten tight around ankle, between foot and pastern, and smooth hair over it. In twenty minutes, horse will show lame. Do not leave it on over nine hours.

To make horse lame.-Take a single hair from the tail, put through the eye of a needle, lift front fore leg, and press the skin between outer and middle tendon or cord, shove the needle through, cut the hair off on each side, and let the foot down; horse will go lame in twenty minutes.

How to make a horse stand by his food, and not take it. - Grease the front teeth, and the roof of the mouth, with common beef tallow, and he will not eat till you 
wash it out. This, in connection with the above, will consummate a perfect founder.

How to stop a horse of the crib, or sucking wind.Saw between the upper teeth to the gums.

How to put a young countenance on a horse.-Make a small incision in the sunk place over the eye, insert the point of a goose quill, and blow it up; close the external wound with thread, and it is done.

To cover up the heaves. - Drench the horse with one-fourth pound of bird shot, and he will not heave until they pass through.

To make a horse appear as if he had the glanders.Melt four ounces fresh butter, and pour it into his ear.

To distinguish between distemper and glanders. - The discharge from the nose in distemper will float in water; in glanders it sinks.

How to make a true pulling horse balk.-Take tincture cantharides one ounce, and corrosive sublimate one drachm; mix and bathe his shoulders at night.

How to nerve a horse that is lame.-Make a small incision about half way from the knee to the joint on the outside of the leg, and at the back part of the shin bone; you will find a small white tendon or cord; cut it off, close the external wound with a stitch, and he will walk off on the hardest pavement, and not limp a particle. 


\section{TRAINING STEERS.}

AS TAUGHT BY A. H. ROCh WELL.

\section{How to Teach Sreers to Obey the whip.}

First get your steer into a room, or small yard, so that he cannot run from you; then approach him gently and slowly, and if he runs, do not be in a hurry; wait until he gets to the end of the enclosure, then approach him slowly, as before. A steer will often run from you in this way six or eight times. Do not try to stop him with your whip, or force him to think he will be at all injured, until he will stand and suffer you to approach him. As soon as this is accomplished, gently tie a rope around his body, near the shoulders, rather loosely. Then take another rope or strap, and gently fasten one end to the near forward foot, then pass the other end over the rope, or surcingle beneath the body. This rope should be sufficiently long to allow him to run to the end of the enclosure without your moving, at the same time you holding the rope firm to compel him to move on three legs. Then approach him again, quietly; he will not run off in this way but a few times before he fully comprehends that he will not be injured, when he will suffer you to approach and handle him just as you please. Now take a short hold of the strap with your left hand, your whip in your right, 
which pass over his shoulders, and quietly touch him upon the off side of his head, at the same time saying "haw," and continue this until he moves his head a littie towards you. Then stop and caress him upon and about his neck and head. Repeat this until he haws around towards you. If he attempts to run from you, pull upon the strap, saying "whoa," and at the same time hitting him lightly upon the head with the whip. As soon as he learns in this way to stop at the word of command, and comes toward you readily, take off the strap and surcingle, and turn him out. Then take the mate, and give him the same course of training until you can accomplish with him a like result. Then turn him out. By this time the first steer is cool, and rested, ready to receive another lesson. Now drive him into the enclosure and repeat his lessons with the whip. Then quietly touch him gently upon the near side of the head, at the same time saying, "gee," until he will step around from you, then caress, and repeat until he will gee or haw readily. Then repeat the same lesson with his mate, which is all that is necessary to be done the first half day. Then take both together in the same room, or yard, and repeat these lessons until they have a through understanding of what you have done. Then take one of them near the wall, standing by his side, hit with your whip gently over the head, at the same time saying, "back," until he will step back, for which caress. Repeat this until he will go back at the word readily. Then 
give the other steer the same lesson. You will find this course of training will make your steers quite obelient, and willing to haw, gee, or back, which will be all that you should require in one day's time. The next morning, or when you have time, repeat this lesson with both together. Then place the yoke upon them and let them go for an hour or two, or sufficiently long to become fully reconciled to the restraint of the yoke. Then repeat your lesson in open yard, until they filly understand what you require of them yoked together.

This course of training does not excite, while it conveys the idea most clearly of what is required, and will enable the trainer to accomplish more in a given time, than has yet been done by any other system of managing steers. If your steers have learned to run away from you, which is a common result of tne ordinary method of training, put on the rope and strap, to the foot. If hitched to a wagon, or stone load, let your man hold the foot strap, which run back between the steers, and the moment they attempt to run, he pulls up the feet, while you whip over the head, which will stop them immediately, and will very soor break up the habit. 


\section{TRAINING DOGS.}

The dog is the most domesticated, and (next to the horse) the most intelligent of all animals. $\mathrm{He}$ is easily taught, and, if properly treated, is a faithful and willing servant of man; if misused, and ill. treated, he is very apt to become disagreeable, and a nuisance. The dog being a favorite of mankind, it becomes a duty to educate him in such a manner that he will not only reflect credit, but become useful to his master, besides being an agreeable inmate to all members of the household. I have given particular attention to this subject, it being one which cannot fail to interest all readers. I have at present two of the best trained dogs in the country-Minrie, an Italian greyhound, and Tasso, a black and tan. They are made to understand any words of the English language, simply by teaching them the act, and then the word from the act. The rules whereby any person can educate a dog, are simple, and easily understood, but it is necessary to be patient, kind: and persevering (the same as in all things.) I give a few rules sufficient to enable the operator to practice many more. There are different breeds of dogs, and, or course, as many different habits and dispositions as breeds; consequently it will require judgment to train them to that to which they are best adapted by 
nature. For instance, the St. Bernard is a faithful watch dog, while the setter will scent game without training; a terrier will catch rats, and the greyhound takes to running from his birth. It is necessary, therefore, in attempting to teach the dog, to bear in mind these natural habits, being careful not to urge upon him the performance of any duties or tricks, which are manifestly not in his nature to do. When selecting dogs for any particular lesson, study this subject closely, as undoubtedly it is the most useful lesson to be taught. In educating the shepherd to drive, or the watch dog, I have not given so much attention. Not being so fond of this kind as the more intelligent class of dogs, learning them certain tricks, \&c., but I will give you the knowledge of the above, as I obtained it from a celebrated dog trainer.

\section{Training the Shepherd to Drive.}

Take a well-bred shepherd dog, about six months old, reared in some secluded place, hearing no words with a meaning intended to be attached, except his name. He should know nothing of the ordinary words in use towards dogs, and not have been handled by boys or careless persons. Take him alone with you in a large room. The first thing to be done is to learn him to lead, placing a strap around his neck, that cannot hurt him, to which attach a cord six or eight feet in length; stand still and hold up on the cord for a few minutes, until he ceases struggling to get away. It is best to give one 
lesson each day during the whole training. The first two lessons should be devoted to learning him that he cannot get away. Now, commence learning him to corne to you, by pulling upon the rope, and saying, "Here," using only the one word. In the use of this, as well as all other words used in training the dog, one word is all that is best to try and learn him for any one act, it being so difficult to make him understand, if you attempt to learn him more. When he is once fixed in the habit of minding the word, you may then use such other words in connection therewith, as are pleasant to the ear, as, for instance, "come here, sir." Without the word here he will not know what you mean, and the others being meaningless to him, do not puzzle him. He will also be less liable to have too many masters, as the one word will not be likely to be used every time by a person unacquainted with your mode of training. Of course, if you prefer it, you may, in giving the lesson, substitute other words for those laid down; but I give those which are readiest to the tongue. $\Lambda$ s the dog comes up, whether voluntarily or not, say "Do," and caress him. A lesson of an hour or two, working slowly and patiently, will be about right, each time. Proceed with it until he will come to you from any portion of the room, at the word "Here." He will have learned by this time, probably, that the word "Do" is for him to understand that you are through with him. When he perfectly realizes this, you may then prefix words, and say 


\section{7}

"That will do," emphasizing upon the word do each time. You may also now say, "Come here," remembering that the words here and do are the only ones he obeys. He cannot connect sentences, or be made to understand them when once connected. You now wish to learn him the words "Go," and "Halt." To do this you will place yourself in a portion of the room opposite to where the dog would naturally desire to go (the door, for instance, or something that would attract him, such as food,) say, "Go," and by coaxing and urging him, start him along; as he gets part of the way, say, "Halt," pull upon the string, stopping him, and say, "Halt," again. Proceed with this until he has learned to obey both the words, "Go" and "Halt." To teach these four words named, will generally take three or four weeks.

Now learn him to bark at the word "Speak," by holding up something which he wants very much, for instance, food when he is very hungry. You may now let him loose, and let him run about with you, (previously keeping him confined, but not in a narrow place,) being watchful that he does not stray off, nor be hurt, or handled by others. He will soon become handy about the house. You having control of him through the words you have taught him, can keep him in his place by word of command. For instance, if you wish him to go out of doors, show him the door, and say, "Go out." The word "go " will start him, and in a little while he will become familiar with the word "out." Give him a 
fixed place to sleep, and learn him its name. If you have a dog already trained to drive, and go behind, take him out with him to drive in the cattle. He will learn that they will run from him. Say nothing to him while he is with the other dog, unless he attempts to go to the head of any of the cattle. 'This you must not allow. After two or three times, take him out without the other dog, and allow him to run after the cattle, provided the cattle are used to being: driven by dogs. It will not do to let him run where there is a chance of his being turned upon. If he runs them too fast, say, "Steady." He will not know what you mean, but, as you use words with him only when they mean something, he will be apt to pay attention, and go slower. If he does not, say, "Halt," then "Go," steadying him by the word "Steady," if possible. He will gradually learn its meaning by its repetition. If you have no other dog, you will let him go without being more watchful of him, that he does not go to the head of the cattle; otherwise say nothing to him, except "Go," not letting him start until he gets the word. After a while you may proceed to practice upon the other words he knows. If he shows no disposition to bite at the heels, or pull at the tail, take a rope, and tie a knot a short distance up, finger out the end, and play with him with the rope, letting him catch hold of it, and causing him to bark at it by using the word "Speak." When he takes hold of the rope, say, "Up," and when you wish him to let 
go, "Do." You may then, with a slow cow, call him up, and taking hold of his tail, say, "Up," and "Speak," to teach him to take hold of the tail and bark, when you say, "Start 'em up," and "Speak to them," and to let go when you say, "That will do." Now accustom him to the word "Fetch," for sheep, and "Get," for cattle, \&c., so that when you say, "Go and get the cattle," he knows you mean cattle instead of sheep or horses. You may now teach him to know the right from the left, and to obey your orders in that respect, by taking him into a large room, and by the motion of your right hand try to have him go to the right, from you, saying, "Go-right." If he does not do it, say, "Halt," and repeat. When he does do it, say, "That will do." Continue this until he will go to the right at the motion of your hand and the word "Right," then with your left hand making motions, and the word "Left," you learn him the opposite. By these motions, and an appeal to the intelligence of the dog, by your countenance and eyes, you can start him for the fields in any direction. you choose, and he soon learns to do your wants with very little telling. Following these rules will satisfy you that the dog can be taught indefinitely respecting all things which pertain to his peculiar nature.

\section{The Watch Dog.}

For a good watch dog, select one of a breed adapted to the business. There is but little that you can 
teach such an one, as it is somewhat of a natural trait, and any other than a natural watch dog, however much you may labor with him, will never be reliable. A barking dog, one that will be noisy on the approach of intruders, is the best; a dog that bites, but does not bark, is only fit to put in barns, or other out-buildings nights, chaining him up daytimes; and then he is dangerous, even to his keeper, as a sudden start will cause him to bite any one. To learn your dog, give him something to watch, saying, "Take care of it," as you place him near the object. He will soon learn the word, and upon being directed to any particular thing, will faithfully guard it. While learning him, allow no one but yourself to approach him, without setting him on. You may have a stranger approach him and tease him, you urging him to drive the stranger away, and as soon as he starts, let the person run, you calling the dog back. While young, do not compel him to stay too long at one thing, and when you go up to him and say, "That will do," feed him something. After the manner spoken of in the previous illustration, whenever you wish the dog to bite, or go at any person or thing, you will teach him the words the reverse of what you mean, such as, "Be still," "Get out," "Lie down." You will see that a person not understanding the dog, will not be very apt to get near him, as he would naturally make use of those words, and they would be setting him on, instead of quieting him. To call him yourself, use such convenient word 
as you choose, but not one naturally used by others. As this ingenious use of words is about the only new idea I can suggest, to teach watch dogs, the master can use his own ingenuity to render it practical.

\section{The Trick Dog.}

Many amusing tricks may be taught, which will exhibit, in a wonderful degree, the intelligence of the dog. As I have before said, much depends upon the breed. A dog of one peculiar breed may be learned a certain class of tricks, while that of another breed will be entirely different in his characteristics. A well bred dog is hard to learn any tricks except those pertaining to his nature; while a mongrel cur is quite easy to learn any. Perhaps a Spaniel poodle dog is the most tractable of any, a Black-and-Tan is quite apt. I give a few examples, sufficient to form a ground-work for the intelligent operator to extend his list of tricks at his pleasure.

\section{The First Step to be Taken.}

When you are preparing the dog to receive his first lesson, it is necessary to place him where you can control him. Procure a piece of cord ten feet long, and one fourth of an inch in diameter; tie a knot in each end-one that will not slip. Take one end, place it around the dog's neck, to get the size, then tie another knot, and again place it around his neck, slipping the end with knot through, and make fast. The proper way of training him is with a whip, 
a small riding whip. In giving him his first lesson, should he attempt to run from you, (as he undoubtedly will,) give him a sudden jerk, and say, "Come here;" as he comes back, talk gently, pat and caress him; that is to show him he has done right in coming back. A few pulls with the cord, and he will not attempt to leave you.

\section{To Learn Him to Sit Down.}

Press your hand upon his back toward his hind legs, and say, "Sit down," at the same time tapping with your foot upon the floor. If he attempts to lie down or draw his feet under him, coax him up, and learn him that "sit down" is what you are after, tapping him under the chin to keep his head well up. He will, after a few lessons, sit down at the word, and a tapping of your foot on the floor, or with your whip, holding him by the cord, tap him lightly on the top of the quarters, saying, "Sit down," each time a little harder, until he sits down, then pat him to show he has done right.

\section{To Make a How.}

When he gets handy, and will sit down at the word, then say to him, "Make a bow." This trick you can learn him in a very short time. As he sits down, place your right hand on the top of his head, and with a quick move, press down, saying, "Make a bow." By accompanying the word with the act, 
quite often, each day, for a few days, he will understand the word without the act, and obey readily.

\section{To Learn Him to Sit Up.}

Sit him up in the corner, and with a switch, hit him lightly under the mouth, snapping your finger. and saying, "Sit up." As he comes down, put him. back and repeat, until he remains, which he will do in a few minutes, then say, "That will do," and coax him down, and caress him. When he has learned this sufficiently, sit him up against a wall and try the same thing. This will require more patience, as he can so easily get over to either side. When, however, he will do it, then take him out in the centre of the floor; this will take still longer, but if followed up, kindly, and perseveringly, he will learn to perform the trick at the word and the snapping of the finger.

\section{To Stand Up.}

Take some food in your hands, and offer it to him, holding it well up, and say, "Stand up." Repeat this until he will stand up quite readily, holding out your unoccupied hand for him to support his fore-feet on. Graclually take away your hand, each time that he comes up, saying, "Stand up." Then take him by the forward feet, and lift him up quite hard, and say, "Stand up." You will soon get him so that when you lift him, he will straighten up and show signs of standing; then make the effort to learn him to stand 
up at the word, and the holding out of your band. You may now combine this with the last trick, saying, "Sit up," "Stand up," "That will do." These are the first tricks he should be taught, as they are the foundation for others.

\section{Tw Get into a Chair.}

This is easily done, taking your own way to coax him into the chair, using the word "Chair" whenever you cause him to get into it. When he becomesfamiliar with the word, accompanied with a motion of the hand towards a chair, you may use other words in connection therewith, "Go and get into the chair." After he will do this handy, you may then learn him to put his paws upon the back of the chair, by asking him to "Put them up," or saying "Up," assisting him at first. When he will do it readily, you may teach him to put his head down upon his paws, by placing it there, and repeating the word "Down," of course caressing him each time that be complies. To have him hold up his head, tap him under the mouth and say "Up," remembering to say, "That will do," when you are through the trick. You may learn him to jump over the chair by playfully coaxing him to do so, saying, "Jump."

It is now very easy to learn him to "Sit down" on a low stool or a chair. You may then learn him to "Take a seat"on the stool by leading him around by his forward feet, and sitting him on the stool with his forward feet held up, saying, "Seat." You then 
have him learned to go on all fours, and sit down on the stool, and to go on his hind feet and take a seat with his forward feet up.

\section{To Make Him Go Lame.}

Tap him with a little rod on the hind foot saying, "Lame," learning him to stand and hold it up whenever you say, "Lame." Now coax him along, and if he puts it down, hit him quite smartly on the foot, making him keep it up until he will go lame, at the word and a motion of the rod. Now whenever you send him into the chair, as before, as he goes to jump down, stop him, teaching him to wait for the word "Do;" as he comes down with his fore-feet on the floor say, "Steady," and learn him to stop with his hind legs up in the chair. He is now ready.

\section{To Run on his Forward Legs.}

To teach him this, take hold of his hind legs, lift them up and walk him around in a circle, and place them in a chair, saying, "Round." Do this every time you perform the trick of having him get into the chair. After a while take him by the tail and lift him up, and switching his hind legs lightly, walk him around in the same manner, saying, "Round," as before. With patience and perseverance he will learn to lift up his hind legs at the motion of the whip, and on the words, "Go around," perform a circle, walking on his forward feet, and place his hind 
feet in the chair; of course the height of the chair must be adapted to the length of the dog's legs.

\section{To Teach Him to Find Things.}

Take something with which he is accustomed to play, and after getting him enlivened with play, call him up to you and blindfold him, and throw the article a short distance from you. If the dog has good scent, tell him you have "Lost," then remove the blindfold and he will search and find it. Repeat this, throwing it farther each time, until you can throw your knife or anything which you have held in your hand, at a distance, you looking in the direction and saying, "I have lost my knife." $\mathrm{He}$ will search until he finds and brings it to you. If the dog has not good scent, learn him to look down at the word "Find," and up at the word "Up," doing as before. I have now given a sufficient number of examples to set forth the important rules which govern the teaching of Dogs. By an observance of these, you may teach your dog to climb ladders, to fetch things to you, carry baskets, roll over, lie down, shut doors, and an almost innumerable number of tricks. To teach the dog, however, you must have perfect control over your temper, never whip severely, never get out of patience. 


\section{TURF CALENDAR.}

Flora Temple, the fastest trotting horse in the world, was sired by One Eyed Hunter-the pedigree of her dam is not known. Flora is now twenty years old, 1865; is owned by A. Welch, Esq., of Chestnut Hills, Philadelphia. Her best time was made at Kalamazoo, October 15th, 1859, a full mile in 2 min. $193-4$ sec., which is the best time ever made by a trotting horse. She beat Geo. M. Patchen, on the Union course, in 2.21; she beat Ethan Allen, and mate, in 2.20 1-2.

George M. Patchen trotted under the saddle, on Union course, Nov. 21, 1850, in 2.24 .

Brown Dick beat Patchen in 2.25 1-4.

Ethan Allen's best time, single, was 2.251 .2 ; trotted with a running mate, Sept. 5, 1861, on Fashion course, in $2.193-4$.

The fastest time on record, for a three years old, was made by Cora, in $2.373-4$.

Gen. Butler's best time was 2.21. Dexter beat him three straight heats on the Fashion Course, Sept. 7, $1865-2.261-2,2.241-2,2.221-2$.

Toronto Chief beat Vanderbilt, on the Fashion course, Sept. 9, 1865, in 2.23, 2.27, 2.27 3-4. Vanderbilt trotted one heat in $2.273-4$. 
The fastest running time on record, for a single mile, was made at Cincinnati, by Legal Tender in 1 min. $44 \mathrm{sec}$. The best time ever made in England is 1.39 , made by Gladiator. It is said that Bay Middleton ran the same mile in 1.60 , but there is no record of such time.

Brown Dick made the best time for three mile heats, in 5.28 .

Pocahontas paced a full mile in 2.17 1-2, which is the best time on record.

The greatest performance in double harness, on record, a 2.12 gait to road wagon. Lady Palmer and Flatbush Mare, driven by their owner, Mr. Bonner, taken out of his stable untrained, to a road wagon, in public, May 10th, 1862, one mile in 2.26; May 13th, two miles in 5.01 1-2, the second quarter of the second mile in 33 seconds, being a 2.12 gait to a road wagon.

Since the writing of this book, Flora Temple's time has been beaten. Dexter in his great match against time on the fashion course, October 10th, 1865 , trotted a mile under the saddle in the unparalleled time of 2.18 1-5. 


\section{LATEST AND FASTEST TIME RECORDED.}

1 mile in harness, $2.171-4$, Dexter.

1 mile to wagon, 2.24, Dexter.

1 mile under saddle, 2.18, Dexter.

1 mile 100 lb. wagon, 2.28, Ethan Allen.

1 mile, double team, 2.19 3-4, Ethan Allen and mate, and Lantern and mate; dead heat.

1 mile, double team, 2.15, Ethan Allen and running mate, beating Dexter.

2 miles in harness, 4.50 1-2, Flora Temple.

2 miles in double harness, 5.19, Lady Suffolk and Rifle.

3 miles under saddle, $7.321-2$, Dutchman.

3 miles to 350 lb. wagon, 8.38, Kemble Jackson.

4 miles in harness, 11.42 , Smotes.

5 miles to road wagon, 14.42, Mary Warren.

10 miles in harness, $28.081-4$, Prince.

20 miles in harness, 58.25, Captain McGowan.

50 miles in harness, 3.50: 4, Spangle, to wagon and driver, $400 \mathrm{lbs}$.

100 miles in harness, $8.55: 53$, Conqueror.

100 miles in harness, double team, $10.17: 22$, Master Burke and Robin.

Pacing, 1 mile, 2.17 1-2, Pocahontas. 


\section{0}

2 miles in harness, 4.561 -2, Hero.

2 miles to wagon, 4.38 1-2, Young America

Leaping Horse, 38 feet over water, Chandler.

34 feet, over hurdles, Calvesthorpe.

30 feet over wall, Lottery. 


\section{STABLE MANAGEMENT.}

This is a very important part of my subject, even as it regards the farmer, although there are comparatively few glaring errors in the treatment of the agricultural horse; but it comes more especially home to the gentleman, who is too often and too implicitly under the guidance of an idle, ignorant and designing groom. I will arrange the important points of general management under the following heads :

\section{Air.}

The breathing of pure air is necessary to the existence and health of man and beast. It is comparatively lately that this has been admitted even in the management of our best stables. They have been close, hot, and foul, instead of airy, cool and wholesome. The stable should be as large, compared with the number of horses that it is destined to contain, as circumstances will allow. A stable for six horses. should not be less than thirty feet in length, and thirty feet wide. If there is no loft above, the inside of the roof should always be plastered, in order to prevent direct currents of air and occasional droppings from broken tiles. The heated and foul air should escape, and cool, pure air be admitted, by elevation of the central tiles; or by large tubes carried through the roof, with caps a little above them, 


\section{2}

to prevent the beating in of the rain ; or by gratings placed high up in the walls. These latter apertures should be as far above the horses as they can conveniently be placed, by which means all injurious draught will be prevented. If there is a loft above the stable, the ceiling should be plastered, in order to prevent the foul air from penetrating to the hay above, and injuring both its taste and its wholesomeness; and no opening should be allowed above the manger through which the hay may be thrown into them; for they will permit the foul air to ascend to the provender, and also in the act of filling the mangers, and while the horse is eagerly gazing upward for his food, a grass seed may fall into his eye, and produce considerable inflammation. At other times, when the careless groom has left open the trap-door, a cold stream of air beats down on the head of the horse. The stable with a loft over it should never be less than twelve feet high, and proper ventilation should be secured, either by tubes carried through the roof, or by gratings close to the ceiling. These gratings or openings should be enlarged or contracted by means of a covering or shutting, so that spring, summer, and autumn, the stable may possess nearly the same temperature with the open air, and in winter a temperature of not more than ten degrees above. that of the external atmosphere. A hot stable has, in the mind of the groom, been connected with a glossy coat. The latter, it is thought, cannot be obtained without the former. To this I reply, that in 
winter a thin glossy coat is not very desirable. Nature gives to every animal a warmer clothing when the cold weather approaches. The horse, the agricultural horse especially, acquires a thicker and lengthened coat, in order to defend him from the surrounding cold. Man puts on an additional and a warmer covering, and his comfort is increased, and his health improved by it. He who knows anything of the farmer's horse, or cares about his enjoyment, will not object to a coat a little longer, and a little roughened when the wintry wind blows bleak. The coat, however, not to be so long as to be unsightly, and warm clothing, even in a cool stable, will, with plenty of honest grooming, keep the hair sufficiently smooth and glossy to satisfy the most fastidious.

The over-heated air of a close stable saves much of this grooming, and therefore the idle attendant unscrupulously sacrifices the health and safety of the horse. When I have presently to treat of the hair and skin of the horse, this will be placed in a somewhat different point of view. If the stable is close, the air will not only be hot, but foul. The breathing of every animal contaminates; and when in the course of the night, with every aperture stopped, it passes again and again through the lungs, the blood cannot undergo its proper and healthy change; digestion will not be so perfectly performed, and all the functions of life are injured. Let the owner of a valuable horse think of his passing twenty, or 


\section{4}

twenty-two out of the twenty-four hours, in this de bilitating atmosphere.

Nature does wonders in enabling every animal to accommodate itself to the situation in which it is placed, and the horse that lives in the stable, even suffers less from it, than would scarcely be conceived possible. But he does not, and cannot possess the power and hardihood which he would acquire under other circumstances. This air of the improperly close and heated stable is still further contaminated by the urine and dung, which rapidly ferment there, and give out simulating and unwholesome vapors. When a person first enters an ill-managed stable, and especially early in the morning, he is annoyed not only by the heat of the confined air, but by a pungent smell, resembling hartshorn; and can he be surprised at the inflammation of the eyes, and the chronic cough, and the disease of the lungs, by which the animal who has been all night shut up in this wretched atmosphere is often attacked; or if the glanders and farcy should occasionally break out in such stables? It has been ascertained by chemical experiment that the urine of the horse contains an exceedingly large quantity of hartshorn, and not only so, but that, influenced by the heat of a crowded stable, and possibly by other decompositions that are going forward at the same time, this am. moniacal vapor begins to be rapidly given out, almost immediately after the urine is voided. When disease begins to appear among the inhabitants of these 
sll-ventilated places, is it wonderful that it should rapidly spread among them, and that the plague spot should be, as it were, placed on the door of such a stable? When distemper appears in spring, or autumn, it is in very many cases to be traced to such a pest house. It is peculiarly fatal there. The horses belonging to a small establishment, rationally treated, have it comparatively seldom, or have it lightly. But among the inmates of a crowded stable it is sure to display itself, and there it is most fatal. The experience of every veterinary surgeon, and of every large proprietor of horses, will corroborate this statement. Every stable should possess within itself a certain degree of ventilation. The cost of this would be trifling, and its saving in the preservation of valuable animals may be immense. The apertures need not be large, and the whole may be so contrived that no direct current of air shall fall on the horse. A gentleman's stable should never be without a thermometer. The temperature should seldom exceed $70^{\circ}$ in the summer, or sink below $40^{\circ}$ or $50^{\circ}$ in the winter.

\section{Litter.}

Having spoken of the vapor of hartsorn, which is so rapidly and so plentifully given out from the urine of the horse in a heated stable, I next take into consideration the subject of litter. The first caution is frequently to remove it. The early extrication of gas shows the rapid putrification of the 
urine; and the consequences of which will be rapid putrification of the litter that is moistened by it.

Everything hastening to decomposition should be carefully removed, where life and health are to be preserved. The litter that has been much wetted or at all softened by the urine, and is beginning to decay, should be swept away every morning; the greater part of the remainder may then be piled under the manger, a little being left to prevent the painful and injurious pressure of the feet, on the hard floor during the day. The soiled and soaked portion of that which was left, should be removed at night. In the better kind of stables, however, the stalls should be completely emptied every morning. No heap of fermenting dung should be suffered to remain during the day, in the corner, or in any part of the stable. With regard to this, the directions of the master should be peremptory. The stable should be so contrived that the urine shall quickly run off, and the offensive and injurious vapors from the decomposing fluid, and the litter, will then be materially lessened; but if this is effected by means of gutters, and a descending floor, the descent must be barely sufficient to cause the fluid to escape, as if the toes are kept higher than the heels, it will lead to lameness, and is also a frequent cause of contraction of the foot. Stalls of this kind certainly do best for mares, but for horses we much prefer those with a grating in the center, and a slight inclination of the floor on every side, towards the middle, and short 
branch may communicate with a larger drain, by means of which the urine may be carried off to a res- ervoir outside the stable. Traps are now contrived, and may be procured at a little expense, by means of which neither any offensive smell nor current of air can pass through the grating. Humanity and interest, as well as the appearance of the stable, should induce the proprietor of the horse to place a moderate quantity of litter under him during the day.

\section{Light.}

This neglected branch of stable management is of far more consequence than is generally imagined; and it is particularly neglected by those for whom these treatises are principally designed. The farmer's stable is frequently destitute of any glazed window, and has only a shutter, which is raised in warm weather, and closed when the weather becomes cold. When the horse is in the stable only during a few hours in the day, this is not of so much consequence, with regard to horses of slow work; but to carriage horses, and hackneys, so far, at least, as the eyes are concerned, a dark stable is little less injurious than a foul and heated one. In order to illustrate this, reference may be made to the unpleasant feeling, and the utter impossibility of seeing distinctly, when a man suddenly emerges from a dark place into the full blaze of day. The sensation of mingled pain and giddiness is not soon forgutten, and some minutes pass before the eye can accommodate itself to the increased light. If this were to happen every day, 
or several times in the day, the sight would be irreparably injured, or possibly blindness would ensue. Can we wonder, then, that the horse, taken from $a$. dark stable intu a glow of light, feeling probably, as we should do under similar circumstances, and unable for a considerable time to see anything around him distinctly, should become a starter; or that the frequently repeated violent effect of sudden light should induce inflammation of the eye, so intense as to terminate in blindness? There is, indeed, no doubt, that horses, kept in dark stables, are frequently notorious starters, and that abominable habit has been traced to this course. If plenty of light is admitted, the walls of the stable, and especially that portion of them which is before the horse's head, must not be of too glaring a color. The color of the stable should depend on the quantity of light. Where much can be admitted, the walls should be of a gray hue; when darkness would otherwise prevail, frequent whitewashing may, in some degree, dissipate the gloom. For another reason, it will be evident that the stable should not possess too glaring a light-it is the resting place of the horse. The work of the farmer's horse, indeed, is confined principally to the day. The hour of exertion having passed, the animal returns to his stable to feed, and to repose, and the latter is as necessary as the former, in order to prepare him for renewed work. Something approaching to the dimness of twilight is requisite to induce the animal to compose himself to sleep. This half-light 
more particularly suits horses of heavy work. In the quietness of a dimly-lighted stable, they obtain repose, and accumulate flesh and fat.

\section{Grooming.}

Of this, much need not be said to the agriculturist, since custom, and apparently without ill effect, has allotted so little of the comb and brush to the farmer's horse. The animal that is worked all day, and turned out at night, requires little more to be done to him than to have the dirt brushed off his limbs. Regular grooming, by rendering his skin more sensible to the attraction of temperature, and the inclemency of the weather, would be prejudicial. The horse that is altogether turned out, needs no grooming. The dandruff, or scurf, which accumulates at the roots of the hair, is a provision of nature to defend him from the wind and the cold. It is to the stabled horse, highly fed and little or irregularly worked, that grooming is of so much consequence. Good rubbing with the brush, or the curry-comb, opens the pores of the skin, circulates the blood to the extremities of the body, produces free and healthy perspiration, and stands in the room of exercise. No horse will carry a fine coat without either unnatural heat or dressing. They both effect the same purpose; they both increase the insensible perspiration; but the first does it at the expense of health and strength, while the second, at the same time that it produces a glow on the skin, and a determination of blood to it, rouses all the energies of the frame. It would be well for the pro- 
prietor of the horse if he were to insist and, see that his orders are really obeyed, that the fine coat in which he and his groom so much delight, is produced by hand rubbing, and not by a heated stable and thick clothing, and most of all, not by stimulating or injurious spices. The horse should be regularly dressed every day, in addition to the grooming that is necessary after work.

When the weather will permit the horse to be taken out, he should never be groomed in the stable, unless he is an animal of peculiar value, or placed for a time under peculiar circumstances. Without dwelling on the want of cleanliness, when the scurf and dust are brushed from the horse, they lodge in his manger, and mingle with his food. Experience teaches that if the cold is not too great, the animal is braced and invigorated to a degree that cannot be attained in the stable, from being dressed in the open air. There is no necessity, however, for half the punishment which many a groom inflicts upon the horse in the act of dressing; and particularly on one whose skin is thin and sensible. The curry-comb should at all times be lightly applied. With many horses, its use may be almost dispensed with; and even the brush need not be used very hard, or the points of the bristles so irregular, as they often are.

A soft brush, with a little more weight of the hand will be equally effectual, and a good deal more pleasant to the horse. A hair cloth, while it will seldom irritate, and tease, will be almost sufficient 
with horses that have a thin skin, and that have not been neglected. After all, it is no slight task to dress a horse as it ought to be done. It occupies no little time, and demands considerable patience, as well as dexterity. It will be readily ascertained whether a horse has been well dressed by rubbing him with one of the fingers. A greasy stain will detect the idleness of the groom. Where, however, the horse is changing his coat, both the curry-comb and brush should be used as lightly as possible. Whoever would be convinced of the benefit of friction to the horse's skin, and to the horse generally, needs only to observe the effects produced by well rubbing the legs of a tired horse. While every enlargement subsides, and the painful stiffness disappears, and the legs attain their natural warmth, and become fine, the animal is evidently and rapidly reviving; he attacks his food with appetite, and then quietly lies down to rest.

\section{Exercise.}

My observations on this important branch of stable-managernent must have only a slight reference to the agricultural horse. His work is usually regular and not exhausting. He is neither predisposed to disease by idleness, nor worn out by excessive exertion. He, like his master, has enough to do to keep him in health, and not enough to distress or injure him; on the contrary, the regularity of his work prolongs life to an extent rarely witnessed in the stable of the gentleman. My remarks on exercise, then, must have a general bearing, or have prin- 
cipal reference to those persons who are in middle stations of life, and who contrive to keep a horse for business or pleasure, but cannot afford to maintain a servant for the express purpose of looking after it.

The first rule I would lay down is, that every horse should have daily exercise. The animal that with usual stable feeding, stands idle for three or four days, as is the case in many establishments, must suffer. He is predisposed to fever, or to grease, or worse than all, disease of the feet, and if, after three or four days of inactivity, he is ridden far and fast, he is almost sure to have inflammation of the lungs or of the feet. A gentleman's, or tradesman's horse suffers a great deal more from idleness than he does frorn work. A stable fed horse should have two hours' exercise every day, if he is to be kept free from disease. Nothing of extraordinary, or even of ordinary labor, can be effected on the road or in the the field, without sufficient and regular exercise. It is this alone which can give energy to the system, or develop the power of any animal. In training the trotter and the running horse, regular exercise is the most important of all considerations, however, it may be forgotten in the usual management of the stable. The exercised horse will discharge his task, and sometimes a severe one, with ease and pleasure, while the idle and neglected one will be fatigued ere half his labor is accomplished, and if he is pushed a little too far, dangerous inflammation will ensue. How often, nevertheless, does it happen, that the horse 
which has stood inactive in the stable three or four days, is ridden or driven thirty or forty miles in the course of a single day? This rest is often purposely given to prepare for extra exertion-to lay in a stock of strength for the performance of the task required of him, and then the owner is surprised and dissatisfied if the animal becon, es stiffened, or seriously ill.

Nothing is so common, and so preposterous, as for a person to buy a horse from a dealer's stable, where he has been idly fattened for sale for many a day, and immediately to give him a long drive, and then to complain bitterly, and think he has been imposed upon, if the animal is exhausted before he arrives at his destination, and is compelled to be led home suffering from inflammation: Regular and gradually increasing exercise would have made the same horse appear a treasure to his owner. Exercise should be somewhat proportioned to the age of the horse. A young horse requires more than an old one. Nature has given to young animals of every kind a disposition to activity, but the exercise must not be violent. A great deal depends upon the manner in which it is given. To preserve the temper and promote health, it should be moderate, at least at the beginning and the termination. The rapid trot, or even the gallop, may be resorted to in the middle of the exercise, but the horse should be brought in cool. There are many other points in stable management I would like to mention, but the size of this little volume will not admit of it. 


\section{BREEDING.}

To all persons engaged in raising horses, the sub-

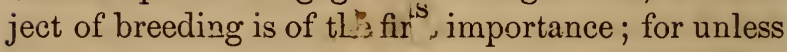
the laws which govern reproduction be, to some extent, understood and acted upon, all efforts to improve existing stocks, or to produce horses for particular kinds of service, must depend on chance, and of course, in most cases prove unsatisfactory. The great law of reproduction, that "like begets like," obtains, with universal sway, both in the animal and vegetable kingdoms of nature. But every circumstance, however trifling, affecting either the male or the female, will have a corresponding influence on the offspring. Every farmer knows how mysteriously his genuine white wheat becomes degenerated, when his neighbors pay no attention to keeping a good stock of wheat. And this degeneracy is only the result of the fine dust from the bloom (called pollen) being carried by the wind from their fields to his. As a general rule, nature endeavors to impress the offspring with the type of both parents; and we usually find a more or less perfect blending of the qualities of both in the offspring, with a decided prominence of those qualities peculiar to only one of the parents. 
And this does not extend merely to physical organization, but is equally true of mental characteristics, and also extends to the propagation of the diseased condition, or predisposition to the diseases of the parents. There is scarcely a malady to which the horse is subject which is not hereditary, or to which a predisposition, at least, may not be transmitted. This is most certainly true of thick wind, roaring, blindness, spavin, curb, contracted feet, grease, and many other diseases; and particularly of viciousness. But as the male only furnishes the vivifying principle (the pollen) to the egg (the ovum) of the female, while the female furnishes the nutriment of the embryo animal from her own secretions, we would naturally expect the offspring to partake more of the qualities of the female than of the male. And this fact shows that the selection of a mare to breed from is of more importance than the selection of the horse to breed to; a truth which seems to have been almost entirely overlooked, practically, at least in this country, for we find that farmers, as a general thing, instead of breeding their best mares, keep them for labor, and breed those which are unfit for labor on account of their age, their viciousness, or even their positively diseased condition. Hence, although very good stallions are to be found in every part of our country, at least four-fifths of all our horses bear evident marks of hereditary disease, malformation, or viciousness. Though the defects of 
the parents may not appear in the immediate progeny, they will most certainly be found in the second generation. From the foregoing considerations, we may deduce the following important points to be observed in breeding.

First, the mare should be selected from a stock known to be suited to the purpose for which it is proposed to breed. She should be of proper age and size, well formed, of good color, proper gait, and free from any disease or malformation, or any hereditary taint.

Second, select a stallion of good blood, but not of near kin to the mare, which will be as nearly as possible a perfect complement to the mare; by which it is meant that if she is deficient in any point, this shall be remedied by his peculiar excellence in the same point.

Third, it is more important that the ancestry of the mare should be known to be healthy and of good stock than that the same should be known of those of the stallion, for although some mares breed after the horse, I believe that it may be truly stated that three-fourths breed after their own stock.

To illustrate more fully these principles, suppose the mare to be too fine in her limbs; to remedy this in the offspring, the horse should be even heavier limbed than desirable, but not clumsy. The dam and the sire should always be paired; their points should be well compared, so that any defect in the 
one may be counteracted by a contrast in the other. A breeder often puts several mares to the same horse, and by so doing seldom gets the kind of horses he intends to raise; for it cannot be supposed that any man will be so careful in selecting his mares as to have them all suitable to breed to the same stallion. Farmers often pursue this course because it is more convenient to have all their breeders served by the same horse, but they pay dearly for their convenience when their best mares bring colts of the most inferior character, and fit for anything else than the object for which they intended them. This subject demands the most careful consideration by all who would perpetuate a good stock or improve an inferior one.

Another very important point to be observed in breeding is, never to put a mare to a stallion of the same stock, if they are nearly akin, for the foal will be delicate, and seldom as good or as large as either the dam or the sire, and never as durable or as well mettled. Natural deformity may generally be traced to the fact that the dam and sire were too nearly akin. A distinguished author justly remarks on the subject of "breeding in and in," as it is called, that "it is a fact, however much some may deny it, that strict confinement to one breed, however valuable or perfect, produces gradual deterioration." In Europe, where the writer practiced until within the last twelve years, the raiser of horses for the turf is particularly cautious of this practice. No sportsman 
would purchase a race-horse, if he knew the sire and dam to be closely related.

The farmer and liveryman are equally careful on this subject. To pursue successfully the system of crossing, requires much judgment and experience, for the bad qualities of the cross are easily engrafted on the original stock, and once there, are not for several generations got rid of; and the good ones of both are occasionally neutralized to a most mortifying extent. Crossing should be pursued with great caution, and the most perfect of the same breed should be selected, but varied by being frequently taken from different stocks.

I must again recur to the very pernicious but frequent practice of breeding on infirm, small, ill-shaped, bad-colored mares, and those positively diseased, or predisposed to disease by hereditary taint - a practice which cannot be too severely censured. I once interrogated a number of gentlemen who had bought, at auction I believe, several small, ill-shaped and diseased mares, to know why they should have purchased such, when they were certainly able to have got good-sized, well-formed, and sound ones. One of the gentlemen replied that he knew his mare was unfit for much service, but he got her cheap, and as he had plenty of grass, he intended to turn her to breed. "My friend," I replied, "your mare is better suited to any other purpose. Suppose you put her to a horse and raise a colt, you cannot expect it, at 
the age of four or five years, to bring more than fifty or seventy-five dollars; and if any hereditary ailment should descend to it, it will not bring enough to pày the keeping of the dam for the six months she suckled it. Now suppose you had taken the opposite course, and purchased a large, well-formed, goodblooded mare, free from hereditary ailment, and put her to a judiciously selected stallion, you would have stood a fair chance of raising a colt worth double the price of the former, and you would also have had the profitable labor of the mare." Two of these gentlemen followed my counsel, disposed of their scrub mares and purchased others, and are now raising, perhaps the best horses in their vicinity.

Another subject of importance, to which I will now call attention, is the unpardonable practice of breeding mares at two years old. This hinders the growth and spoils the form of the mare. Thus, before her constitution is matured or her strength developed, she is overladen, which crushes down her joints, especially the fetlock, changes the natural symmetry of the body, and also has a tendency to injure the form of the back and ribs. After this burden is got rid of, at foaling, then comes the reduction on the system by the suckling of the foal. All these influences combined destroy the strength, form and size of the mare. Besides all this, the foal comes of small size, not having had room in the space allowed by nature, and will necessarily be very 
delicate. It also has to be suckled by a mare that must continue to grow, and needs all that nature furnishes for that purpose. Thus both the dam and foal must be deprived of the full, natural-demands of their systems, and they are both injured for all future time.

If a mare is well treated through life, allowing her to mature before putting her to breed, she will continue to bring good foals until she is twenty, and some even above that age. But if hard worked and poorly fed, so as to show the effect of such treatment, she cannot be expected to bring and raise as good foals as if she had been otherwise treated.

The mare is said to go with foal eleven months, or three hundred days; but fully developed foals have been brought forth five weeks earlier than this, while in other instances mares have carried their foals six weeks beyond this time. Farmers should not lose sight of this in putting their mares, for they should have their colts come at a time when there is some grass, as the mare will do much better not to be confined entirely to dry feed at foaling. Some writers say that from the time a mare is put to the horse, she may be used generally. But from this opinion my own observation and experience constrain me to dissent. I insist that she should be allowed to stand idle until the sensation of her heat, or season, as it is sometimes called, subsides. After conception, every mare, if permitted to go free, will 
stand by a fence or tree in a dormant position, after her heat goes off. Now if at this time she be overworked or scared, she will cast the conception and will require to be served again. I need not explain the cause of this, as there is no remedy or preventive for it, only to let the mare have ease and peace, to allow nature to fulfill her allotted functions.

There can be no doubt, however, that after a mare has been a few weeks with foal, moderate work will do no injury, but will rather be of service to her. She may do farm work up to the time of foaling, but must never be placed in a situation where she will be at all likely to receive severe jolts, kicks, or any other violence. Another evil to the conception is turning mares out with string-proud or badly castrated horses, to be teased by these pests. This is very pernicious to their conception. On this the farmer needs no theory, as the best preventive of the evil is good fences to keep these fellows away from his breeding mares.

To show the importance of attention to this point, I will state a few cases which have come under my observation. A neighbor of mine put a fine gray mare to a horse. She was proved on the regular trial day, and showed all signs of conception. About three weeks after being served, she stood dozing by a fence, and the owner coming up, thinking her sick, started her rather suddenly. The fright so shocked her nervous system that she sickened, lay down and 
cast the embryo. Another in the same township aborted by a horse teasing her.

I knew a gentleman who put a mare that had bred several colts; but at this time, and also the year following, she was grazed in a pasture adjoining one in which a string-proud horse was kept, and of course was teased by him. The consequence was, she had no colt for two years. On being asked my opinion of the cause of this, I went to see the mare, knowing that bad treatment or debility of the system must have given rise to the difficulty. When I arrived, I ascertained the above facts. The mare was at once removed from her tormentor, and for a number of years following never failed to breed. I knew another mare to be grazed in a field back of the stable in which the horse was kept to which she had been put. She lingered about the stable and kept her heat up, and did not conceive until removed to another field, when she immediately gave signs of conception, and in due time brought a foal.

Previous to the time of foaling there will be noticed a furrow-like fold on each side of the spinal bone, extending from the tail to the haunch. This, and the increased size of the udder, or bag, are all the symptoms of approaching foaling that will be observed until about twenty-four or forty-eight hours previous, when there will be seen an adhesive substance protruding from each teat, like drops of milk. This is a certain indication, and as soon as it is ob- 
served, measures must be taken to secure the safety of the foal, which will require that the mare shall be kept in a suitable place, where some careful person can look after her safety.

Recurring again to the subject of putting a mare, I would remark that the virgin mare, or one which bas not for one season had a colt, is to be put when she is found in season. But the mare that has had a colt will be found in season some time in the first month after foaling, and if it is desired to breed her again, she must be put at this time. She should be put on the ninth day after foaling; some say the eighth, but I think the ninth better. Others prefer the eleventh day, but it is dangerous to wait longer than this, for in nine cases out of ten the mare will have come her heat, and will not receive the horse until too late for that season. The chief reason of this is, that suckling reduces the system of the mare too much to allow conception to take place, and thus a year's service of the breeder is lost. I have known many instances of this kind. I know only one remedy for this, and it is too barbarous to be practiced, and any one who would resort to it should be punished by law. After putting a mare, the days for trial are the ninth after service, the seventh after this, and the fifth after this again, making twentyone days. Some return again, commencing with the ninth day, and follow up as before, making fortytwo days. But I insist that, as twenty-one days is 
the period elapsing between a mare's going out of heat and coming in again, making her periodical term thirty days, twenty-one days is sufficient to prove a mare.

Every breeder should be able to judge of the conception of a mare, which will require attention to the following points : After the first service of the horse, and before the next trial, on examining the vagina, or bearing, as some call it, if conception has not taken place, it will be of fresh, bright, or florid and moist appearance, with a clear drop appearing at the lower part, and which, if touched, will incline to extend; but if conception is present, a different appearance of the vagina will be presented. It will be found dry, and of a dirty brown or rust color, and a dark, brown-looking drop will replace the former clear drop. Where these latter appearances are present, pregnancy may be regarded as certain.They may be relied on as a sure criterion in the purchase of a mare alleged to be with foal.

Strange as it may appear, some mares, even though with foal, if teased at about the expiration of the first month, or part of the second, will be induced to admit of the service of the horse. I have frequently seen this proved. The author once put a mare to a horse in May. She stood every trial. In harvest or in September, I believe, I rode her by the stable in which the horse was kept. She forced toward the stable. I took her there and found that she stood 
the teasing, and should have let the horse serve her, but the groom not being at home, I was unable to do so. Subsequently, I deferred putting her on account of the lateness of the season. This mare proved to be with foal, and brought a colt early the following spring.

Especial care should be taken of a mare about the fourth and fifth months of her pregnancy, and from this time forward. It is about this time when abortion is most likely to occur. Her feeding should be increased, as she cannot endure hunger. She has peculiar need of additional feed, as the rapid growth . of the embryo is a material tax on her system, calling for an increased quantity of nutriment. There are two animals to support on the food of one. This must not be overlooked, or abortion will often be the consequence. Another cause of abortion, which I will mention, is showing a mare food which she likes, and has been in the habit of eating previous to this time, and not letting her have it. Seeing or even smelling such food is dangerous. I saw a mare taken to a mill in the month of November, and hitched on a floor near a heap of bran, which she tried very hard to reach, but could not. Soon after, being taken off the floor, she took sick, and had a visible appearance of abortion; but a veterinarian who was present, and had seen the whole transaction, took some of the bran and fed it to the mare, and the spasms, or throes, left her, and never returned again 
until the full term. I have known other similar in stances. Feeding hogs by the place where mares, not grain-fed, are kept, is ultimately dangerous.

If a mare once slinks her colt, she will be very likely to do so at the same period of her pregnancy the next year, and continue the habit, especially if anything like the same provocation occurs. But if she slinks, or aborts, from a hurt, a strain, or some disease, she will not be so liable to contract it as a habit. The best remedy I have ever found, when a mare shows symptoms of abortion, is to take the feathers of wild birds, (pigeon feathers are the best,) and burn them on a pan, or iron, holding them so that she can inhale or breathe the smoke.

If a mare is in the habit of slinking her foal, she should not be kept in the same lot with other breeding mares; for, though it may seem strange, the act of one mare slinking will be almost certain to cause the others to do the same. This is the result of sympathy - some writers say of imagination. But I rely for its explanation on that great sympathy whose delicate and mysterious chain binds not only the different organs of the same animal, but reaches out even to others of the same species, and even of different species, particularly if in close contact; so that an impression made on one does not stop with itself, but finds a response in the others. The nervous system is the medium through which this sym pathy acts, and as this is always exalted in its sensi- 


\section{- 157}

bilities during pregnancy, we might reasonably expect such a result as abortion from sympathy. Imagination, indeed, may produce abortion, but by an entirely similar impression on the nervous system to that produced by fright. Hysteria is a disease of a nervous, spasmodic character, generally resulting from the sympathy of the uterus, or womb, with other organs, especially the stomach. The nervous system here is the medium through which the morbid impression is transmitted, and this peculiar organ is susceptible of being affected even by mental impressions.

An acquaintance, a large breeder, had several mares slink their foals the same night. I have read of several similar instances. Three cases, which fell under my observation, were caused by the owner purchasing a mare in the habit of slinking. The first year, at Christmas, she and three others aborted, and the next year five. The third year, the habitual aborter was separated from the others and followed her usual habit, but all the others went to their term, as they did ever after. 


\section{CLOSING REMARKS.}

Now, dear reader, a word with you, and I am done. I have endeavored, in writing the system, to fully explain it, so that none need go astray; but it must be remembered, in handling wild and vicious horses, you have different dispositions to contend. against. "Every one who understands the true philosophy of horsemanship, knows when we have a horse that is high mettled, wild, and lively, we can train him to our will in a very short time, for they are generally quick to learn, and always ready to obey. But there is another kind that are of a stubborn or vicious disposition, and although they are not wild, requiring no taming in the sense that is generally understood, they are just as ignorant as a wild horse, if not more so, and need to be educated just as much. And in order to have them obey quickly, it is necessary that they should be made to fear their masters ; for in order to obtain perfect obedience from any horse, we must first have him fear us, for our motto is, "Fear, love, and obey," and we must have the fulfillment of the first two, before we can expect the latter; and it is by my philosophy of creating fear, love, and confidence, that I govern to my will any kind of horse whatever. Then in order to take horses as I find them, or more particularly if they 
are of a stubborn or mulish disposition - if he lays back his ears as you approach him, or turns his heels to kick you - he has not the regard or fear of man that he should have, to enable you to handle him quickly and easily. In such cases, give him a few sharp cuts with the whip about the legs, pretty close to the body. It will crack keen, as it plies around his legs, and the crack of the whip will effect him as much as the stroke. Beside, one sharp cut about the legs will effect them more than two or three over the back, the skin or inner part of the legs, or about the flank, being thinner and more tender than on his back. But I do not whip him much - just enough to scare him. It is not because I want to hurt the horse that I whip him, I only do it to scare the barl disposition out of him. But whatever you do, do quickly, sharply, and with a good deal of force, but always without anger. If you are going to scare him at all, you must do it at once; never go into a pitched battle with your horse, and whip him until he is mad, and will fight you. You had better not touch him at all; for you will establish, instead of fear and regard, a feeling of resentment, hatred, and ill-will. It will do him no good, but an injury, to strike a blow, unless you can scare him; but if you succeed in scaring him, you can whip him without making him mad, for fear and anger never exist together in the horse; and as soon as one is visible, you will find that the other has disappeared. As soon as you have frightened him so that he will 
stand up straight, and pay some attention to you, approach him again and caress him a good deal more than you have whipped him; then you will excite two controlling passions of his nature-love and fear - and then he will fear and love you too, and as soon as he learns what to do, he will quickly obey. With these remarks upon the principles of my theory, I have endeavored to teach you how to put them in practice, and all of the instructions written you may rely on as having been proven practically by my own experiments; and knowing from experience just what obstacles I have met with in handling bad horses; I have tried to anticipate them for your good, and assist you in surmounting them, by commencing with the first steps taken with the colt, and accompanying you through the whole task of breaking. 


\section{SIGNS OF DISEASE IN THE HORSE.}

The horse being unable to describe to us his feelings, and tell us the seat of his pain, we are compelled to rely on such signis and symptoms as we can discover, by various means, to determine the nature of his ailments. A few of the more common symptoms, or signs of disease, will now be considered. But to determine exactly the character of any particular case of disease, the combination of symptoms present will have to be considered. In this article, however, important landmarks are presented, which may be useful in guiding to correct conclusions.

\section{The Pulse.}

The pulse of a medium-sized, healthy horse beats about forty per miuute. The pulse of a small horse may be a few more, or of a larger one, a beat or two less. Age decreases the pulse slightly. Any considerable increase of the pulse over forty per minute indicates fever or inflammation, and other symptoms must be looked for to determine the particular locality of the disease. When great weakness ensues, the pulse becomes fluttering.

\section{The Membrane of the Nose.}

This, in health, is of a light pink color; in fever or inflammation, it is red. If of the lungs or air- 
passages, it is more deeply colored, and specked with brown mucus. In the very last stage of most diseases, when death is about taking place, the membrane of the nose becomes of a dark, leaden, or livid color. In glanders it is of a light blue and reddish color, with specks of ulceration over it. In scarlet fever it is covered with scarlet spots.

\section{The Ears,}

In disease, lose their erectness and quickness of motion, and become dull, loose and fallen; falling forward if the head is down, and backward if it is raised, in all diseases affecting the system generally. The ears are cold in inflammation of the lungs and pleurisy, slightly so in other diseases, as colic, etc.

\section{The Eyes.}

Weeping of the eyes is ubserved in colds, strangles, catarrhal fever and glanders. When the eyes become glassy in the advanced stage of disease, it indicates that death is about to take place.

\section{The Mouth}

Is hot in fevers and inflammations. The mouth and tongue are clammy and offensive in severe fevers.

\section{The Breathing.}

The breathing is rapid in fevers; laborious in inflammation of the lungs; laborious, short and catching, in pleurisy; and difficult in thick-wind. The nostrils are much spread in inflammation of the lungs and pleurisy. The breath is hot. Deep, snoring breathing, indicates disease of the brain. 


\section{The Feet.}

Coldness of the feet indicates inflammation of important internal organs, as the lungs, pleura, bowels, bladder, etc. Heat and tenderness of the feet occur in founder.

\section{The Hair.}

The hair is dry and staring in farcy, glanders, indigestion, hide-bound from any cause, worms, mange, consumption, surfeit, all diseases of the skin, and starvation. The hair comes out in patches in mange and in spots in surfeit.

\section{The Skin.}

Heat of the skin is one of the principal signs of external local inflammation; it also shows the presence of some fevers of a general character. A yellowness about the mouth, eyes and nose, shows jaundice or inflammation of the liver. Redness of the skin of the heels is a forerunner of grease or scratches. Dryness and huskiness of the skin and hair indicate constitutional derangement, either of a chronic character, or it may be some acute disease already present or just corning on, as pleurisy or inflammation of the lungs, in which the skin of the legs is cool or cold throughout.

\section{The Dung.}

The appearance of the horse's dung shows the condition of his digestion. The dung very offensive, like that of the hog or human, indicates a want of action in the absorbent vessels of the bowels, which 
is a form of indigestion. The dung-balls are slimy in glanders, farcy and worms.

\section{The Water.}

The urine of the horse undergoes very great changes of quantity, color and thickness, when the animal is in perfect health. Stopping of the urine, or when it passes only a little at a time, and that attended with great straining, indicates stricture, inflammation of the kidneys or bladder. Diabetes is told by the composition of the urine and the quantity; bloody water by its being mixed with blood.

The flanks heave in inflammation of the lungs, pleura, and bowels. They are tucked up in glanders, farcy, indigestion, jaundice, and other diseases. in which digestion is impaired. A kernel will be felt in the inside of the loose skin of the flank, in the groin, in mange. The flanks throb in thumps.

Drooping of the head is a sign present in a great variety of diseases, and of opposite characters. When it is observed, other symptoms should be looked for. It is most marked and perfect in diseases of the brain.

\section{Lying Down.}

In flatulent colic the horse lies down carefully, rolls, and tries to keep on his back. He then gets up quick. In spasmodic colic he lies down quick, rolls over quickly several times, and gets up, or he may only rise on his hips and sit for awhile, and then 
roll again, or get up. In inflammation of the bowels he lies down carefully, and lies stretched out, and paws or strikes with his four feet.

\section{Standing Still.}

In locked-jaw, the horse stands wide, and fixed as a statue. In inflammation of the lungs he stands with his head inclining and his fore feet forward, and does not want to move; and if he lies down, he gets up instantly. In pleurisy the same way, but may lie down for a time.

\section{Pointing with the Nose.}

The horse points with his nose to the flanks, in inflammation of the bowels and colic; and turns his neck carefully and looks at his side, but does not put his nose to the body, in pleurisy. In inflammation of the foot or acute founder, he points his nose to the foot.

Pointing the fore feet indicates atrophy of the muscles of the shoulder, called sweeny. Pointing first one and then the other, is a symptom of chestfounder, or rheumatism. Dragging the fore foot shows dislocation of the shoulder-joint.

Staggering, in most diseases, as colic, for example, indicates approaching death. It is a symptom of hysterics, palsy, and poisoning with narcotics.

Straddling is a symptom of inflammation of the kidneys, bladder, and strain of the back. 
Stiffness in walking occurs in big-head, farcy, founder, lung fever, pleurisy, hysterics and rheumatism. Twitching of the skin on the side occurs in pleurisy.

Delirium occurs in inflammation of the brain, vertigo, apoplexy and stomach staggers.

Drying up of the perspiration, or sweat, very suddenly, when the horse is being driven or worked, is an indication that he is about taking pleurisy or inflammation of the lungs, or some other severe form of inflammation. 


\section{THE OLD ENGLISH}

\section{MYSTERIOUS HORSE FARRIER. \\ DR. TIDBALL,}

Offers his valuable work ov THE Horse to the citizens of this country-all comprised in this one copy of 88 recipes. The old Doctor has had forty years' practice in the different diseases of the horse, and his success has induced him to offer the result of his experience to the public.

\section{RECIPES.}

No. 1. Fistula and Poll Evil before breaking.Rowell from the bottom to the top of the swelling with tape, wet the rowel with tincture cantharides every third day. Move the rowels every morning, washing them clean with soap and water. Leave them in until the swelling has gone down, then draw out and the cure is performed. Bleed one gallon when the operation is performed.

No. 2. After Breaking-Rowel from the top of the pipe down through the pipe, then bleed, and anoint the rowels with Blue Ointment every day until it runs a bloody matter. This is never known to fail.

No. 3. Blue Ointment.-Take half an ounce of verdigris, one ounce of blue vitriol, four ounces of ointment of rosin, one ounce spirits of turpentine, 
grind all fine, mix well with one pound lard, and it is fit for use. Common rosin will do, if the ointment is not convenient.

No. 4. The Hooks, or Weak Eyes.-Rowel in the jaw, or under the eyes, then bleed. Apply the eye lotion every third dwy, with a feather. Move the rowels every morning. Leave them in for fifteen or twenty days; feed on corn.

No. 5. Eye Lotion.-Take one pint of linseed oil, add two ounces of gum camphor, one ounce of ether. Shake it well, and it is fit for use. This cures all weak eyes that are curable.

No. 6. Spavin and Ringworm Ointment.-Take two ounces cantharides, one ounce gum ophorboum, two aunces turpentine, one ounce tincture of iodine, and three drachms corrosive sublimate. Grind all fine, and mix with two pounds of lard.

No. 7. Hoof Bound.--Have horse shod with shoes narrow at the heel. Have them made with calks one inch long, flaring out from bottom to the top. Use the Hoof Ointment every third day.

No. 8. Hoof Ointment.-Take half a pound of lard, and four ounces rosin. Heat them over a slow fire until melted, take the pot off the fire, add one ounce of pulverized verdigris, stir well to prevent it running over. When partly cool, add two ounces turpentine. Apply it from the hair down one inch. Work the horse all the time.

No. 9. Big Leg.-Apply the Liquid Blister every third hour until it blisters. In three hours grease the 
leg with linseed oil. In'six days wash it clean with soap and water. Repeat every six days 'until the swelling goes down. If there should be any callous left, apply the Spavin Ointment.

No. 10. Liquid Blister.-Take half pint linseed oil, one pint spirits turpentine, and four ounces aqua ammonia; shake well, and it is fit for use. Apply every third hour until it blisters.

No. 11. Hoof Evil or Thrush.-Physic and bleed, then poultice the foot with boiled turnips. Renew every twenty four hours, for three times, then apply the Blue Ointment every third day, merely anointing the sore parts. Wash clean before applying. Keep the horse out of the mud and wet. This will never fail to cure in four or five weeks.

No. 12. Founder.-Bleed in the neck until the horse staggers or falls down. Turn up his feet, and fill them with boiling lard. Give him a physic-ball, and foment his legs with hot water every five or six hours. Give him a mash of scalded bran. This will cure in twenty-four hours.

No. 13. Lung Fever.--Symptoms: The horse is taken suddenly ill, either after being taken from the stable, or on returuing to it. He gives evidence of pain by looking around at his side. He never offers to lie down; his nostrils are distended; he breathes hard; his chest is sore, or over his lungs; he cannot bear you to press your hand hard on his chest; very dry, but cannot drink.

CurE.-Bleed three gallons. Take one ounce of 
lavender, two ounces spirits nitre, half pint water; drench him. Repeat every four hours until better. Blanket him as warm as possible. Then apply the liquid blister all over the chest opposite the lungs, every third hour until it blisters. If he is not better in six hours, repeat the bleeding, and inject with the following clyster : half-gallon warm water, halfpint linseed oil, and a small handful salt. Never physic, or he will die.

No. 14. Button Farcy.-Symptoms: swelled legs, and running sores on the legs.

Cure.-Bleed largely, then physic; then give the "following balls or pills, in forty-eight hours after the physic has operated. Take two ounces gentian, and four ounces ginger; make this in a paste with honey or molasses. Divide it into ten parts, add to each part ten grains arsenic. Roll it in paper, and give one, morning and evening, until it physics, or makes him slobber, then omit, and give him one ounce of lardanum. Feed on green or light food. Wash the sores clean, and apply the Blue Ointment every other day. If there should be any swelling left in the legs, apply the General Liniment every day or two.

No. 15. Water Farcy.-Symptoms: The horse is dull and loses his appetite, and swells along the body or chest, and between the fore legs.

CuRE.-Rowel in the breast and along each side of chest as far as the swelling goes. Leave the rowels in until the swelling goes down. Give a spoonful of cleansing powders morning and night. 
No. 16. Nasal Gleet, or running at the nose, or to dry up distemper.-Take half a pound of alum, half pound of rosin, half a pound of blue vitriol, four ounces of ginger, and enough fenugreek to scent; grind all fine. Give the horse a spoonful, two or three times a day. This will cure all discharges or distempers, if not glanders.

No. 17. Chronic Cough.-Take powdered squills one ounce, ginger two ounces, cream tartar one ounce, mix well, and give a spoonful each morning and evening, in wet bran. This is good after hard riding or driving. It cures all coughs and colds, and will prevent the lungs from swelling.

No. 18. Cleansing Powder.-Take of ginger two ounces, four ounces fenugreek, one ounce black antimony, and two ounces rhubarb. Grind all fine, mix it well, and it is fit for use. Give a large spoonful, morning and night. This is the best condition powder ever used. It gives a good appetite and fine coat, and life to the animal.

No. 19. Fits.-Symptoms: The horse commences jerking his head, and falls down; in a short time he will get up, and is apparently well.

Cure.-Give two ounces of the tincture of asafœetida every morning for ten days. Tie the gum on his bit, and make him wear it for six or eight days. He will never have a fit after the first dose.

No. 20. Jaundice Yellow Water. - Symptoms: The hair in the mane and tail gets loose, the white of his eye turns yellow, and the bars of his mouth; 
he refuses to eat, and limps in his right fore leg generally.

CuRE.-Physic, but never bleed; then every morning give him one drachm of calomel in one ounce of spirits of camphor, for eight or ten days, also give him a dose of the Cleansing Powders every night. This is a sure sure.

No. 21. Nicking Balsam. - Take a half pound of fresh butter, add to this one ounce oil origanum, and half an ounce tincture of iodine. Mix well, and it is fit for use. This is used on the tail after nicking, and on bruises, saddle galls, corks, and all kinds of sprains and rheumatism.

No. 22. Thumps or Palpitation of the Heart.Symptorns. The horse is almost exhausted, breathing is very hard. The difference between thumps and lung fever is the distress of the heart, which you may hear flutter at a distance of twenty feet.

CurE.-Bleed largely, and it will suddenly stop. Dissolve one drachm of nitre and a large spoonful of salt in half a pint of water. Drench three times every six hours. Do not work the horse for a week.

No. 23. Shoulder Jam, or Sweeny.-Rowel from the top of the shoulder blade down, as affected. Put in a few drops tincture cantharides every third day. Move the rowels every day, keeping them clean with soap and water. Keep them in from twenty to thirty days, and the cure is performed.

No. 24. Stoppage of the Urine.-Symptoms : Fre- 
quent attempts to urinate, looking round at his sides, lying down, rolling and stretching.

CURE.-Take half a pound hops, three drachms oil of camphor, grind, and mix. Mix this into three pills. Give one every day, with a drench made of a small teaspoonful of saltpetre and two ounces of water. This generally cures.

No. 25. Physic Ball. - Take two ounces aloes, one ounce turpentine, and an ounce of flour. Make into a paste with a few drops of water, wrap in a paper, and give with a bailing iron.

No. 26. To Remove Warts. - Cut them out by the roots, and if they bleed much, dissolve one grain of nitrate of silver in two ounces of water, bathe, and it will stop immediately. Then apply the Blue Ointment every day until it heals.

No. 27. Inflammation of the Kidneys.--Symptoms: The horse is weak across the back, and passes urine very often, which is very highly colored.

CURE.- Bleed one gallon, then blister across the kidneys, and give the following powder: Two ounces rosin, one ounce of hellebore, one ounce gentian. Mix, and apply the General Liniment.

No. 28. Stifle Spruins. - If it has never been out of place, bleed two gallons, then physic, and bathe with hot water every twenty-four hours, and apply the General Liniment. Will cure all cases in ten or twenty days. Never put on the stifle shoe.

No. 29. Loss of Appetite.-Bleed half a gallon, then give a few doses of Cleansing Powders. If he 
lacks life, then give him a few drops of the Restorative Liquid.

No. 30. Restorative Liquid.-This will give life to all that is not dead. Tak oil of cloves one ounce, oil of anise one ounce, tincture cantharides one ounce, tincture asafoetida two ounces, oil rosemary one ounce; shake well, and it is fit for use'; give ten or fifteen drops in a bucket of water.

No. 31. Hoof Liquid.-This is for contracted feet or bruises in the soles of the feet, or after joint sprains: take four ounces oil of spike, four ounces spirits of turpentine, and $\frac{1}{2}$ pint linseed oil; shake well, and apply over the crust of the foot every day. This will remove fever and soreness of the foot, and hoof bound, but the ointment is best.

No. 32. General Liniment.-Take half a pint linseed oil, half a pint of turpentine, four ounces oil of origanum; shake well, and it is fit for use. This is for all sprains and a General Liniment. It is used in the different diseases spoken of.

No. 33. Sore Mouth or Tongue.-First take his grain from him; then take half an ounce of alum, two drachms of sugar of lead, one pint vinegar, and a half gallon of water, open the mouth and swab it out with this, every morning and night. This will cure in all cases in five or six days.

No. 34. Mange.-Symptoms: The hair will rub off, and the skin break out in scabs.

CuRE.- Physic and bleed for this is humor in the blood, then make the following ointment, and 
grease well every day wherever he is affected, for three or four days, and let hin stand in the sun. For killing lice, take half pound of sulphur, two ounces spirits turpentine, and mix well with three pounds of lard; do not let him get wet; give a few doses of the Cleansing Powder.

No. 35. To Stop Blood. - If you can get hold of the artery or vein, tie it up. If not, take the following: Ten grains of nitrate of silver and four ounces of water, apply to the wound, and it will stop immediately. Apply this to warts, after cutting them out.

No. 36. Chest Founders. - Symptoms: Not unlike lung fever. The horse is stiff, but has no fever in his feet, very sore in his chest, inclines to stand very wide with his fore legs.

CuRE.-Bleed, physic, and rowel in the breast, then commence bathing his breast and chest with hot water every six hours, and blanket him. This will cure, if not of too long standing.

No. 37. Melanders is a disease of the feet and pasterns. It commences after the grease heels. Symptoms: The hair stands out.

CurE.-Apply the Spavin Ointment every six days, for two or three times. It will run the callous off. Then apply the Blue Ointment until well.

No. 38. Soap Liniment, for sprains and swellings. Take one half gallon of alcohol, one pint soft soap, four ounces spirits of camphor, and four ounces spirits turpentine, stir over a slow fire. This is cheap and good when you cannot get the General Liniment. 
No. 39. Opedeldoc.-Take one half gallon of alcohol, two ounces gum camphor, and one half an ounce of rosemary. Heat this by setting a jar or pot on the stove. Take pure castile soap, shave it thin, and put in as long as the liquid will eat it. This is sure.

No. 40. Nerve and Bone Ointment.-To one quart clarified neats foot oil, add two ounces oil turpentine, four ounces oil origanum, and one pint alcohol; shake it, clean with red sanders, and strain it.

No. 41. Lock Jaw.-Bleed largely, and apply chloroform to the nose until the jaws fly open, put a gag into the mouth, and give two ounces tinct. asafoetida every six hours, and a dose of physic. This will cure, if there is any cure.

No. 42. Heave Powders to trade on.-Half a pound of Spanish brown, and half a pound of ginger; give a teaspoonful three times a day.

No. 43. Gravel in the Foot. - If it is of long standing, poultice the foot with boiled turnips, or any other drawing poultice, until it draws, then dress with Blue Ointment a few times. If there is much fever, apply the Hoof Liquid for a few times.

No. 44. In Nicking, if much swelling follows, bleed, and use the Nicking Balsarn every other day on the root of the tail. Never apply water to the tail. Let it stay up four weeks ; let the blood dry, and rub it off, then dock and put in the pulleys five or six days.

No. 45. Cure for Colic. - Take two ounces sweet oil, two ounces laudanum, one pint warm water, and drench. - It never fails while there is life. 
No. 46. Big Head.- One ounce oil origanum, two ounces sweet oil, two ounces aqua ammonia, two ounces tincture cantharides, two ounces spirits turpentine, and one ounce oil rosemary. Give one spoonful saltpetre every third day; rub the mixture in twice a day.

No. 47. Bots. - As much red precipitate as will lie on a ten cent piece; mix with dough, and make into a pill. If one does not relieve, repeat in an hour.

No. 48. Gravel.-Steep half a pound of hops in a quart of hot water, give it as hot as the horse can stand it.

No. 49. To Remove the Scum from the Eye in Twenty-four Hours. - Take five cents worth of pulverized lunar caustic, and mix well with one ounce of lard, and it is fit for use.

No. 50. Weak Eyes. - One spoonful of honey, two two spoonfuls fresh butter, one spoonful black pepper, and the yolk of an egg. Stew it for fifteen minutes over a slow fire, and strain through a woolen cloth. Apply in and above the eye.

No. 51. Wounds.-One quart of alcohol, one ounce cayenne pepper, one pint spirits turpentine. Shake well, and it is fit for use.

No. 52. Scratches. - Two ounces castile soap; two ounces rosin, one ounce lard, two ounces copperas, and white of an egg; stew it for fifteen minutes, and it is fit for use. Bind it on the part for 24 hours, then wash it well, and the cure is performed.

No. 53. Sweating Liniment.-Take the yolks of 


\section{8}

six dozen eggs, and one pint of salt; beat them together until it forms a paste; rub the affected part well with the paste, leaving it from four to six hours; wash it off with strong salt and water, as hot as you can put it on.: Then blanket it well for ten hours. It cures all sprains.

No. 54. Dope to Trade on. - One ounce of black antimony, mixed with an ounce of cantharides. A small spoonful twice a day will fatten a horse in ten days to trade on.

No. 55. To Remove Callousness by Absorption in a shorter time than by liniment. One ounce of alcohol, and one ounce of pulverized sal ammonia; bathe the leg every two hours; bind the leg with straw bands from the hoof to the top of the callous, fill a sponge with the liquid, and place it on for twentyfour hours; for spavin, add to this liquid half an ounce of cantharides.

No. 56. Fistula after Breaking.-Take lye from the small black hickory and the roots of the prickly ash, burnt together; boil down to potash; put a small portion into the hole, and let it remain four or five days; remove it, and put in about twenty drops of aqua fortis.

No. 57. Salve to heal wounds.-Take a piece of poke root about the size of an egg, and two Indian turnips ground fine, and stew one minute with a pound of lard. Put it on every third day.

No. 58. Fistula or Poll Evil before breaking or matter is formed. Two ounces oil of turpentine, two 
ounces venice turpentine, two ounces golden tincture, one ounce oil origanum, and half a pint alcohol; mix well, and apply every 24 hours for three times.

No. 59. Heaves.-Take one quart sweet milk, add one tablespoonful oil of vitriol; take four quarts of mash feed, wet the same with one half the prescription; next day, give the balance. In one week repeat the prescription; so on for six weeks.

No. 60. For Curbs.-Take benoidide of mercury three drachms, lard two ounces, mix it well; clip the hair close, just the size of the enlargement, rub the ointment on with the finger. In three or four days the matter which oozes from the enlargement will form a thick scab; soften with fresh lard and pick it off ; rub dry with the hand, and apply as above. Five or six applications will remove any curb. For splints, apply in the same manner.

No. 61. Mud Fever and Cracked Heels.-Take equal parts lard, gunpowder, and glass; pulverize the glass and powder as fine as flour, and make into an ointment; wash the diseased parts with castile soap and soft water; rub dry, and apply the ointment once a day till cured.

No. 62. Infallible Cure for Ringbone and Spavin.

Liquid Ammonia............................1 oz., 9th.

Red Precipitate...............................1 oz., $8 \mathrm{~h}$.

White Pine Turpentine......................1 oz, 3rd.

Spanish Flies................................1 oz., 7th.

Origanum Oil...............................1 oz., 6th.

Iodine...............................2 drachms, 5 th.

Corrosive Sublimate.....................2 drachms, 4 th

Strong Mercurial Ointment.................31/1/ oz., 1st.

Lard $31 / 2$ oz., honey $8 / 4 \mathrm{lb}$., gum forbium.......1 oz., $2 \mathrm{nd}$. 


\section{0}

The reader asks why this recipe is written in such a form. It is prepared just as written : 9th is first placed in the mortar; 8th is next, and well mixed with 9 th ; 3 rd is then thoroughly mixed with 8 th and 9 th. Thus each article is applied separately; and thoroughly mixed. 7 th is the next, and so on until your ointment is finished. This is the best spavin and ringbone ointment known. Clip the hair, and apply the same as for curbs; remove the scale with lard, and wash with castile soap and soft water. Rub dry, and apply again.

No. 63. Physic Ball for Horses. - Cape aloes from six to ten drachms, castile soap one drachm, spirits of wine one drachm, syrup to form the ball. If mercurial physic be wanted, add from one-half a drachm to one drachm of calomel. Previous to physicing a horse, and during its operation, he should be fed on bran mashes, allowed plenty of chilled water, and have exercise. Physic is always useful; it is necessary to be administered in almost every disease. It improves digestion, and gives strength to the lacteals by cleansing the intestines, and unloading the liver, and, if the animal is properly fed, will improve his strength and condition in a remarkable degree. Physic, except in urgent cases, should be given in the morning, and on an empty stomach ; and if required to be repeated, a week should intervene between each dose. Before giving a horse a ball, see that it is not too hard or too large. Cattle medicine is always a given as a drench. 
No. 64. Physic for Cattle. - Cape aloes, four drachms to one ounce. Epsom salts, four to six ounces, powdered ginger three drachms. Mix, and give in a quart of gruel. For calves, one-third of this will be a dose.

No. 65. Tonic for Horses and Cattle.-Sulphate of copper one ounce to twelve drachms, white sugar one-half ounce. Mix, and divide into eight powders, and give one or two daily in the animal's food.

No. 66. Cordial for Horses and Catlle.-Powdered opium one drachm, ginger powdered two drachms, allspice powdered three drachms, caraway seeds powdered four drachms. Make into a ball with molasses, or give as a drench in gruel. For Gripes and Hove in Cuttle, add to the above a teacupful of spirits of oil; and repeat every two hours until the animal is found to be relieved.

No. 67. Diuretic Ball.-Hard soap and common turpentine each four drachms, oil of juniper twenty drops, powdered rosin to form the ball. For Dropsy, Water Farcy, Broken Wind, or Febrile Diseases, add to the above allspice and ginger, of each, two drachms. Make four balls, and give one, morning and evening.

No. 68. Diuretic Powders. - Powdered rosin and nitre, each four ounces; mix, and divide into twelve parts. Give one daily.

No. 69. Alterative or Condition Powders. - Rosin and nitre, each two ounces, levigated antimony one ounce. Mix for eight or ten doses, and give one at 
- night and morning. When this is to be given to cattle, add glauber salts one pound.

No. 70. Fever Ball.-Cape aloes two ounces, nitre four ounces, molasses to form a mass. Divide into twelve balls, and give one, morning and evening, till the bowels are relaxed, then give No. 68 or 72 .

No. 71. Sedative and Worm Ball. - Powdered white hellebore one-half drachm, linseed powdered one-half ounce. If necessary, make into a ball with molasses. This ball is specific for weed, in horses and cattle.

No. 72. Anodyne Ball. - Opium one drachm, camphor two drachms, ginger powder one and a half drachms; molasses to form a ball. Give night and morning after the bowels are opened, in tetanus or lock-jaw. With the addition of powdered catechu two drachms; this forms an excellent cure for diarrhoea or purging.

No. 73. Cordial Astringent Drench for Diarrhoea, Purging and Scouring.- Tincture of opium one-half ounce, allspice two and a balf drachms, powdered caraways one-half ounce; catechu powders two drachms, strong ale or gruel one pint. Give every: morning till the purging ceases. This will make four doses.

No. 74. Blister Ointment.-Hog's lard four ounces, oil of turpentine and spanish flies, each one ounce; mix. This ointment is strong enough for every purpose.

No. 75. Powder of Angleberries. - After cutting 
them off, when they exist in clusters, sprinkle them daily with equal part of muriate of ammonia and powdered savin.

No. 76. Fever Powder for Horses. - Nitre from one half ounce to one ounce, camphor and tartar emetic each from one to two drachms, powder and mix. To be used after the bowels have been opened.

No. 77. Astringent Ball for Horses.- Opium from one half to one drachm, ginger one and one hălf drachms, prepared chalk three drachms, flour two drachms. Powder and make it into a ball with molasses.

No. 78. Stomachic Purgative Ball, for thin, ill-conditioned Horses.-Aloes one and one half ounces, rhubarb two drachms, calomel one drachm, ginger one and one half drachms, oil caraway ten drops, castile soap two drachms; molasses sufficient to make it into a ball.

No. 79. For Fermenting Swollen or Stocked Legs.Procure one pound of smartweed, place the same in an eight gallon kettle - add four gallons of soft water, place over a slow fire and boil down to two gallons, strain the solution into another iron or tin vessel-get one pound of alum, place in a mortar and pulverize fine; sift the alum into the liquid, again place over the fire, and stir until well dissolved. Now wind the limb tight with a hay rope, pour one pint of the solution in at the top of the bandage when blood warm. Repeat every hour for forty-eight hours. This is the best fermentation 


\section{4}

used. It will remove all inflammation and swelling in two days. If there is a cut or wound after fermenting, arply Blue Ointment No. 3 until healed. In case of strain or bruise, apply the General Liniment.

No. 80. For Distemper.- Oil of origanum one ounce, oil cedar one ounce, tincture cantharides one ounce, olive oil four ounces. Shake well and bathe the throat and glands morning and evening for six days, rub in well with the hand; he will throw out freely, and the cure is performed.

No. 81. To Remove Splint.-Croton oil half an ounce, quick silver one drachm, clip the hair close, the size of the enlargement. Shake the bottle well or it will not mix, (the quicksilver being so much heavier than the oil,) immediately after the bottle is well shaken, take two or three drops on the ends of your fingers and rub on the point of the enlargement. Be careful of getting it on the other parts of the leg, for you must remember it is one of the most powerful blisters known. In six or eight days after applying it to the enlargement, wash off with castile soap and warm water; do not pick the bunch off ; let it loosen and work off gradually. After it comes out, apply the Blue Ointment once a day until healed.

No. 82. For Worms in Horses.-Take ten grains of arsenic, place in a short ounce vial with mouthpiece large, take on the point of your pocket knife about as much as would lay on half of a three cent piece, and mix in two quarts of dampened shorts, in 
two or three days repeat the same, and so on, for ten or twelve days. This recipe will effectually destroy all worms in horses.

No. 83. The Best Spavin Preparation Known.Spirits turpentine, half ounce, oil origanum half ounce, citric acid, half ounce, oil wormwood half ounce, spanish fly to thicken, clip the hair, scarify, and apply about the thickness of a piece of note paper, let it remain without touching until it stops running, then carefully wash with soft water and soap. Let the horse remain idle for four weeks.

No. 84. For the Eye-Calomel three scruples, olive oil one ounce, belladonna three scruples; bathe with an eye brush or feather once a day until cured.

No. 85. For Windgalls and Soft Puffs. -Oil origanum four ounces, oil hemlock, one ounce, oil lavender, one ounce, oil wormwood, two ounces, oil spike, one ounce, sweet oil, eight ounces; apply to parts affected morning and evening, and rub well with the hand.

No. 86. For Thrush.-Poultice the foot with turnip poultice for twelve hours, wash clean with warm water, then with a stiff feather apply iodine forte around the frog once a day, for three or four days, after which apply spirits of salts two or three times. In one week the cure is performed.

No. 87. Hoof Rot.-Get a strong solution of white oak bark, then add equal parts of tobacco and gunpowder, let it stand until you get the strength, bathe 
the foot night and morning for ten days ; then apply the Hoof Ointment to grow them out.

No. 88. Heave Remedy.-Balsam of fir and balsam of copaiva, equal portions, add calomel and magnesia, equal parts, to thicken, make into rolls the size of yolk to an egg. Give twice a day, morning and evening. 


\section{A BRIEF DICTIONARY,}

As a Safe Guide to the Farmer and Young Practitioner.

\section{A.}

Anterior, before; the front part of the body.

Anti-spasmodic, a medicine that relieves spasms or cramps.

Anti-septic, medicines which stop decay or decomposition. Septic poison is a deadly poison in all dead bodies not bled to death. Anus, the outlet of the bowels at the tail ; the fundarnent. Appendage, an addition; an ornament, such as the hair, etc. Appreciate, to set a value on; to understand the valuee of. Approach, to come near to.

Approximate, near to.

Articulate, to join end to end, as bones in a joint. Articulating, working hinge-like.

Asphyxia, death by depriving the lungs of air.

Assimilate, to make like.

Astragalus, the name of the largest bone of the hock-joint below the oscalcis.

Ascend, to climb or go up.

Astringent, a medicine that contracts or puckers.

Astringents, medicines which stop discharges, by contracting the parts, such as blood, mucus, etc.

Atrophy, a wasting away of the parts.

Angment, to increase.

Authenticated, made certain.

A rocation, a business.

Azote Nitrogen, an element of many articles of food, especially of flesh.

Abdomen, the belly.

Abortion, foaling before the young animal can live.

Abrupt, sudden ; rude ; quick.

Abscess, a swelling or cavity containing matter or pus.

Absorb, to swallow up.

Absorption, soaking, or taking up by fine vessels called absorbents. Accelerate, to make quicker or faster. Acid, sour. There are several kinds. 
Acute, sharp; an acute disease, one quick in its approach ; violent. Adage, an old saying or proverb.

Allhesion, a sticking together.

Adhesiveness, the property of gluey substances.

Aeration, exposing to the air, such as the blood in the lungs, to free it from carbon.

Affinity, nearness; the quality which causes the parts of a substance to keep together.

Albuminons, resembling the white of an egg in substance.

Alterative, a medicine which generally improves health mildly. Aliment, the food.

Alimentary Canal, the bowels.

Analoyy, resemblance; likeness.

Analysis, to consider separately anything in parts; to separate. Auatomy, the description of the different parts of the animal body. Anchylosis, the stiffening of a joint permanently. Antagonist, one that opposes another.

\section{B.}

Balking, refusing to pull or go forward.

Base, foundation.

Beneath, under the lower part.

Be-stud, to set thickly; to cover with patches or spots.

Bereling, cutting with a slope or bevel.

Biliary, relating to the bile.

Bounded, surrounded.

Boot, a leather boot worn to prevent one foot cutting the other, called in Europe, buffer.

Bongie, an instrument to open the uretha, or urinary passage.

Breeding In and In, putting a mare to a horse of the same family or stuck.

Bridoon, an extra bridle-bit used in conjunction with another, each having a separate rein.

\section{C.}

Cannon-Bone, the shank, or bone below the knee or hock.

Canker, the name given to a certain kind of eating sores.

Capsular Ligaments, the ligaments surrounding the joints.

Capsicum, Cayenne pepper; a small red pepper.

Capillaries, the little fine vessels connecting the arteries and veins.

Carminatives, medicines that drive wind out of the stomach and bowels.

Carbon, the principal part of wood: charcoal is impu:e carbon; poisonous substance in the blood extracted by the oxygen of the air in the lungs; diamond. 
Careass, the animal body.

Carped, gathered up; rounded.

Contact, lying or coming trigether.

Cartilage, gristle; a smooth white substance covering the ends of bones moving or working on each other, as in joints, etc.

Castrate, to deprive of the seeds or testicles.

Catheter, an instrument to draw off the water, urine, etc.

Cathartic, medicines which move the bowels; a physic.

Canterize, to burn the flesh with medicine or a hot iron.

Caustic, a medicine which burns or destroys the flesh, when touched with it.

Cavity, a hollow, low, or open space.

Celebrity, distinction ; greatness ; famousness.

Cellular Tissue, the tissue that joins the skin to the body, and unites the parts or fibres of the muscles, and in which the fat is deposited.

Chaff, a name given to cut feed, hay, straw, etc.

Characteristic, a symptom of character; a disposition of, or a natural and general instinct.

Characterize, to distinguish.

Chemical, relating to chemistry.

Chronic, a lingering disease, after the acute stage.

Circumference, the distance around anything.

Circumseribed, marked around, limited.

Cleft, a notch ; a division ; a furrow.

('oagulate, to clot or thicken like blood, or become like jelly.

Coagulable Lymph, albumen, (which see.)

Co-exist, to be or exist together.

Cohesion, sticking to); sticking together.

Cohort, a large number.

Combustion, burning.

Component, entering into as a part.

Concave, a hollow or cupped surface; the opposite of convex.

Conception, the act of getting with young, after service by the male.

Condition, in good plight; fleshy.

Congestion, the clogging of the blood in the parts, lungs, etc.

Constituting, forming; making up.

Contagious, catching; infectious diseases are contagious.

Contraction, drawing up; narrowing.

Contrast, a difference of color, shade, or form, etc.

Convex, oval or rounding; the opposite of concave.

Copious, pleutiful, abundant.

Coronet, the upper part of the hoof, where it joins the skin.

Corroborate, to agree in giving evidence, or proof.

Cranium, the skull. 
Crest, the back or upper part of the neck.

Criterion, a rule to judge by.

Crust, the hoof is 80 called.

Cultivate, to improve the form, size, or intellect.

\section{D.}

Debility, weakness; feebleness.

Decrease, to make less.

Decompose, to decay ; to separate into its component parts.

Deduce, to form an idea or conclusion.

Defective, not perfect.

Dense, close ; sulid; hard.

Delirium, craziness; want of sense.

Deterioration, to make less or worse.

Dissent, to differ from.

Develop, to show muscular form; to bring up to perfection.

Diaphoreties, medicines which arouse sweating.

Diaphragm, the broad muscle which separates the chest and belly, and assists in the act of breathing.

Diffuse, to spread out; extend; drive out.

Digestive, relating to digestion.

Dilated, opened wide; gaping open.

Dilute, to make fluid medicine thin or weak, as with water, eto.

Diminution, lessening or decreasing.

Dislocation, putting out of joint.

Distorted, crooked or deformed; out of shape.

Distended, stretched out; forced out, or swelled.

Diuretics, medicines which increase the flow of urine.

Divest, to turn aside from.

Docile, gentle; tame; obedient.

Domestication, taning or bringing from a state of nature.

Dominion, control; authority ; power.

Ducts, pipes or openings; canals; tubes.

Duodenum, the first gut next the stomach; the bile enters through it.

\section{E.}

Economy, saving; good management.

Effusion, the flowing out of a fluid.

Elastic, springy, as a spring or India rubber.

Elude, to escape observation; to shun.

Embryo, the unborn animal.

Enamel, the hard covering of the teeth.

Einsue, to follow. 
Epiglottis, the covering of the glottis.

Epidemic, a disease affecting many, as if it existed in the air.

Erect, standing up straight.

Eruption, a breaking out on the skin of pimples or blisters.

Ewe-Necked, low-necked, like a sheep shorn.

Exalted, dignified; raised.

Exanthema, an eruption on the skin with fever.'

Excretiug, throwing out from the body.

Excrement, the dung and urine.

Exert, to act diligently, promptly.

Exhale, throwing or forcing out, as blowing the breath.

Exhaustion, being tired, or worn out by fatigue.

Exhilarate, to make lively, or cheerful.

Exist, to live, to be.

Expansion, increasing in size.

Expedite, to hasten.

Expel, to throw out, or drive out.

External, on the outside.

Extensor Tendon, tendon that extends, or stretches out the limbs, etc.

Exterior, the outside.

Extravasate, to flow out of the proper vessels.

Extremity, the limbs are so called.

Exude, to soak out through.

\section{F.}

Facility, an ease ; easiness.

Fallacy, an error; not true; deceit.

Felorifuges, medicines which cool fevers.

Femur, the thigh-bone proper.

Fibula, the smallest of the two bones above the back.

Fibrous, composed of fibres or fine thread-like substances.

Fibrous Membrane, a membrane composed of fibres.

Fissure, an opening, or crack.

Flatulent, windy; relating to gas, or wind in the stomach, etc.

Flex, to bend, or gather up.

Fluid, a liquid, such as water; air is so called.

Florid, red or scarlet like.

Fomentation, applying warmth and moisture by poultices, etc.

Forceps, long, pointed pincers, or nippers.

Fracture, the breaking of a bone.

Friction, rubbing.

Function, the office or duty of anything.

Fundament, the anus, or last end of the gats. 


\section{G.}

Gangrene, mortification.

Generative, concerned in producing or begetting or breeding.

Generate, to produce; to beget offspring or young.

Genital, belonging to the organs of breeding or generation.

Gland, a soft body, with a tube leading from it, which secretes fluid.

Granulate, to form new flesh, or matter which has the appear. ance of small grains.

Groove, a channel; or gutter.

Group, a collection, or several together.

Gullet, the æsophagus or passage to the stomach.

H.

Habit, eustom, or practice.

Haggard, worn; ghastly; death-like.

Haunch, the bony region of the hips.

Hectic, constitutional fever, produced by ulcers or sores, etc.

Hereditary, bred in the offspring from the parents, as disease, color, etc.

Hue, a color.

Humerus, the upper arm-bone,

Hysteries, a nervous disease of females.

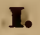

Imagination, what the mind dictates or suggests.

Impediment, an obstruction; hindrance ; fault; an eye-sore.

Impede, to hinder.

Imperceptible, not noticeable.

Implicit, a perfect faith.

Impression, an idea or conclusion; a mark.

Impnlse, a disposition.

Impurity, unfitness for use; adulterated.

Inadequate, not sufficient.

Innate, inherent in itself.

Incisor, the front or cutting teeth are called incisors.

Incision, a clean cut.

Inculcated, taught; instructed.

Indurated, hardened.

Infection, the poisun which causes the same disease by coming in contact with a healthy animal ; inoculation.

Inferior, a bad quality.

Instinct, brute sense; void of reason. 
Inocnlation, producing the same disease by virus of one animal getting to a sore on another, or in any way getting into the blond.

Insertion, when anything is put into another by cutting, etc.

Internally, inwardly; medicines given by the muuth are said to be given internally.

Intensity, in an extreme degree.

Intervals, space of time.

Intestines, the bowels; the guts.

Interfering, cutting one foot with another in passing it.

Inject, to throw into; also to cause disease by injection.

Invert, to turn round, or upside down.

Invigorating, strengthening.

\section{J.}

Jets or Spurts, a name given to the bleeding of arteries. Jugular, the large neck vein.

\section{L.}

Lacerate, to tear; to drag asunder.

Lamellæ, small plates.

Langnor, weakness; faintness.

Lateral, to the one side.

Lens, a part of the eye.

Lever, anything stiff used to raise weights at one end, with a force applied to the other.

Ligaments, strong bands about the joints.

Local, near; in a certain place.

Lubricate, to moisten, to oil, such as joints are by the joint oil. Lucrative, profitable.

Lunar, relating to the moon.

\section{II.}

Macerate, to soak in fluid, such as water, etc., before dissecting.

Malady, a disease or ailment is so called.

Malformation, an unnatural shape of structure.

Malignant, severe; low ; dangerous.

Masticate, to chew; the act of chewing.

Materia Medica, medical materials.

Materially. importantly; that which concerns.

Mature, full grown; ripe.

Medinm, midway ; middle sized; the center of the whole.

Medullary, the marrow of the bune.

Membrane, a thin covering; one covers the brain, others the bones and different organs. 
Mental, relating to the mind.

Miasma, poison in the air, causing disease.

Migratory, changing from place to place.

Modern, new ; of late date.

Moral, discreet ; just and peaceably minded.

Morbid, unhealthy; there are morbid sores, secretions, etc.

Mortification, the death of any part of the animal, diseased by sore or wound, called gangrene.

Mucilage, a jelly like fluid.

Mucus, the secretions of the nose, and all mucus surfaces of the animal.

Muscles, the fleshy portion of the animal.

Mysterious, hard to understand.

N.

Nauseate, to sicken the stomach.

Nauseants, medicines that nauseate.

Narcotics, medicines which stupefy or cause sleep.

Nervous, relating to the nerves; weak-nerved animals are called nervous.

Neutralize, to destroy the force, or effect.

Nitrate of Silver, lunar caustic.

Nutritive, strong, healthy food is so called.

Obedience, submission; tameness.

oblique, slanting; crooked.

Obviate, remedied; avoided.

Obvious, clear; plain; certain.

Optic, relating to the eye or sight.

Opprobrium, reproach.

Organic, composed of organs.

Organism, the living body.

Organized, composed of organs; complete.

Origin, the first existence, or beginning.

Ossification, turning into bone.

Os, the technical name of bone.

Os Calsis, the tip of the hock.

Oval, round; egg-shaped.

Oxydation, converting into air (oxyd); the process performed on the blood in the lungs by contact with the air.

Oxygen, the element in the air which principally sustains life.

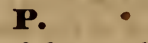

Palate, the upper part or roof of the mouth.

Palatable, pleasant to the taste. 
Pancreas, the sweet-bread.

Perceptible, that may be seen or known.

Perforated, full of small holes.

Periosteum, the membranous covering of the bones.

Permanently, continuing a lung time in a fixed state or place.

Perpendicular, straight up and down.

Perpetuate, to continue.

Pervert, to change or turn from its former uses.

Pernicious, evil ; bad.

Pharynx, the opening into the gullet or passage to the stomach.

Phenomenon, an unusual appearance.

Pliysical, ability or strength.

Placenta, the membrane covering the foal in the womb.

Plautar, belonging to the feet.

Plethora, full of blood; a full habit.

Pleura, the serous membrane that lines the chest and contents, and reflects on the same, lubricating or oiling them with its secretious.

Posterior, the hinder end.

Predispose, to fit for; to give an inclination to.

Pregnancy, the act of being with young.

Prevalent, existing plentifully ; often occurring.

Process, long spikes or points of bone.

Profuse, plentiful; of great abundance.

Progeny, the offsuring of any ancestors.

Prominence, an elevation of a part.

Propagate, to plant ; to produce offspring.

Protracted, continued a long time.

Pulmonary, belonging to the lungs.

Pulse, the beat of the arteries.

Pumiced, the falling down of the coffin-bone on the sole, caused by inflammation.

Pnncture, to make a hole with a pointed instrument.

Pupil, the apple or ball of the eye.

Putrefaction, corruption; rottenness; decomposition, etc.

\section{Q.}

Quittor, an ulcer inside the foot, of the character of fistula.

\section{R.}

Radius, the large bone of the lower arm above the knee.

liadiated, like the rays of the sun.

Rancid, a rank, strong, sour smell.

Recent, lately; not long since.

Recognize, to know a former acquaintance. 
Rectum, the last gut.

Reproduction, the act of breeding.

Respiration, the act of breathing.

Response, an answer to a query or requirement.

Ketention, stoppage or holding; the urine is so held.

s.

Salivary, the glands that throw out the saliva or spittle.

Salivate, to cause an increased flow of saliva or spittle.

Saliva, a spittle.

Saphena Major and Minor, veins of the hind leg.

Scalloped, hollowed out; the edges of a circle cut in segments. Seaphoid, shaped like a boat.

Sear, to burn with a hot iron (cautery).

Secretion, hiding; throwing off fluid.

Semi-circle, a half circle.

Sensitive, having feeling; also wit.

Sensitive Lamella, the lamellæ of the coffin-bone.

Sensibiiities, feelings of impressions, hurts or shocks, etc.

Septic, poison in dead bodies, called virus in the living.

Sinuses, small holes containing matter or pus.

Skeptical, doubtful; not believing.

Slonghing, rotting or mattering away.

Socket, a depression or hole for an organ to work in.

Spasmodic, relating to cramps, fits and spasms.

Specious, pleasant to the view.

Species, the same class of animals, plants, etc.

Spontaneous, a plentiful growth ; not planted.

Strangury, stopping; choking any passage; holding tight.

Stricture, stoppage or tightening of any of the passages of the body by morbid or spasmodic action.

Structure, the formation of anything.

Stupor, dullness ; sleepiness; seuselessness.

Sternum, the breast-bone.

Styptics, articles in medicine which stop bleeding.

Subsequent, since a certain period of time.

Subside, to sink; go down quick; quit swelling.

Subtile, crafty ; tricky.

Superficial, the upper or outer-side view.

Superiority, exceeding another in any way.

Suppuration, mattering.

Susceptible, easily influenced; capable of receiving.

Sustenance, food ; support ; keeping.

Sutures, stitches; fastenings; joinings. 
Symmetry, well built ; stout; well proportioned.

Sympathy, affection; a nervous connection between different parts of the same body.

Temporary, only for a time.

\section{T.}

Tendon, the small end of a muscle near a joint; the back sinews of the log, ctc.

Tent, a plug tent or pledget.

Testicles, the stones of the stallion.

Thorax, the chest.

Tibia, a bone of the hind-leg above the hock; thigh-bone.

Tonics, medicines that add strength and vigor.

Transmitted, passed from one to another, as from parent to offspring.

Transparent, clear; that can be seen through.

Trapezium, one of the bones of the knee.

Tread, to tramp on; the part of the hoof that rests on the ground.

Tubercle, a small tumor; a forerunner of consumption.

Tumefaction, a puffy swelling of any part.

Tumor, a swelling or eulargement.

Turbinated, having a round crown or top.

Turret, a tower; the rings of a harness through which the lines pass.

\section{U.}

Ulcers, running sores.

Ulna, a bone of the arm.

Ulterior, beyond any form or division; a last result.

Unciform, shaped like a finger-nail.

Ureter, the tube conveying the water from the kidneys to the bladder.

Uterus, the womb.

\section{$\mathbf{v}$.}

Vacantly, thoughtlessly; foolishly.

Vascular, highly organized, or furnished with blood-vessels.

Ventilate, to supply with pure air.

Vermifuges, medicines that destroy worms.

Vill, small, fine fibres, like hairs.

Virus, poisonous; contagious or infecting matter.

Vision, the sight; the art of seeing

Vital, having or containing life.

Vivifying, bringing to life. 
Withers, the high process of the vertebrø between the neck and the back.

\section{Z.}

Zoologist, one who examines and describes animals. 


\section{RULES AND REGULATIONS}

For the government of Trotting and Pacing over the Fashion Course, as adopted by most of the Turf As. sociations of the State of New York and other States.

ARTICLE 1.-All trotting and pacing over the Fashion Course shall be governed by the following rules and regulations, unless otherwise agreed upon by parties making matches or sweepstakes.

2.-Entries. - All entries must be made under seal, inclosing the entrance money for the purse and forfeit in sweepstakes, and be addressed to the Secretary, or some person authorized by the Asso. ciation, at such time and place as may have been announced by public advertisement. An accurate and satisfactory description of all unknown entries will be required. After the time has expired for closing the entries, the Secretary, or some person authorized, shall open and make known the entries in public, and publish them in one or more newspapers. No purse shall be given for a walk-over. All entrance-money for purses is one-balf forfeit to the Association, and when only one entry appears on the course, he shall receive the other half. 
3.-IN CASE of DeATH.-All engagements are void upon the decease of either party. If a race is made "play or pay," or with a forfeit, the death of a horse shall not affect the engagement.

4.-Qualifications. - As many entries may be made by one owner, or as many horses trained in the same stable as may be desired, but only one that has been owned in whole or in part by the same person or persons, or trained in the same stable within ten days previous to the race, can start in any race of "heats," and all such forfeited entries will be added to the purses, or given to the second best horse in the race, at the option of the Association.

5.-W EIGHTS. - Every horse starting for a purse, sweepstakes, or match, or in any trotting or pacing race, shall carry, if to wagon or sulky, $150 \mathrm{lbs}$., exclusive of harness; and if under saddle, $145 \mathrm{lbs}$., the saddle and whip only to be weighed.

6.-Distances.-In heats of one mile, 80 yards shall be a distance; in heats of two miles, 150 yards shall be a distance; in heats of three miles, 220 yards shall be a distance; in heats of one mile, best three in five, 100 yards shall be a distance. All horses whose heads have not reached the distance stand as soon as the leading horse arrives at the winningpost shall be declared distanced. If any jockey shall ride or drive foul, his horse shall be declared distanced. Whenever the winner of a heat is distanced by any default in riding, weight, or other- 
wise, the heat shall be awarded to the next best horse.

7.- TIMe BeTween Heats. - The time between heats shall be twenty-five minutes for mile heats, best three in five; and for mile heats, twenty minutes; for two mile heats, thirty minutes; for three mile heats, thirty-five minutes; and should there be a race of four mile heats, the time shall be forty minutes.

8. - Size of WHIPS. - Riders and drivers will be allowed whips of the following lengths : for saddle horses, two feet, ten inches; sulkies, four feet, eight inches; wagons, five feet, ten inches.

9.- Selection of Judges. - There shall be chosen by the Fashion Association three judges for the day or race, from among the members of the Pleasure Ground Association, except in matches, when the parties making the race can select their judges, who must be members of the Association.

10.- Pow ER OF JudGes. - The judges of the day or race shall have power to appoint Distance and Patrol judges; they shall decide all questions and matters of dispute between the parties of the race that are not provided for in the Rules and Regulations; when deemed requisite, they may call to their assistance competent and disinterested persons for consultation and advice; when any rider or driver shall cause unnecessary delay after the horses are called up, either by neglecting to prepare for the 
race in time, or by making false starts or otherwise, the judges may give the word without regard to the offending party or parties; when any horse or horses keep so far ahead of others that the judges cannot give a fair start, they shall give the offending party or parties notice of the penalty attached to such offensive conduct, and should they still persist in their offensive course, the judges may give the word, and such offending parties shall not win the heat, although they come to the score ahead of all others, and shall be placed behind all others in the heat; when horses are refractory, or from other causes which may prevent the judges from giving the word, they may, after a reasonable time, give the word, without reference to the position of the refractory horse or horses, or, after a lapse of twenty-five minutes, may call them to the score and start them.

11.-Distance and Patrol Judges. - In all races of heats, there shall be a Distance judge appointed by the judges of the day, who shall remain in the Distance stand during the heats, and immediately after each heat shall repair to the judges' stand, and report to the judges the horse or horses that may be distanced, and any act of foul, if any has occurred under his observation; the Patrol judges shall repair in like manner to the judges' stand, and report any act of foul, if any has occurred under their observation; the report of the Distance and Patrol judges shall alone be received. 
12.-JUDGES' DutY. - The judges should be in the stand fifteen minutes before the time of starting; they shall weigh the riders or drivers, and draw for positions of the horses; ring the bell or give other notice five minutes previous to the time announced for the race to come off, which shall be notice to all parties to prepare for the race at the appointed time, when all the horses must be ready; and any party failing to comply with this rule shall be liable to forfeit or to be ruled out. The judges shall not notice or receive complaints of foul from any person or persons except those appointed by the judges for that purpose, and riders and drivers in the race; the result of a heat shall not be announced until the judges are satisfied as to the weights of the riders or drivers, and sufficient time has elapsed to receive the reports of the Patrol and Distance judges.

13. - Power of Postronement.- - In cases of unfavorable weather or other unavoidable cause, the proprietor shall have power to postpone to a future time all purses or sweepstakes, to which he shall have contributed, upon giving notice thereof. And if darkness shall intervene during any race, it shall be the duty of the judges to continue the race over until next day, when it'shall be resumed and decided, and all the bets shall go with the race. But in order to obviate the necessity for such continuation, it shall be the duty of the judges to give the word to as good a start as can be had, when there has been a reason. 


\section{4}

able amount of scoring. In matches, the race can only be postponed by the consent of the parties thereto. This rule to take effect Monday, June 17 1867.

14.- Judges' Stand. - None but the judges shall be allowed in the judges' stand.

15.- Accidents. - In case of accidents, ten minutes shall be allowed; but the judges may allow more time when deemed necessary and proper.

16.-Disputes ANd Contingencies. - When disputes and contingencies arise which are not provided for in the Rules and Regulations, the judges shall have power to decide in such cases.

17.-Starting and Keeping Positions.-The judges shall inform the riders and drivers of their positions in starting for the race; the horse winning the heat shall take the pole the succeeding heat, and all others shall take their positions in the order in which they came home in the last heat. When two or more horses shall make a dead heat, the horses shall start for the succeeding heat in the same positions they occupied at the finish of the dead heat. In coming out in the home-stretch, each horse shall keep the position first selected, except the hindmost horse, who, when there is sufficient room to pass on the inside, or anywhere in the home-stretch without interfering with others, shall be allowed to do so; and any party interfering to prevent him shall be 
distanced, or lose the heat, as the judges may determine; any party violating this rule willfully shall be distanced. If a horse should at any time cross or swerve on the home stretch, so as to impede the progress of a horse behind him, he shall not be entitled to beat him in that heat; and if, in the opinion of the judges, such crossing or swerving was willful on the part of the rider or driver, he shall be distanced.

18. - DeCoRuM. - If any owner, trainer, rider, driver or attendant of a horse use improper language to the officers of the course, or be guilty of improper conduct, the person so offending may be, by the judges of the day or race, ruled off the course, and not be permitted to ride, drive, or attend a horse on this course again, in any race under the control of the Association, unless such ruling-off be rescinded at a regular monthly meeting of the members of the Pleasure Ground Association, by a majority vote of the members then present.

19.- Placisg Horses.- Horses distanced in the first heat are equal in the race; but in all succeeding heats, horses that are distanced in the same heat shall rank in the race in the order which they were entitled to at the start of the heat; that is, horses having won two heats, better than those winning one; a horse that has won a heat, better than a horse only making a dead heat; a horse winning one or two 
heats and making a dead heat, better than one winning an equal number of heats, but not making a dead heat. When horses winning an equal number of heats shall be distanced in the same heat, they shall rank in the race in the order in which they started for the heat in which they were distanced. When two or more horses shall have won an equal number of heats, they shall rank in the race as they are placed in the last heat in which contend; horses not winning or making a dead heat, the same. In case this article should not give specific decision as to second or third money, etc., the judges are to decide according to the best of their ability and turf usages in general, and all outside bets to be governed thereby.

20.- HoRses Breaking.-- When any horse or horses break from their gait, in trotting or pacing, their riders or drivers shall immediately pull them to the gait in which they were to go in the race; and any party refusing or neglecting to comply witr. this rule shall lose the heat, and the next best horse shall win the heat, and all other horses shall be placed ahead in the heat; the judges shall also have discretionary power to distance the offending horse or horses. Should the rider or driver comply with this rule, and a horse should gain by breaking, twice the distance so gained shall be taken from him or them at the coming out. A horse breaking at the score shall not lose the heat by so doing. 
21.-Winning Horses. - A horse must win a majority of the heats to be entitled to the purse or stakes, unless such horse shall have distanced all others in one heat.

22.-Relative to Heats and Horses Eligible To StaRT.-In heats, one, two, three, or four miles, a horse not winning one heat in three shall not start for a fourth, unless such horse shall have made a dead heat. In heats, best three in five, a horse not winning a heat in five shall not start for a sixth, unless such horse shall have made a dead heat. A dead heat shall be considered a heat as regards all excepting the horses making such dead heat, and those only shall start for the next heat which would have been entitled had the heat been won by either horse making the dead heat; a horse preventer from starting by this rule shall not be distanced, but ruled out.

23. - Collusions or Frauds. - When the judges are satisfied that any race is being, or has been conducted improperly or dishonestly, either on the part of the riders, drivers, or the parties controlling the horses or race, they shall have the power to declare that neither horse nor horses have won the race nor the money; and all outside bets shall be declared null and void. Also, when there is any interference with riders, drivers, their horses or vehicles, either at the start or during the race, the judges shall have 
power to decide equitably between the horses, and their decision shall be final and conclusive, and all outside bets shall be governed thereby.

24.-Dress of Riders aNd DRIVERS.--Judges may require riders and drivers to be properly dressed.

25.- Weigints AND Weighing. - Riders and drivers shall weigh in the presence of one or more of the judges previous to starting for any race, and after each heat shall come to the starting stand, and not dismount or leave his vehicle without permission of the judges. Any party violating this rule shall be distanced, if not of as much bodily weight as the rules of the course require; and when of sufficient bodily weight it shall be discretionary with the jadges to rule him off, or distance him for a contempt of the Rules and Regulations. But a rider or driver thrown or taken by force from his horse or vehicle, after having passed the winning-post, shall not bə considered as having dismounted without permission of the judges; and if disabled, may be carried to the judges' stand to be weighed, and the judges may take the circumstances into consideration, and clecide accordingly.

26. - FouL. - If a horse, driver, or rider shall cross, jostle, or strike another horse, driver, or rider, or do anything that impedes another horse, accidentally or not, it is foul, and the horse that impedes the 
other may be adjudged distanced. Although a leading horse is entitled to any part of the track, except after selecting his position on the home-stretch, if he cross from the right to the left, or from the inner to the outer side of the track, when a horse is so near him that, in changing his position, he compels the horse behind him to shorten his stride, or if he causes the rider or driver to pull him out of his stride, it is foul; and if, in passing a leading horse, the track is taken so soon after getting the lead as to cause the horse passed to shorten his stride, it is foul. A rider or driver committing any act which the judges may deem intentionally foul, must be declared distanced; this rule should at all times be rigidly enforced. All complaints of foul by riders and drivers must be made at the termination of the heat, and before the rider or driver dismounts or leaves his vehicle by order of the judges.

27.- Handicaps and Miscellaneous Weights. - In matches or handicaps, where extra or lesser weights are to be carried, the judges shall carefully examine and ascertain, before starting, whether the riders, drivers, or vehicles are of such weights as have been agreed upon or required by the match or handicap, and the riders, or drivers, who shall carry during the race and bring home with them the weights which have been pronounced correct and proper by the judges, there shall be no penalty attached to any party for light weight in that heat, 
provided the judges are satisfied of their mistake, and that there has been. no deception on the part of the rider or driver who shall be deficient in weight, but all parties thereafter shall carry full weight.

28.-- All races shall be started at 3 o'clock P. M., from the 1st day of April to the 15th day of September; and after that date, at 2 o'clock P. M., until the season closes.

29. - All races to which the Association adds money shall be started from the new stand. Also all matches, unless otherwise agreed upon by parties making said matches, in which case they shall give the proprietor three days' notice of their agreement.

\section{Betting Rules.}

1.-All bets are understood to relate to the purse, or stake, or match, if nothing be said to the contrary at the time of making the bet.

2.-A bet made on a horse is void, if the horse betted on does not start.

3.- - Horses shall be placed in a race, and bets decided as they are placed in the official records.

4.-When a race is postponed beyond the first day published for it to come off, all by-bets, except they are play or pay, shall be off.

5.-A bet made during the running of a heat is not determined until the race is over, if the heat is not mentioned at the time of making the bet. 
6. - When a play or pay bet is made on a horse or horses, they must start, or the party betting on them loses.

7.-Either of the bettors may in person demand stakes to be made, and on a refusal declare the bet to be void.

8.-Outside bets cannot be declared off on the course, unless that place was named for staking the money, before the race should take place, and then it must be done by filing such declaration in writing with the judges, who shall read it from the stand before the race commences, and demand if any person will make stakes for the absent party, and if no person consent to do so, the bet may be declared void.

9. - When a bet is made on one horse against the field, he must start, or the bet is off, and the field is what starts against him; but there is no field unless one start against him.

10. - When a bet is made between two horses, they both must start, or the bet is off.

11. - A person betting odds has a right to choose a horse on the field, and when he has chosen his horse, the field is whatever starts against him, but there is no field unless one or more start with him.

12.-Parties wishing all the horses to start for a bet must so name it at the time the bet is made.

13. - If, in the final heat of a race, there be but 
one horse placed, no horse shall be considered as second in the race.

14.-All races made play or pay, outside bets not to be considered play or pay, unless so understood by the parties.

15. - If a race of a single dash at any distance is made, and the horses make a dead heat, the race is a draw.

16.-When a bettor undertakes to place the horses in a race, he must give each a specific place, as first, second, third, and so on. The word "last" shall not be construed to mean fourth and distanced, if four start, but fourth only, and so on. A distanced horse must be placed distanced.

17.-If a bet is made on any number of straight heats, and there is a dead heat made, the heats are not straight, and the party betting on straight heats loses.

18.- It is optional with the judges of the race to decide disputes left to their arbitration by bettors, but it is their duty to decide disputes between parties to the race.

19. - When a bet is made between two or more horses in a race, and neither wins a heat, nor makes a dead heat, and neither is distanced, the horse coming out ahead in the last beat is best. A hure distanced in a dead heat is beaten by one that is drawn at the termination of the same heat. A horse rrak. 


\section{3}

ing a dead heat is better than one not winning a heat, nor making a dead heat, if neither is distanced or both distanced in the same heat. A distanced horse, although having made a heat or won a heat, is beaten by a horse that is not distanced, or distanced in a succeeding heat.

20.-Betting on Tine.-When a race is coming off, and a party bets that a heat will be made in two minutes and thirty seconds (2.30), and they shall make two-thirty (2.30), he would win. If he bets they will beat two minutes and thirty seconds $(2.30)$, and they make exactly two-thirty (2.30), he loses; but if he takes two minutes and thirty seconds (2.30) against the field, and they make exactly two-thirty (2.30), it is a tie or draw bet. All time bets are decided accordingly.

21.-Hurses drawn before the conclusion of a race shall be considered distanced.

22.-Bets between outside bettors are void on the decease of either party.

23.-All horses that are ruled out or drawn before the conclusion of a race, shull be considered distanced, in betting and placing, unless the contrary is specified at the time the bet is made.

24.-In pools and pool-betting, the pool stands good for all the horses that start in the race; but for those horses that do not start, the money must be returned to the purchaser. 
